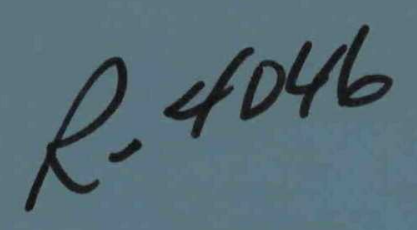

MASTER

\title{
TRANSIENT CURRENT DISTRIBUTIONS IN POROUS ZINC ELECTRODES IN KOH ELECTROLYTE
}

by

\author{
Ming-Biann Liu, Y. Yamazaki, \\ G. M. Cook, and N. P. Yao
}

ARGONNE NATIONAL LABORATORY, ARGONNE, ILLINOIS

Prepared for the U. S. DEPARTMENT OF ENERGY

under Contract W-31-109-Eng-38 
The facilities of Argonne National Laboratory are owned by the United States Government. Under the terms of a contract (W-31-109-Eng-38) among the U. S. Department of Energy, Argonne Universities Association and The University of Chicago, the University employs the staff and operates the Laboratory in accordance with policies and programs formulated, approved and reviewed by the Association.

\section{MEMBERS OF ARGONNE UNIVERSITIES ASSOCIATION}

The University of Arizona

Carnegie-Mellon University

Case Western Reserve University

The University of Chicago

University of Cincinnati

Illinois Institute of Technology

University of Illinois

Indiana University

The University of Iowa

Iowa State University
The University of Kansas

Kansas State University

Loyola University of Chicago

Marquette University

The University of Michigan

Michigan State University

University of Minnesota

University of Missouri

Northwestern University

University of Notre Dame
The Ohio State University

Ohio University

The Pennsylvania State University

Purdue University

Saint Louis University

Southern Illinois University

The University of Texas at Austin

Washington University

Wayne State University

The University of Wisconsin-Madison

NOTICE

This report was prepared as an account of work sponsored by an agency of the United States Government. Neither the United States Government or any agency thereof, nor any of their employees, make any warranty, express or implied, or assume any legal liability or responsibility for the accuracy, completeness, or usefulness of any information, apparatus, product, or process disclosed, or represent that its use would not infringe privately owned rights. Reference herein to any specific commercial product, process, or service by trade name, mark, manufacturer, or otherwise, does not necessarily constitute or imply its endorsement, recommendation, or favoring by the United States Government or any agency thereof. The views and opinions of authors expressed herein do not necessarily state or reflect those of the United States Government or any agency thereof.

Printed in the United States of America

Available from

National Technical Information Service

U. S. Department of Commerce

5285 Port Royal Road

Springfield, VA 22161

NTIS price codes

Printed copy: A05

Microfiche copy: A01 


\section{DISCLAIMER}

This report was prepared as an account of work sponsored by an agency of the United States Government. Neither the United States Government nor any agency Thereof, nor any of their employees, makes any warranty, express or implied, or assumes any legal liability or responsibility for the accuracy, completeness, or usefulness of any information, apparatus, product, or process disclosed, or represents that its use would not infringe privately owned rights. Reference herein to any specific commercial product, process, or service by trade name, trademark, manufacturer, or otherwise does not necessarily constitute or imply its endorsement, recommendation, or favoring by the United States Government or any agency thereof. The views and opinions of authors expressed herein do not necessarily state or reflect those of the United States Government or any agency thereof. 


\section{DISCLAIMER}

Portions of this document may be illegible in electronic image products. Images are produced from the best available original document. 
Distribution Category:

Energy Storage--ElectrochemicalNear-Term Batteries (UC-94ca)

ANL/OE PM- 80-6

\section{ARGONNE NATIONAL LABORATORY \\ 9700 South Cass Avenue \\ Argonne, Illinois 60439}

TRANSIENT CURRENT DISTRIBUTIONS IN

POROUS ZINC ELECTRODES IN KOH ELECTROLYTE

by

Ming-Biann Liu, Y. Yamazaki,*

G. M. Cook, and N. P. Yao

Chemical Engineering Division

February 1981

*Tokyo Institute of Technology, Japan. 
-

• 


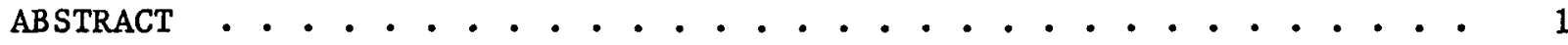

I. INTRODUCTION . . . . . . . . . . . . . . . . . . 1

II. EXPERIMENTAL . . . . . . . . . . . . . . . . 2

A. Preparation of Segmented Porous Electrodes . . . . . . . 2

B. Experimental Procedure . . . . . . . . . . . . 3

C. Results and Discussion ................. 4

1. Current Distributions and Overpotentials . . . . . . 4

2. Initial Current Distributions . . . . . . . . . . 7

3. Reaction Penetration Depth ............ 10

III. THEORETICAL . . . . . . . . . . . . . . . . . 12

A. Mathematical Model . . . . . . . . . . . . 12

1. Electrochemical and Chemical Reactions . . . . . . . 13

2. Redox Electrochemical Overpotential Expression . . . . 13

3. Ohm's Law in the Solution Phase . . . . . . . . . . 14

4. Species Conservation Equations . . . . . . . . . . 15

5. Surface Areas and Precipitation Rate Constant . . . . 16

6. Conservation Equations of Solid Matrix . . . . . . . 19

7. Charge Conservation Equation . . . . . . . . . . 19

B. Computation Procedures for the Mode1 . . . . . . . . 19

C. Results and Discussion ................ 23

1. Electrolyte Conductivity . . . . . . . . . . 25

2. Precipitation of $\mathrm{ZnO}$. . . . . . . . . . . . . 26

3. Exchange Current Density . . . . . . . . . . 33

4. Mass Transfer ................... 33

5. Passivation ................ 36

IV. CONCLUDING REMARKS . . . . . . . . . . . . . . . . 38

ACKNOWLEDGEMENT . . . . . . . . . . . . . . . . . . . . . 4 41

APPENDIX A. . . . . . . . . . . . . . . . . . . . . 4 43

APPENDIX B. . . . . . . . . . . . . . . . . . . . . 4 45

REFERENCES . . . . . . . . . . . . . . . . . . . 59 
1. Segmented Porous Electrode . . . . . . . . . . . . . 3

2. Apparatus for the Measurements of Current Distributions within Segmented Electrodes.................. 4

3. Current Distribution and Potential of Segmented Electrode Discharged at $10 \mathrm{~mA}$. . . . . . . . . . . 5

4. Current Distribution and Potential of Segmented Electrode Discharged at $25 \mathrm{~mA}$. . . . . . . . . . . . 6

5. Passivation Behavior of Segmented Electrode Discharged at $100 \mathrm{~mA}$...................... . . 7

6. Initial Profile of Integrated Fraction of the Charge Transfer Reaction in Simulated Electrode as Function of Normalized Electrode Depth . . . . . . . . . . . . 9 9

7. One-Dimensional Porous Electrode Model . . . . . . . . . . 12

8. Model for Pore Geometry . . . . . . . . . . . . . . 16

9. Predicted and Experimental Current Distribution of Segmented Electrode Discharged at $10 \mathrm{~mA}$. . . . . . . . . 27

10. Predicted and Experimental Overpotential of the Segmented Electrode Discharged at $10 \mathrm{~mA}$............... 28

11. Predicted Current Distributions for Three Values of $\mathbf{k}_{\mathbf{S}}$ with Segmented Electrode Discharged at $25 \mathrm{~mA}$. . . . . . . . 29

12. Predicted Overpotentials for Three Values of $\mathbf{k}_{\mathbf{s}}$ with Segmented Electrode Discharged at $25 \mathrm{~mA}$. . . . . . . . 30

13. Predicted and Experimental Current Distributions for Two Exchange Current Densities with Segmented Electrode Discharged at $25 \mathrm{~mA}$................... 31

14. Predicted and Experimental Overpotentials for Two Exchange Current Densities with Segmented Electrode Discharged at $25 \mathrm{~mA}$. . . . . . . . . . . . . 32

15. Predicted Current Distributions for Three Values of $D_{3}$ with Segmented Electrode Discharged at $25 \mathrm{~mA}$. . . . . . . 34

16. Predicted Current Distributions for Two Values of $D_{3}$ with the Segmented Electrode Discharged at $25 \mathrm{~mA}$. . . . . 35 
17. Predicted Overpotentials for Two Values of $D_{3}$ with the

Segmented Electrode Discharged at $25 \mathrm{~mA} . . . . . . . .36$

18. Predicted and Experimental Current Distribution of the

Segmented Electrode Discharged at $100 \mathrm{~mA}$. . . . . . . 37

19. Predicted and Experimental Current Overpotential

for the Segmented Electrode Discharged at $100 \mathrm{~mA}$. . . . . . 38

20. Predicted Overpotential and Effective Reaction

Penetration Depth vs. Porosity for Electrode Discharge

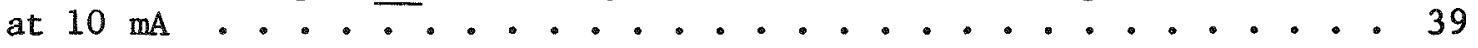

\section{LIST OF TABLES}

No.

Title

$\underline{\text { Page }}$

1. Reaction Penetration Depths Reported for Zinc Porous

Anodes in $\mathrm{KOH}$ Electrolytes . . . . . . . . . . . . . 11

2. The Dimensionless Groups Characterizing the Behavior of

a Zinc Porous Electrode in Alkaline Electrolytes . . . . . . 24 


\section{LIST OF SYMBOLS}

a

$a_{0}$

$a_{m}$

$\mathrm{C}_{2}^{\circ}$

$\mathrm{C}_{2}^{\mathrm{sh}}$

$c_{2}$

$\mathrm{C}_{3}^{\circ}$

$\mathrm{C}_{3}$

$\mathrm{C}_{\mathrm{A}}$

$\mathrm{C}_{\mathrm{B}}$

d

$\mathrm{D}_{2}$

$D_{3}$

E

$E_{2}^{s h}$

$\mathrm{E}_{2}$

F

g

$i_{0}^{0}$

specific surface area per unit volume for the precipitation of $\mathrm{ZnO}, \mathrm{cm}^{2} / \mathrm{cm}^{3}$

initial specific surface area per unit volume, $\mathrm{cm}^{2} / \mathrm{cm}^{3}$

the specific surface area per unit volume for electrochemical reaction, $\mathrm{cm}^{2} / \mathrm{cm}^{3}$

bulk concentration of zincate ions, $\mathrm{mol} / \mathrm{cm}^{3}$

the threshold concentration of zincate ions for the precipitation of $\mathrm{ZnO}, \mathrm{mol} / \mathrm{cm}^{3}$

concentration of zincate ions in pore electrolyte, $\mathrm{mol} / \mathrm{cm}^{3}$

bulk concentration of hydroxide ions, $\mathrm{mol} / \mathrm{cm}^{3}$

concentration of hydroxide ions in pore electrolyte, $\mathrm{mol} / \mathrm{cm}^{3}$

concentration of potassium zincate in the pore electrolyte, $\mathrm{mol} / \mathrm{cm}^{3}$

concentration of potassium hydroxide in the pore electrolyte, $\mathrm{mol} / \mathrm{cm}^{3}$

effective reaction penetration depth, $\mathrm{cm}$

diffusivity of zincate ions, $\mathrm{cm}^{2} / \mathrm{sec}$

diffusivity of hydroxide ions, $\mathrm{cm}^{2} / \mathrm{sec}$

electrode potential, V

dimensionless threshold concentration of zincate ions for precipitation of $\mathrm{ZnO}\left(\mathrm{C}_{2}^{\mathrm{sh}} / \mathrm{C}_{2}^{\circ}\right)$

dimensionless concentration of zincate ions in pore electrolyte $\left(\mathrm{C}_{2} / \mathrm{C}_{2}^{\circ}\right)$

Faraday"s constant, $96500 \mathrm{C}$

surface roughness factor of $\mathrm{ZnO}$

exchange current density evaluated at the bulk concentrations of zincate and hydroxide ions, $\mathrm{mA} / \mathrm{cm}^{2}$ 
Blank

$\bullet$

vii

NOMENCLATURE 


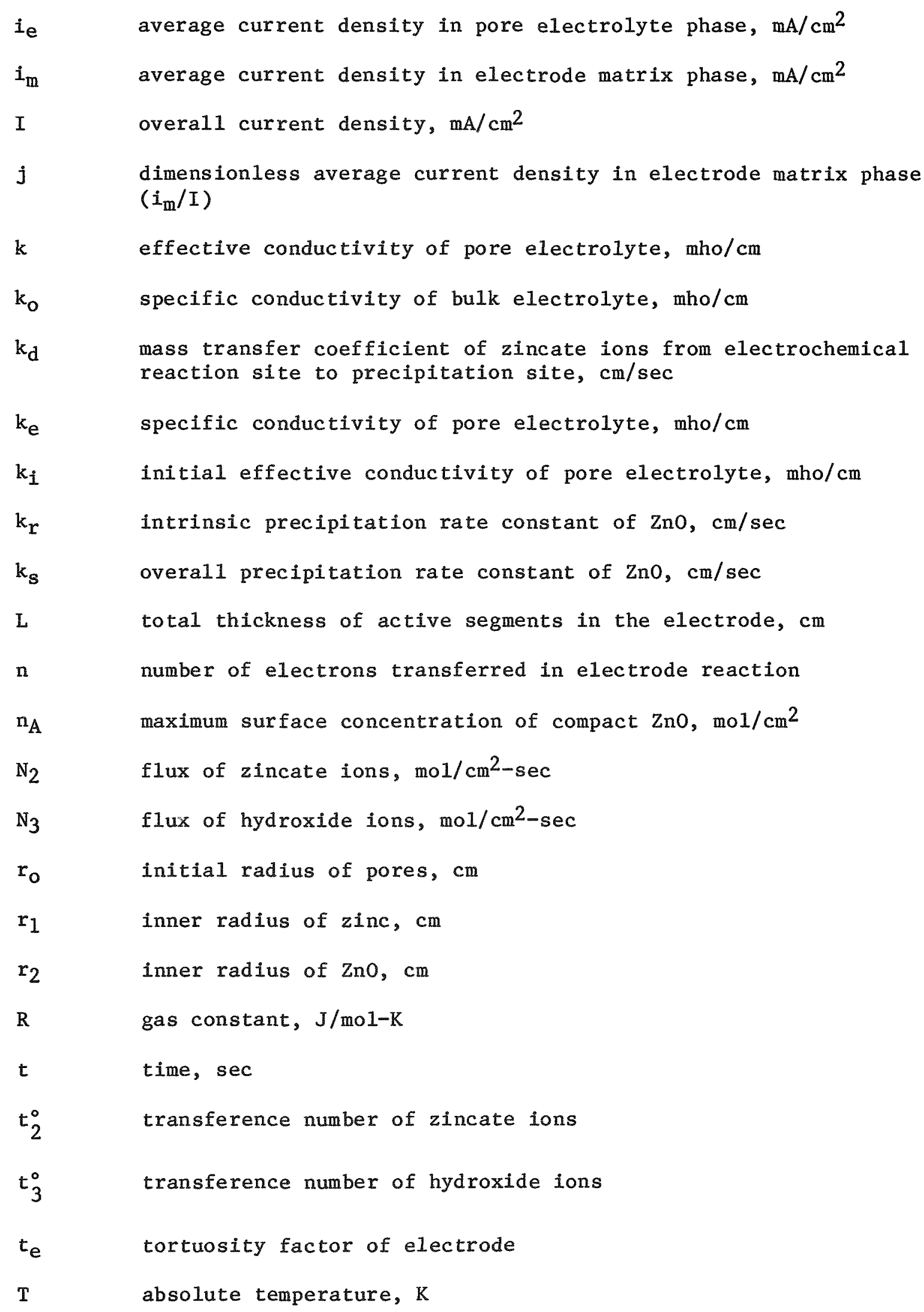









dimensionless time $\left(D_{3} t / L^{2}\right)$

$\phi_{\mathrm{m}}$

local potential of electrode matrix phase, $V$

local potential of pore electrolyte, $\mathrm{V}$

$\phi_{\mathrm{sh}}$

threshold overpotential for formation of compact $\mathrm{ZnO}, \mathrm{V}$

$\psi_{e}$

dimensionless local potential of pore electrolyte $\left(n_{\phi e^{F} / R T}\right)$

$\psi_{\mathrm{m}}$

dimensionless local potential of electrode matrix $\left(n_{\phi m} F / R T\right)$ 


\section{TRANSIENT CURRENT DISTRIBUTIONS IN POROUS ZINC ELECTRODES IN KOH ELECTROLYTE}

by

Ming-Biann Liu, Y. Yamazaki,* G. M. Cook and N. P. Yao

\section{ABSTRACT}

We have used a zero-resistance ammeter circuit with a 10channel operational amplifier to measure the current distribution during a discharge of 10 to $100 \mathrm{~mA}$ with simulated zinc porous electrodes in $7.24 \mathrm{M} \mathrm{KOH}$ saturated with $\mathrm{ZnO}$. The reaction distribution was found to be highly nonuniform, with 70 to $78 \%$ of the charge transfer reaction completed in a depth of $0.01 \mathrm{~cm}$. The high nonuniformity of the initial reaction profile was believed to be due to low conductivity of the electrolyte in the electrode pores. The current distribution changes during passivation of the electrode were experimentally obtained.

A mathematical model based upon a macroscope averaging technique was used to predict the time dependence of charge transfer reaction profiles. With our mathematical model, we predicted current distributions and overpotentials as a function of time for our segmented zinc electrode discharged at a current of 10 to $100 \mathrm{~mA}$; for these predictions, we used assumed values of both precipitation rate constants for porous $\mathrm{Zno}$ and diffusion coefficients for hydroxide and zincate ions. A gradual decrease in the specific conductivity of the pore electrolyte to $20 \%$ of the initial value during discharge yields predictions of current distributions and overpotentials in good agreement with our experimental data. The extent of reduction in the specific conductivity of the pore electrolyte implies a supersaturation of zincate of four times chemical saturation, which has been observed experimentally. At high discharge current (25-100 mA), the passivation behavior of the electrode has been simulated. The results of our experiments and mathematical model show that the effective reaction penetration depth is less than $0.02 \mathrm{~cm}$.

\section{INTRODUCTION}

The literature contains three basic methods for the experimental determination of current distribution in an electrode. In the first method, the reaction distribution of a discharged electrode is measured by sectioning the electrode and then chemically analyzing each section. This method has been applied to a variety of electrodes: zinc electrodes by Nagy and Bockris 1 and Sunu and Bennion, 2 the cadmium electrode by Bro and Kang, 3 and the copper electrode by Alkire. 4 The second method is the direct measurement of the current distribution in a presectioned electrode during discharge; this has been done by Szpak and Katan for the $\mathrm{Ag} / \mathrm{AgCl}$ system, 5 McBreen for the $\mathrm{Ni} / \mathrm{Zn}$

\footnotetext{
*Tokyo Institute of Technology, Japan.
} 
ce11,6 Coleman for the $\mathrm{MnO}_{2}$ electrode, 7 and Gagnon and Austin 8 for the $\mathrm{Ag} / \mathrm{Ag}_{2} \mathrm{O}$ electrode. The third method is the direct measurement of the potential distribution by using numerous reference electrodes along an electrode being discharged; this method has been used by Brodd ${ }^{9}$ in a study of current distribution in a manganese dioxide electrode.

The first method is limited to the case where the electrode reaction causes sufficient solid reaction products during the electrode operation to be measured after sectioning the electrode. The sectioning must be done carefully and quickly since this procedure can result in a net reduction and redistribution of material. The other two direct methods have the advantage of allowing continuous measurements to be made during electrode operation; however, the accuracy of the measurements depends greatly upon the designs of the working electrode and the reference electrodes. The sectioned electrode has been significantly improved by Szpak and Katan, who used thin film technology to fabricate silver electrode segments. 5 Their electrode consisted of six segments of active material, which were $0.07-\mathrm{cm}$ wide and separated by $0.03 \mathrm{~cm}$; these segments were vapor deposited onto a glass slide and had connecting electrical leads insulated by Teflon tape. To simulate the electrode pore structure, Szpak and Katan placed a glass cover slide above the active segments, which was supported on one end by a Teflon spacer and on the other end by a drop of electrolyte which protruded around the counter electrode. The problem with this simulated porous electrode design is that it is significantly different from that of an actual battery electrode (e.g., the electrolyte is not surrounded by active materials).

In the present study, an improved sectioned electrode that closely simulates an actual porous electrode has been designed and fabricated. The zinc electrode was selected as the first to be investigated since it has been used in the $\mathrm{Ni} / \mathrm{Zn}$ cells for electric-vehicle propulsion. The purpose of this study was to measure the current distribution in the zinc electrode by using the improved sectioned electrode; based on these data, the reaction penetration depth of the zinc porous electrode in $\mathrm{KOH}$ electrolyte was calculated. It is necessary to know the distance that the electrochemical reaction penetrates the electrode because electrodes much thinner than the penetration depth behave like planar electrodes, whereas electrodes much thicker than the penetration depth are not fully utilized. In addition, data obtained on the current distribution and overpotential of our electrode provided a basis for the development of a mathematical model.

\section{EXPERIMENTAL}

\section{A. Preparation of Segmented Porous Electrodes}

The electrodes used in this study consist of segments fabricated by a conventional photolithography technique. 10 Zinc sheet with 0.1 -mm thickness and $99.99 \%$ purity from United Mineral and Chemical Corp. (New York, NY) was cut into pieces with dimensions of $4 \mathrm{~cm}$ by $5.5 \mathrm{~cm}$. Each piece of zinc sheet was coated with Kodak photoresist (KPR) mixed with $10 \% \mathrm{KPR}$ blue dye. When exposed to ultraviolet radiation through a photographic transparency with a matrix of 100 black dots, the resist polymerizes in the areas struck by the light; these areas then become insoluble. The resist in areas covered by black dots is removed with KPR developer. The resulting sheet is chemically spray etched with $10 \%$ nitric acid (by volume) to yield a zinc sheet with 
100 holes. The size of the holes was measured by using an optical microscope with a calibrated scale. An electric lead was soldered onto the top of each etched zinc sheet. Zinc sheets were then stacked and glued together until an electrode of desired thickness was formed; the holes were aligned under a Bausch \& Lomb microscope to form pores. In addition, a plexiglass backing plate was added to this stack of segmented electrodes. The entire assembly was checked to be certain that no electric short circuits would occur. A typical segmented electrode design is shown in Fig. 1.

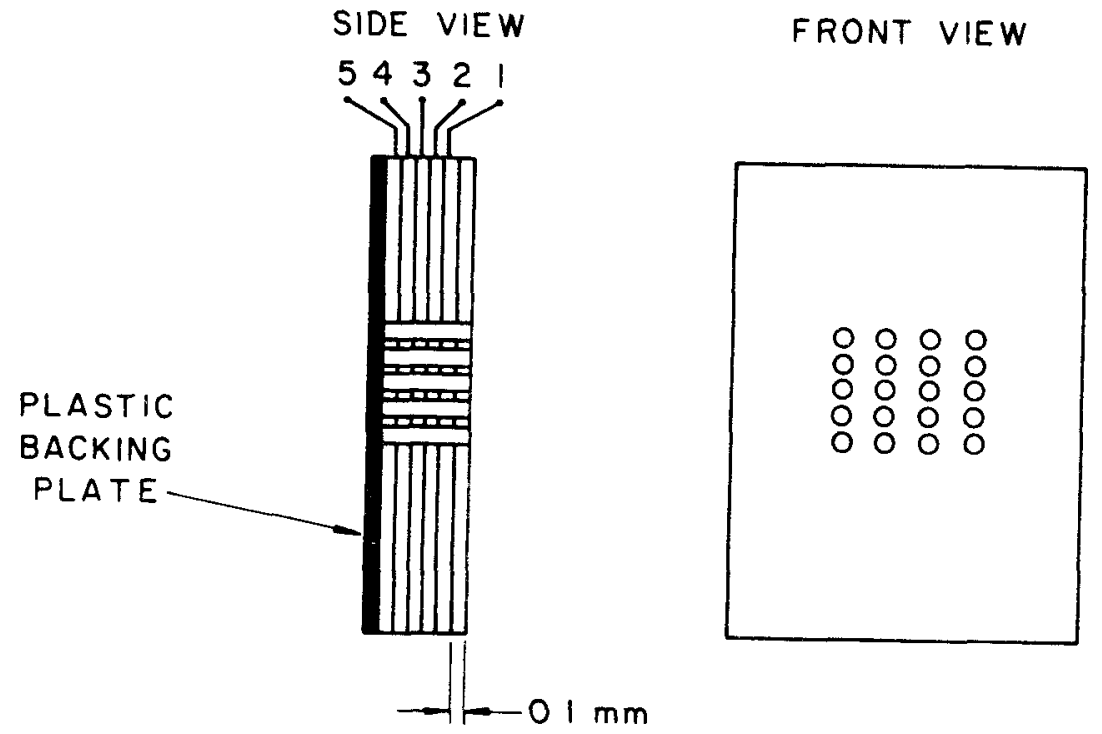

Fig. 1. Segmented Porous Electrode

\section{B. Experimental Procedure}

A schematic of the apparatus for experimental measurements is shown in Fig. 2. The prepared electrode was mounted on plexiglass plates with "Quickmount" purchased from Fulton Metallurgical Products Corp. (Saxonburg, PA) and then placed in the cell with the electrolyte solution. The electrolyte was $7.24 \mathrm{M} \mathrm{KOH}$ saturated with zinc oxide. The $\mathrm{KOH}$ was reagent grade, and the zinc oxide was analytical reagent quality. The electrolyte solutions were prepared with double distilled water and deaerated by passing a stream of purified nitrogen through it. The cell was put in a desiccator and evacuated to ellminate any gas bubbles trapped inside the pores. The counter electrode (CE) was a zinc strip. The $\mathrm{Hg} / \mathrm{HgO}$ reference electrode (RE) was located at the edge of the plexiglass opening, $0.32 \mathrm{~cm}$ from the electrode surface. A Model 173 Potentiostat/Galvanostat equipped with a Model 376 Current Converter (Princeton Applied Research Corp., Princeton, NJ) was used to provide a constant discharge current. The currents passing through each segment were measured with a zeroresistance ammeter circuit 11 having a 10-channel operational amplifier (Fairchild Co.,Mountain View, CA $\mu$ A 759UIC), which provided a virtual ground for each active segment of the electrode. These currents were sequentially 




Fig. 2. Apparatus for the Measurements of Current Distributions within Segmented Electrodes

recorded using a 10-channel scanner (Keithley Instruments Inc., Cleveland, $\mathrm{OH})$; the scanning speed was set at $1 \mathrm{sec} / \mathrm{channel}$. With this experimental apparatus, the current distribution in the simulated porous electrode was measured for constant current discharges of 10,25 , and $100 \mathrm{~mA}$ as a function of time. Furthermore, the potential was measured with the reference electrode. For these measurements, several segmented zinc electrodes were prepared with the following general characteristics: segment thickness, $0.01 \mathrm{~cm} ; 100$ straight pores of $0.0265-\mathrm{cm}$ diameter; negligible resistive film thickness compared with zinc segment thickness; and exposed area of pore matrix, $0.42 \mathrm{~cm}^{2}$.

\section{Results and Discussion}

\section{Current Distributions and Overpotentials}

In the experiment in which a discharge current of $10 \mathrm{~mA}$ was used, the electrode was a stack of one inactive segment (front) followed by five active segments. The inactive segment was necessary because preliminary experiments showed collapse of the resistive film on the front active segment of the electrode when exposed to the bulk electrolyte during discharge, leading to erroneous results. For the other two discharge currents, an additional inactive segment, initially intended for electrode potential monitoring, was placed behind the five active segments and in front of the plexiglass backing plate. Figures 3 and 4 show the current distributions and electrode potentials at discharge currents of 10 and $25 \mathrm{~mA}$, respectively; the active segments are 


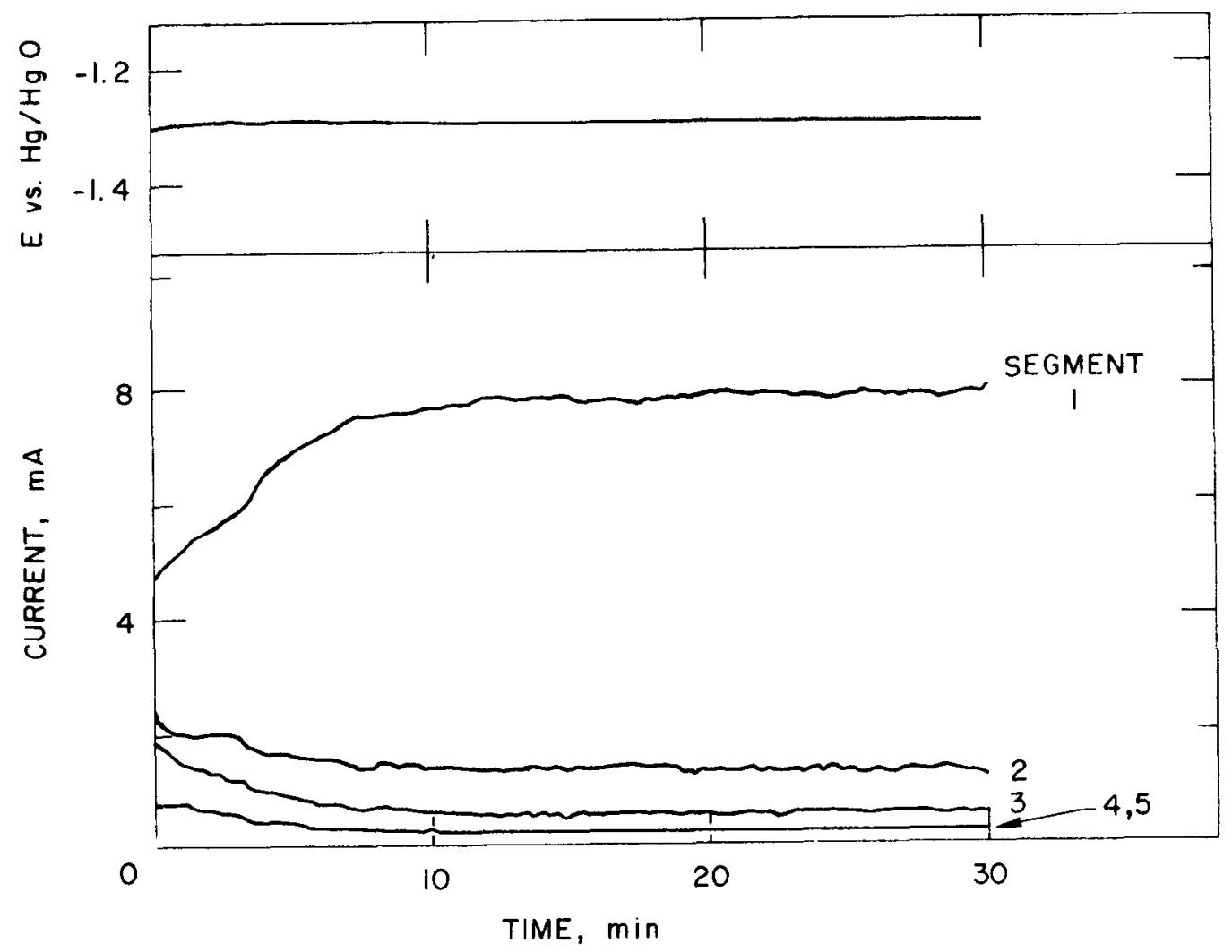

Fig. 3. Current Distribution and Potential of Segmented Electrode Discharged at $10 \mathrm{~mA}\left(23.8 \mathrm{~mA} / \mathrm{cm}^{2}\right)$

numbered consecutively from one to five (See Fig. 1), starting from the front segment facing the bulk electrolyte. Figure 5 is a plot of the stepwise signals recorded by the scanner. As mentioned earlier, all ten channels of the ammeter circult were scanned at a rate of one second per channel. Therefore, the five steps appearing every 10 seconds in Fig. 5 represent the current measured in each of the five active segments for that period. In Figs. 3-5, the currents are integrated quantities for each segment.

Figures 3 and 4 show that the current distributions in the electrodes were highly nonuniform and that slight variations in electrode potential with respect to the reference electrode occurred throughout the measurements. The nonuniformity in current distributions gradually increased with time until a "steady state" was reached; at steady state, $70 \%$ of the charge transfer reaction for the $25-\mathrm{mA}$ discharge ( $78 \%$ for $10 \mathrm{~mA}$ ) had occurred in the first active segment. These two figures illustrate that the electrode at the $25-\mathrm{mA}$ discharge current attained steady-state current distribution faster than did the electrode at $10 \mathrm{~mA}$.

Figure 5 shows the current distribution changes during the passivation of the segmented zinc electrode. The charge transfer reaction at the first active segment increased to a maximum within $40 \mathrm{sec}$, followed by a gradual decrease unt1l $130 \mathrm{sec}$. After $130 \mathrm{sec}$, the current started to increase 


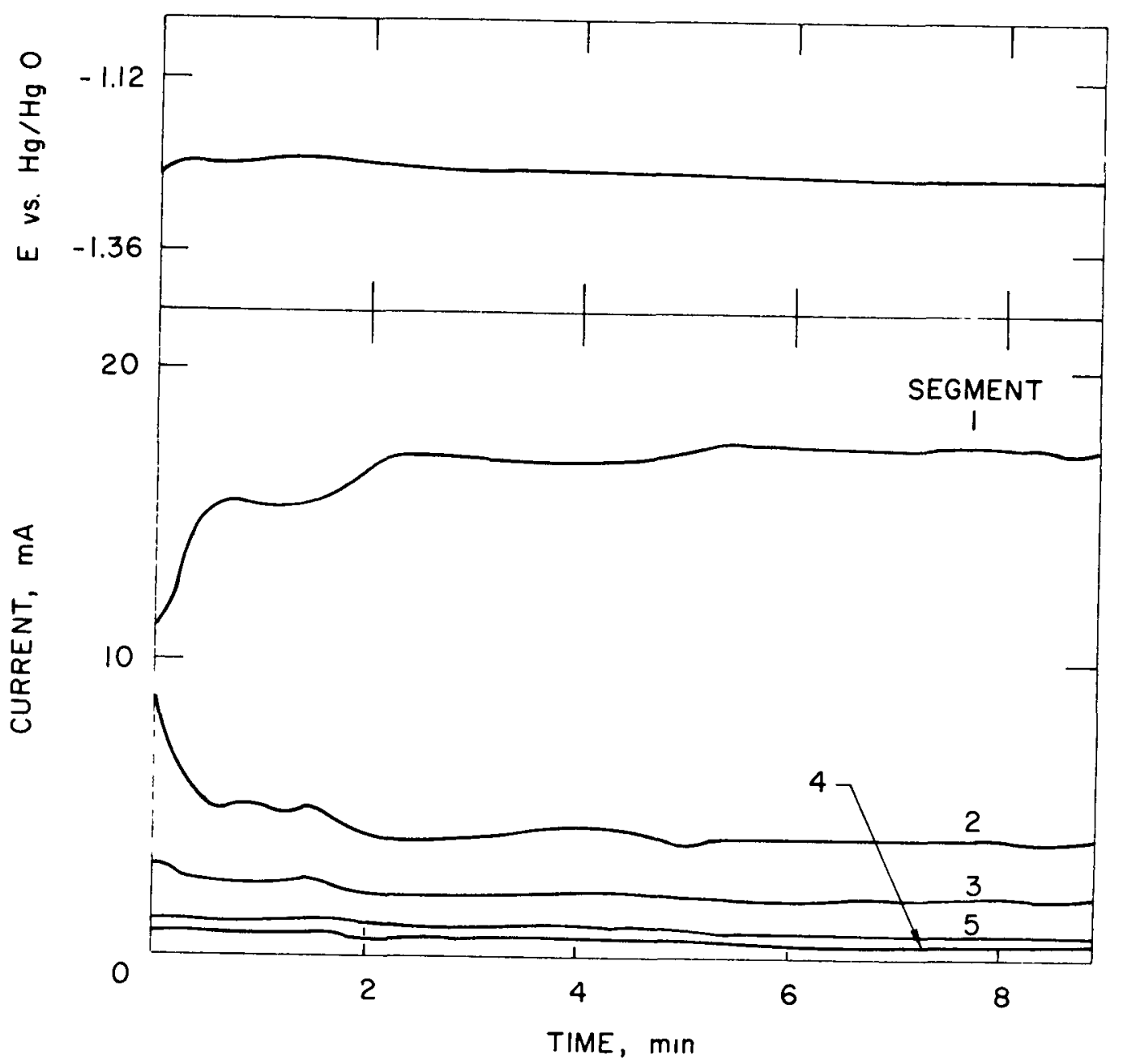

Fig. 4. Current Distribution and Potential of Segmented Electrode Discharged at $25 \mathrm{~mA}$

again as a result of a sharp increase in the electrode potential from -0.8 to $+2.3 \mathrm{~V}$ vs. the $\mathrm{Hg} / \mathrm{HgO}$ reference electrode. The period of gradual decrease in current at the first active segment is believed to be the result of gradual blockage of the electrode surface by compact type II $\mathrm{ZnO}$, which has been reported by Powers et al.12,13 to form at high overpotentials. The increase of current after the sharp increase in the electrode potential is interpreted to be due to zinc dissolution being replaced by oxygen evolution as the electrode reaction. The initial average current density at the first segment was $672 \mathrm{~mA} / \mathrm{cm}^{2}$; at this current density, a planar zinc microanode is expected to undergo passivation within $3 \mathrm{sec} .14$ However, the segmented electrode underwent passivation at $130 \mathrm{sec}$. This may imply that (1) local passivation did not occur uniformly and (2) the charge transfer reaction gradually moved from a passivated surface to a non-passivated area with a consequent increase in the electrode potential until the rate of mass transfer of hydroxide ions to the electrode surface was less than that necessary to maintain the discharge current. On the other hand, when the first segment passivated at $130 \mathrm{sec}$, the inner segments failed to take over the discharge current. This may indicate that the pores were blocked by gaseous bubbles. 


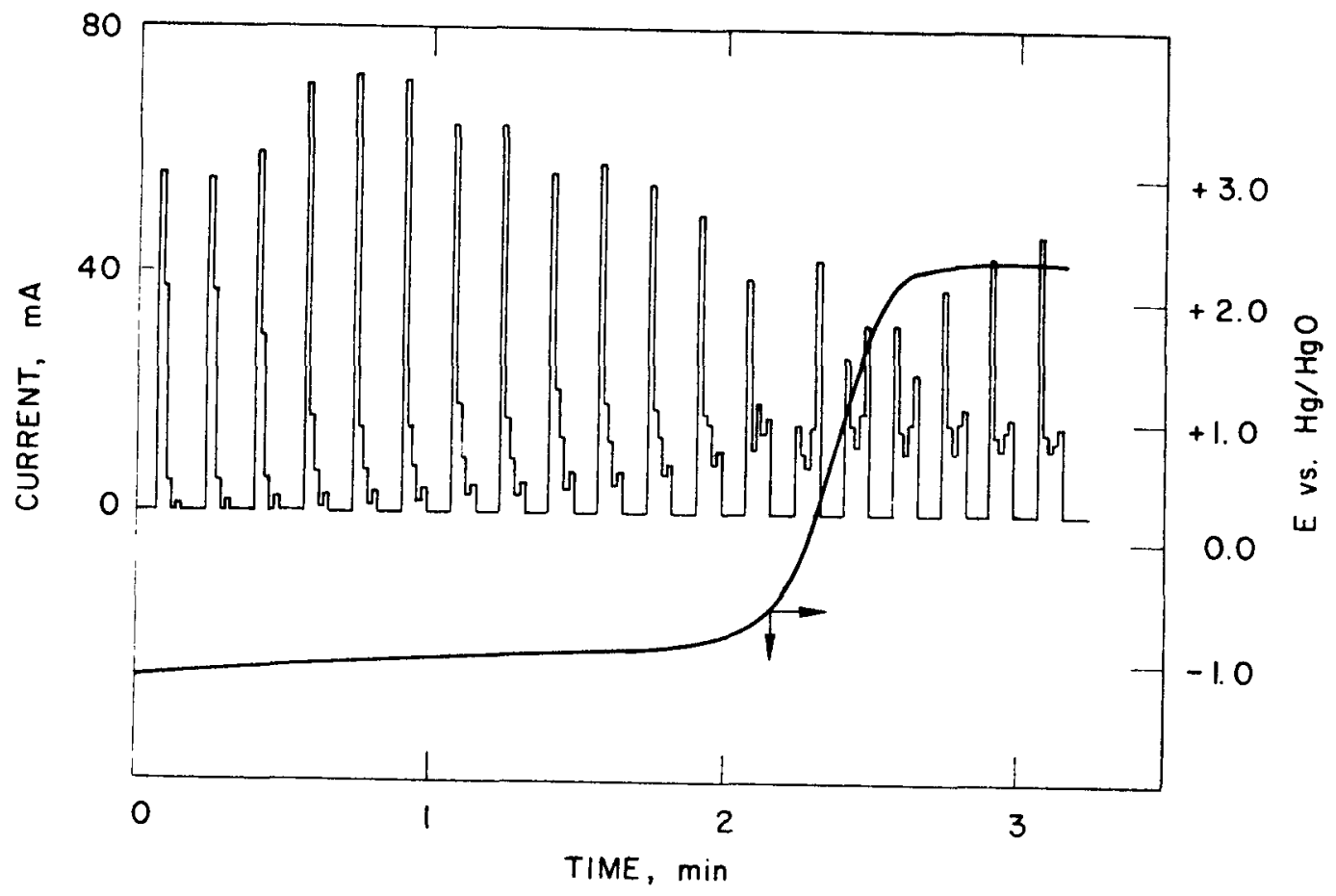

Fig. 5. Passivation Behavior of Segmented Electrode Discharged at $100 \mathrm{~mA}$

\section{Initial Current Distributions}

In each measurement, the simulated porous zinc electrode had been flooded with the electrolyte of $7.24 \mathrm{M} \mathrm{KOH}$ saturated with $\mathrm{ZnO}$. Therefore, the concentration of the electrolyte in the pores was the same as that of the bulk electrolyte. A polycrystalline zinc electrode in the $\mathrm{KOH}$ electrolyte has a high exchange current density, $150.146 \mathrm{~A} / \mathrm{cm}$. This suggests that linear polarization kinetics may be applicable. The problem of current distribution in a porous electrode with constant species concentration and linear polarization kinetics for surface reactions has been solved by Euler and Nonemaker.16,17 In this case, the solution for the current is expressed by the equation,

$$
\frac{1_{m}}{I}=1-\frac{k_{1}}{k_{1}+\sigma_{1}}\left[1+\frac{\frac{\sigma_{1}}{k_{1}} \sinh v(1-y)-\sinh (v y)}{\sinh (v)}\right]
$$

where

$y=$ distance through electrode $(x)$ divided by total thickness of active segments in electrode (L) 


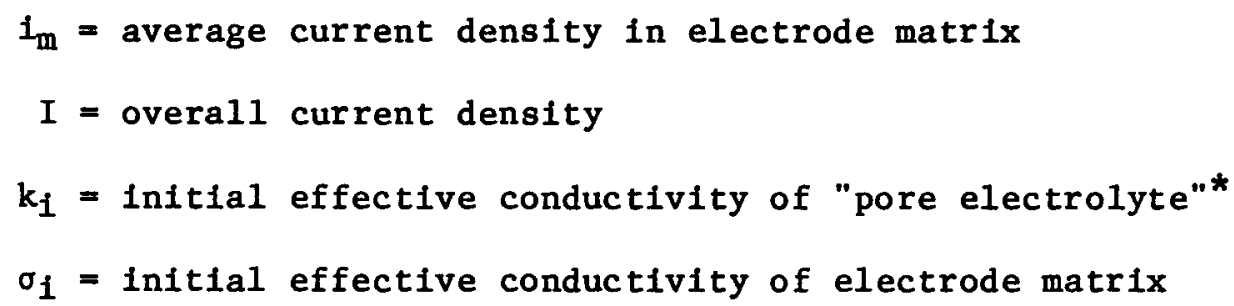

Futhermore, in this equation

$$
\nu=L \sqrt{\left(\alpha_{a}+\alpha_{c}\right) a_{0} i_{0}^{\circ} F\left(k_{1}+\sigma_{1}\right) / k_{1} \sigma_{1} R T}
$$

where

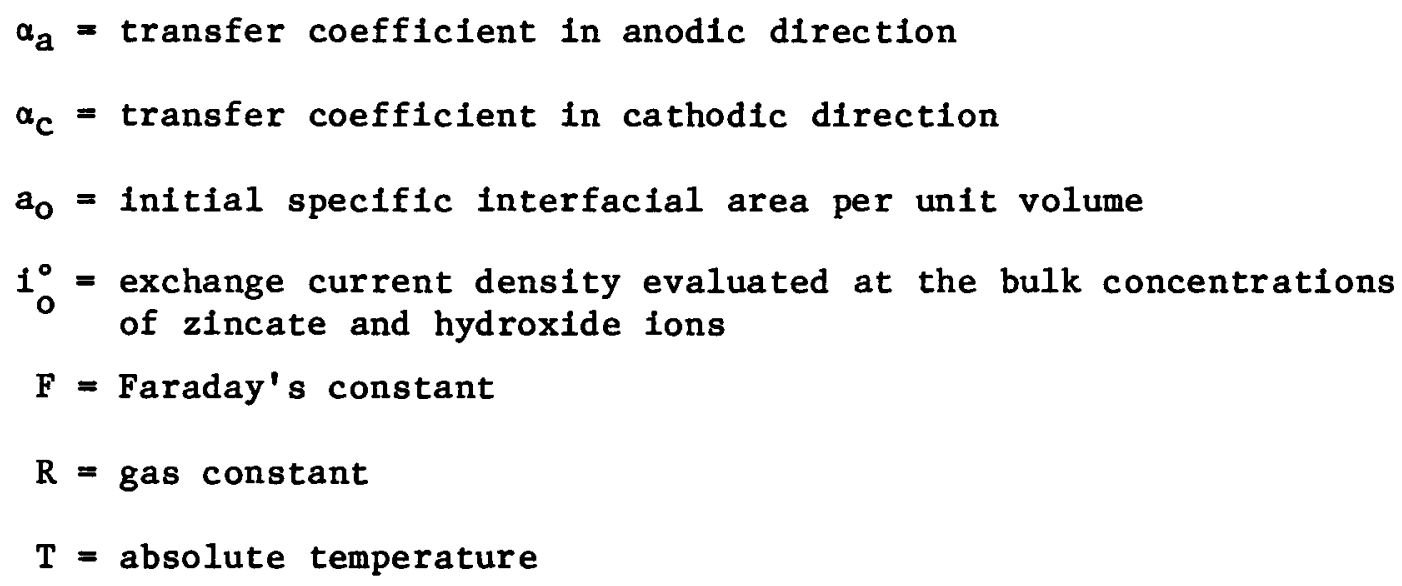

The initial effective conductivities of the pore electrolyte and the electrode matrix can be expressed by

$$
\begin{aligned}
& k_{1}=k_{0} \varepsilon_{0}\left(1+t_{e}\right) \\
& \sigma_{1}=\sigma_{m}\left(1-\varepsilon_{0}\right)
\end{aligned}
$$

where

$$
\begin{aligned}
& k_{0}=\text { specific conductivity of bulk electrolyte } \\
& \varepsilon_{0}=\text { initial porosity of electrode } \\
& t_{e}=\text { tortuosity factor of electrode } \\
& \sigma_{m}=\text { specific conductivity of electrode matrix }
\end{aligned}
$$

\footnotetext{
* The pore electrolyte is defined as the electrolyte within the pores of the electrode.
} 
Equation 1 was used to obtain the initial theoretical current distribution, $i_{m} / I$, as a function of $y$ for our segmented electrodes. The values of $k_{i}$, $\sigma$, and $\nu$ employed in Eq. 1 were derived by substituting the data given in Appendix $A$ into the above three equations. The results of our calculations of $i_{m} / I$ vs. $y$ are plotted in Fig. 6 (dashed curve). Also shown in this figure are the experimental data of initial anodic current distributions (i.e., $t=0$ ) in the simulated zinc electrode at a discharge current of $10 \mathrm{~mA}$ (circles), $25 \mathrm{~mA}$ (squares), and $100 \mathrm{~mA}$ (triangles). For the case of a discharge current of $10 \mathrm{~mA}$ (average current density at the first segment, $59 \mathrm{~mA} /$ $\mathrm{cm}^{2}$ ), there is good agreement between the predicted and experimental data. For the case with discharge currents of $25 \mathrm{~mA}$ (average current density at the first segment, $\left.132 \mathrm{~mA} / \mathrm{cm}^{2}\right)$ and $100 \mathrm{~mA}\left(672 \mathrm{~mA} / \mathrm{cm}^{2}\right)$, our experimental data deviated from the calculated results; this deviation increased with increasing discharge current. This discrepancy between the calculated and experimental data is ascribed to the fact that the current densities of the first segment of the electrodes were near to or exceeded the exchange current density, $146 \mathrm{~mA} / \mathrm{cm}^{2}$. It was concluded that the assumption of linear polarization kinetics is inadequate at high current densities.

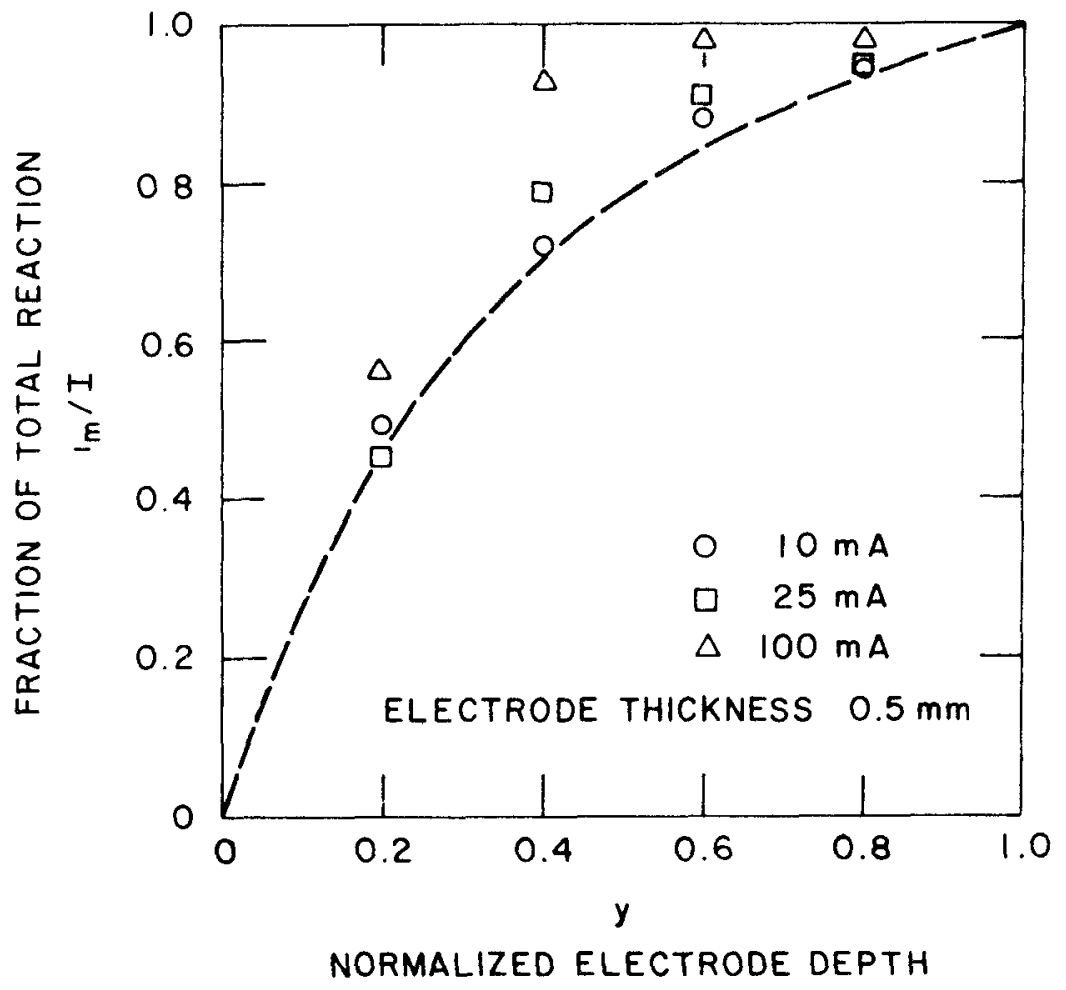

Fig. 6. Initial Profile of Integrated Fraction of the Charge Transfer Reaction in Simulated Electrode as Function of Normalized Electrode Depth (dashed curve predicted from Eq. 1) 


\section{Reaction Penetration Depth}

The reaction penetration depth is an important parameter in opti-

mizing the design of a porous electrode. A few studies in the literature $1,2,18$ have reported the reaction penetration depth of zinc porous electrodes in $\mathrm{KOH}$ electrolytes. Table 1 presents a summary of the results from these studies as well as this study. The reaction penetration depths given in Table 1 were defined as the depth within which $63.2 \%$ of the charge-transfer reaction is completed (analogous to the determination of the time constant of a linear system). In Table 1 , the reaction penetration depths range from $6.5 \times 10^{-3}$ to $3 \times 10^{-1} \mathrm{~cm}$. However, this wide variation of results could be due to the inherent nature of the different electrode designs and different techniques of measurements, which are also listed in Table 1 . Nagy et al.1 left the back side of their electrodes open to a large electrolyte reservoir; and consequently, they obtained a more uniform reaction profile throughout their electrode thickness $(0.3 \mathrm{~cm})$. Katan et a1.19 determined an initial effective depth of reaction of about $0.09 \mathrm{~cm}$ on exposed zinc electrode strips by electrochemical reduction with cathodic current until the onset of sharp polarization. Their results could have been easily affected by the masking on the electrode and the location of the $\mathrm{ZnO}$ precipitated from the zincate. They indicated that, since the polarization was observed to be several times lower than the predicted value, most of the reaction probably penetrated less than $0.09 \mathrm{~cm}$.

The unique feature of our technique is that we were able to make continuous measurements of current distribution throughout discharge. By this technique, a gradual decrease of reaction penetration depths from initial values to "steady state" during galvanostatic discharges was discovered. However, due to limitations in fabrication technique, the pore sizes of our electrodes, $265 \mu \mathrm{m}$, were much larger than those in battery electrodes (microns). Furthermore, in our experiments, electronic currents in the active segments were collected individually through channels of the ammeter circuit (Fig. 2); in an actual battery electrode, ionic currents are changed to electronic currents, which are collected by a conducting plate located at the back of the electrode. Thus, our results are representative of a battery electrode only under the condition that the solid electrode matrix is highly conductive compared with the electrolyte within the electrode pores. If this were not the case, further mathematical treatment would be necessary to account for possible differences in resistive potential between our experimental electrode and a battery electrode. For zinc battery electrodes, the specific conductivity of zinc, $2 \times 10^{5} \mathrm{mho} / \mathrm{cm}$, is five orders of magnitude higher than that of the $\mathrm{KOH}$ electrolyte, $0.4875 \mathrm{~mol} / \mathrm{cm}$. We used about $6 \mathrm{~cm}$ of copper wire (gauge no. 28), which imposed a resistance of about 0.01 on each segment, about $3 \%$ of the conductivity of the pore electrolyte in that segment.

Sunu et al. 2 used pressed zinc powder electrodes resembling a battery electrode and obtained reaction penetration depths similar to our reported depths. Therefore, our electrodes should be a good tool for simulating the behavior of zinc porous electrodes in alkaline batteries. From the results of Sunu et a1.2 and the present work, we believe that the effective reaction penetration depth of zinc porous electrodes in $\mathrm{KOH}$ electrolytes is about $0.01 \mathrm{~cm}$. 
Table 1. Reaction Penetration Depths Reported for Zinc Porous Anodes in KOH Electrolytes

\begin{tabular}{|c|c|c|c|c|}
\hline Authors & $\begin{array}{l}\text { Zinc Porous } \\
\text { Electrode } \\
\text { Design }\end{array}$ & Method & $\begin{array}{l}\text { Current } \\
\text { Density, } \\
\mathrm{mA} / \mathrm{cm}^{2}\end{array}$ & $\begin{array}{l}\text { Reaction Penetration } \\
\text { Depth, cm }\end{array}$ \\
\hline Nagy et al. 1 & $\begin{array}{l}\text { Pressed powder } \\
\text { electrodes with } \\
\text { both sides open } \\
\text { to electrolyte. }\end{array}$ & $\begin{array}{l}\text { Sectioning and } \\
\text { chemical analysis } \\
\text { of } \mathrm{Zn} \text { and } \mathrm{ZnO} \text {. }\end{array}$ & 10 to 50 & $3 \times 10^{-1}$ \\
\hline Sunu et $a 1.2$ & $\begin{array}{l}\text { Pressed powder } \\
\text { electrodes backed } \\
\text { with current } \\
\text { collector plate. }\end{array}$ & $\begin{array}{l}\text { Sectioning and } \\
\text { chemical analysis } \\
\text { of } \mathrm{Zn} \text { and } \mathrm{ZnO} \text {. }\end{array}$ & 20 and 50 & $\begin{array}{l}\left.6.5 \times 10^{-3} \text { (porosity } 0.33\right) \\
\left.9.0 \times 10^{-3} \text { (porosity } 0.60\right)\end{array}$ \\
\hline Katan et al. 19 & $\begin{array}{l}\text { Single pore } \\
\text { electrode casted } \\
\text { in plastics. }\end{array}$ & $\begin{array}{l}\text { Microscopic } \\
\text { measurement of } \\
\mathrm{Zno} \text { front, and } \\
\text { electrochemical } \\
\text { reduction of } \mathrm{Zno} \text {. }\end{array}$ & 714 & $9.0 \times 10^{-2}$ (initial) \\
\hline This Work & $\begin{array}{l}\text { Simulated porous } \\
\text { electrodes } \\
\text { divided into } \\
\text { segments. }\end{array}$ & $\begin{array}{l}\text { Continuous } \\
\text { measurement of } \\
\text { currents through } \\
\text { each segment. }\end{array}$ & $\begin{array}{l}23.8 \\
59.5\end{array}$ & $\begin{array}{l}1.7 \times 10^{-2} \text { (initial) } \\
7.5 \times 10^{-3} \text { ("steady state") } \\
1.45 \times 10^{-2} \text { (initial) } \\
8.5 \times 10^{-3} \text { ("steady state") }\end{array}$ \\
\hline
\end{tabular}


III. THEORETICAL

Equation 1 can not be used to explain the current distribution of our experimental data since (1) the concentrations of hydroxide and zincate fons change with time during discharge and (2) the assumption of linear polarization kinetics is inadequate to account for two higher discharge currents. Therefore, a mathematical model is needed to predict the current distributions in the simulated zinc porous electrodes.

\section{A. Mathematical Model}

The experimental data provide a basis upon which to use a mathematical model for predicting the behavior of the zinc porous electrode system. As indicated in the review by Newman and Tiedemann, 20 several models have been proposed to describe the operation of porous electrodes. Sunu and Bennion ${ }^{2}$ used macroscope averaging* in conjunction with a ternary electrolyte theory to analyze the behavior of zinc porous electrodes. They found good agreement between their experimental results and theoretical predictions. As a result, we used this model, with some simplifications, to simulate our experimental electrode. The assumptions or simplifictions applied to the model of Sunu and Bennion for this report are as follows:

(1) The electrode is one dimensional in the direction perpendicular to the electrode surface (see Fig. 7).

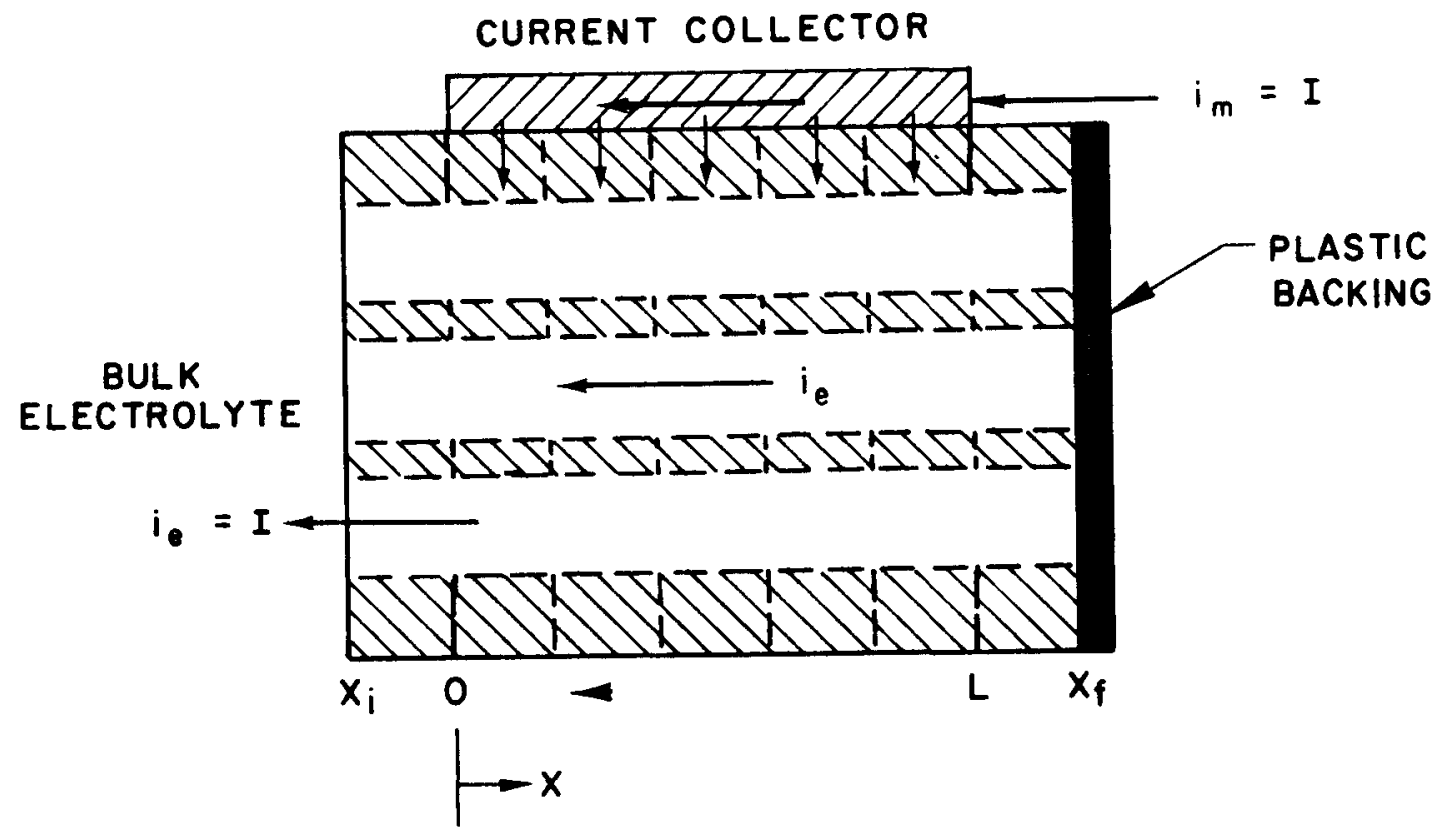

Fig. 7. One-Dimensional Porous Electrode Mode1

\footnotetext{
*In the macroscope averaging treatment, Sunu and Bennion disregarded the actual geometry of the pores and used average values of variables (e.g., current density, pore electrolyte concentration) over a small region of the electrode.
} 
(2) Hydrodynamic (bulk) flow of the electrolyte in the pores is neg1igible.

(3) The solid matrix is "isopotential;" i.e., the zinc has a much higher conductivity than the electrolyte in the pores and the precipitation of $\mathrm{ZnO}$ has minimal effect on the conductivity of the solid electrode matrix.

(4) Diffusion coefficients and activity coefficients of species are constant over the range of concentrations encountered.

(5) The system is isothermal.

(6) Terms in the flux equations describing the interaction of hydroxide ions and zincate ions are neglected.

(7) The insulation film coated on each segment has no effect on the mass transfer in the pore electrolyte.

(8) The nucleation period of $\mathrm{Zno}$ is relatively short so that there is a sufficient number of nuclei for the precipitation of $\mathrm{ZnO}$.

(9) The porosity of the "primary layer" of $\mathrm{ZnO}$ has been found to be $0.85 ; 19$ therefore, the mass transfer resistance of hydroxide and zincate ions through the $\mathrm{ZnO}$ film is assumed to be relatively small.

Based upon the above assumptions, the following seven relations, which constitute the mathematical model, were obtained.

\section{Electrochemical and Chemical Reactions}

The process occurring in the zinc electrode containing $\mathrm{KOH}$ electrolyte saturated with zinc oxide followed a dissolution-prectpitation route.12, 21 Thus,

$$
\begin{aligned}
& \mathrm{Zn}+4 \mathrm{OH}^{-} \longrightarrow \mathrm{Zn(OH)} \frac{2-}{4}+2 \mathrm{e}^{-} \\
& \mathrm{Zn}(\mathrm{OH})_{4}^{2-} \longrightarrow \mathrm{ZnO}+2 \mathrm{OH}^{-}+\mathrm{H}_{2} \mathrm{O}
\end{aligned}
$$

In the above reactions, electrochemical discharge of the zinc electrode produces a supersaturated zincate solution from which $\mathrm{ZnO}$ is precipitated. At high overpotential, the electrochemical process may be expressed by the reaction

$$
\mathrm{Zn}+2 \mathrm{OH}^{-} \longrightarrow \mathrm{ZnO}+\mathrm{H}_{2} \mathrm{O}+2 \mathrm{e}^{-}
$$

\section{Redox Electrochemical Overpotential Expression}

The relationship between the local reaction rate at a point on the pore wall and the conditions existing in the electrolyte and the electrode phase at that point can be represented by the following equation: 


$$
\begin{aligned}
& \frac{d i}{d x}=a_{m} i_{0}^{\circ}\left(\frac{c_{2}}{c_{2}^{\circ}}\right)^{n}\left(\frac{c_{3}}{c_{3}^{\circ}}\right)^{n_{3}} \\
& \left\{\exp \left[\frac{\alpha_{a} F}{R T}\left(\Phi_{m}-\Phi_{e}\right)\right]-\exp \left[-\frac{\alpha_{c} F}{R T}\left(\Phi_{m}-\Phi_{e}\right)\right]\right\}
\end{aligned}
$$

where

$$
\begin{aligned}
a_{m} & =\text { specific area per unit volume for electrochemical reaction } \\
C_{2}^{\circ} & =\text { bulk concentration of zincate lons } \\
C_{2} & =\text { local concentration of zincate ions } \\
C_{3}^{\circ} & =\text { bulk concentration of hydroxide ions } \\
C_{3} & =\text { local concentration of hydroxide ions } \\
\Phi_{m} & =\text { local potential of electrode matrix phase } \\
n_{2}, n_{3} & =\text { orders of dependence of exchange current on the concentrations }
\end{aligned}
$$

Since the specific conductivity of zinc, $2 \times 10^{5} \mathrm{mho} / \mathrm{cm}$, is five orders of magnitude greater than that of electrolyte, the zinc matrix has been assumed to be isopotential and $\Phi_{\mathrm{m}}$ set equal to zero (Assumption (3)).

3. Ohm's Law in the Solution Phase

sented by

Assumption (4) indicates that $\mathrm{Ohm}^{\prime} \mathrm{s}$ law as given by $\mathrm{Sunu}^{2}$ is repre-

$$
i_{e}=-k\left[\frac{d \Phi_{e}}{d x}-\frac{R T\left(1+t_{2}^{\circ}\right)}{n F} \frac{d \ln C_{A}}{d x}+\frac{R T\left(4-2 t_{3}^{\circ}\right)}{n F} \frac{d \ln C_{B}}{d x}\right]
$$

where

$$
\begin{aligned}
& i_{e}=\text { average current density in pore electrolyte phase } \\
& k=\text { effective conductivity of pore electrolyte }\left(k_{e} \varepsilon^{1+t}\right) \\
& \phi_{e}=\text { potential of pore electrolyte } \\
& t_{2}^{\circ}=\text { transference number of zincate ions } \\
& t_{3}^{\circ}=\text { transference number of hydroxide ions }
\end{aligned}
$$




$$
\begin{aligned}
n & =\text { number of electrons transferred in electrode reaction } \\
C_{A} & =\text { local concentration of potassium zincate } \\
C_{B} & =\text { local concentration of potassium hydroxide }
\end{aligned}
$$

The specific conductivity of the $\mathrm{KOH}$ electrolyte, $\mathrm{k}_{e}$, decreases linearly with increasing concentration of zincate up to chemical saturation; 22 no data are available for $\mathrm{KOH}$ supersaturated with zincate. In $\mathrm{KOH}$ electrolyte containing potassium carbonate, the specific conductivity of $8.3 \mathrm{M} \mathrm{KOH}$ was found by Nitabah et al.23 to decrease linearly with the percentage of potassium carbonate up to $100 \%$. By analogy, the specific conductivity of the supersaturated electrolyte was assumed to decrease linearly with increasing zincate concentration; this can be expressed by the equation

$$
k_{e}=k_{0}-\gamma C_{2}
$$

where $\gamma$ is the coefficient of the dependence of the specific electrolyte conductivity on the concentration of zincate ions. For $7.24 \mathrm{M} \mathrm{KOH,} \mathrm{k}_{\mathrm{o}}$ was measured to be $0.62 \mathrm{mho} / \mathrm{cm}$. The value of $\gamma$ was then estimated to be $207 \mathrm{mho} \cdot \mathrm{cm}^{2} / \mathrm{mol}$ from the value for $k_{0}$, the specific conductivity of the electrolyte saturated with $\mathrm{ZnO}(0.4875 \mathrm{mho} / \mathrm{cm})$, and the zincate concentration in the electrolyte $(0.64 \underline{\mathrm{M}})$.

\section{Species Conservation Equations}

We can write the conservation equations in the solution phase as

$$
\begin{aligned}
& \frac{\partial \varepsilon C_{2}}{\partial t}=\frac{-\partial N_{2}}{\partial x}+\frac{1}{n F} \frac{\partial i_{e}}{\partial x}-a k_{s}\left(C_{2}-C_{2}^{s h}\right) \\
& \frac{\partial \varepsilon C_{3}}{\partial t}=\frac{-\partial N_{3}}{\partial x} \frac{-4}{n F} \frac{\partial i}{\partial x}+2 a k_{s}\left(C_{2}-C_{2}^{s h}\right)
\end{aligned}
$$

where $\varepsilon$ is the local porosity of the electrode, a is the specific surface area per unit volume for the precipitation of $\mathrm{ZnO}_{\mathrm{s}} \mathrm{k}_{\mathrm{s}}$ is the overall precipitation rate constant of $\mathrm{ZnO}, \mathrm{C}_{2}^{\mathrm{sh}}$ is the threshold concentration of zincate ions for the precipitation of $\mathrm{ZnO}$, and $\mathrm{N}_{2}$ and $\mathrm{N}_{3}$ are the fluxes of zincate and hydroxide ions expressed by

$$
\begin{aligned}
& N_{2}=-D_{2} \varepsilon \frac{\partial C_{2}}{\partial x}+\frac{i_{e} t_{2}^{\circ}}{Z_{2} F} \\
& N_{3}=-D_{3} \varepsilon \frac{\partial C_{3}}{\partial x}+\frac{i e^{t_{3}^{\circ}}}{Z_{3} F}
\end{aligned}
$$


In Eqs. (10) and (11), $\mathrm{D}_{2}$ is the diffusion coefficient of zincate ions, and $\mathrm{D}_{3}$ is the diffusion coefficient of hydroxide ions.

5. Surface Areas and Precipitation Rate Constant ( $a_{m}, a$, and $\left.k_{s}\right)$

The pore diameter changes with time as discharge current is passed through an electrode due to the precipitation of $\mathrm{ZnO}$. We present a physical model in Fig. 8 for the calculation of the effective specific areas per unit

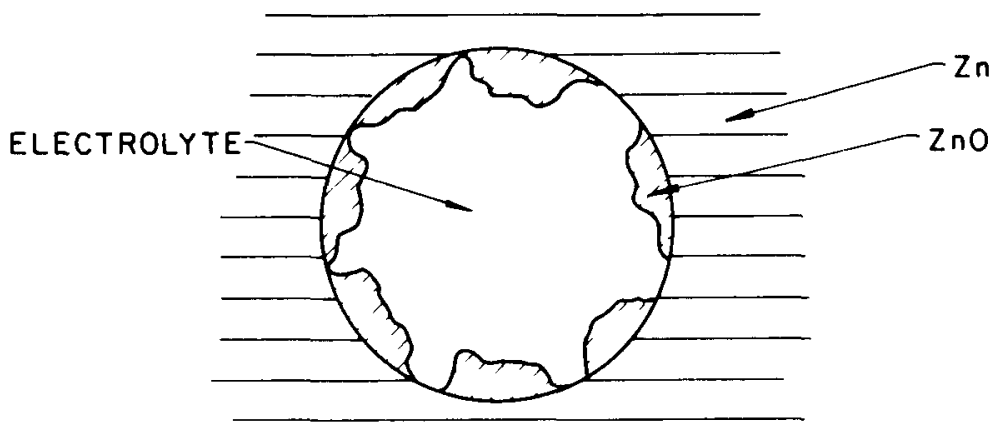

EQUIVALENT TO

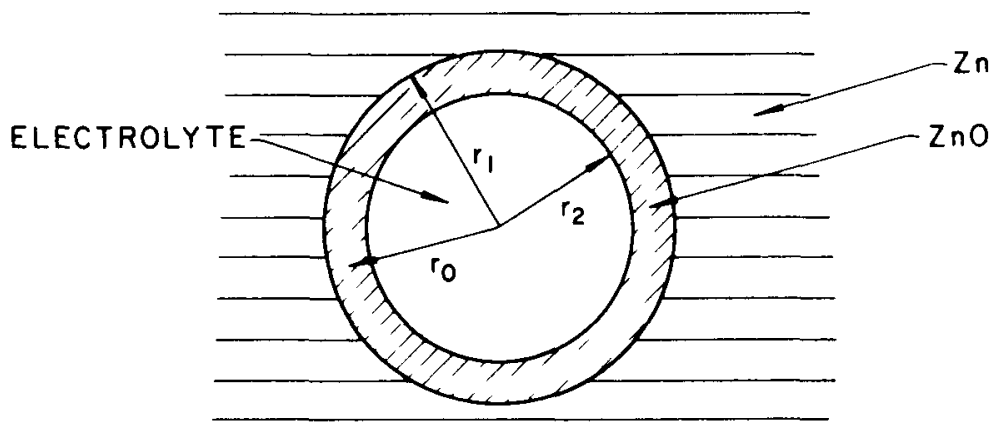

Fig. 8. Model for Pore Geometry

volume for the electrochemical reaction $\left(a_{m}\right)$ and the precipitation of $\mathrm{ZnO}$ (a). In Fig. 8, the boundaries between the $\mathrm{ZnO}$ and the electrolyte as well as between the zinc and $Z n 0$ are defined by the radil, $r_{1}$ and $r_{2}$, respectively; $r_{0}$ is the initial pore radius. At low overpotential, the $\mathrm{ZnO} f i l m$ (type I) has been observed by various investigators 18,24 to be highly porous (about $85 \%$ ). Under this condition, we assumed that the mass transfer resistance of the Zno film was relatively small (assumption 9). Therefore, the effective specific area per unit volume for the electrochemical reaction is expressed by

$$
a_{m}=a_{o}\left(\frac{2 \pi r_{1} d x}{2 \pi r_{0} d x}\right)
$$

or 


$$
a_{m}=a_{0}\left(\frac{r_{1}}{r_{0}}\right)
$$

where $a_{0}$ is the initial specific surface area per unit volume of the pore region in the electrode. The volume fractions of $\mathrm{Zn}$ and $\mathrm{ZnO}$ and the porosity of the electrode are related as follows:

$$
1-\varepsilon_{\mathrm{Zn}}-\varepsilon_{\mathrm{ZnO}}=\varepsilon_{\mathrm{o}}\left(\frac{\pi \mathrm{r}_{2}^{2} \mathrm{dx}}{\pi \mathrm{r}_{0}^{2} \mathrm{dx}}\right)
$$

or

$$
1-\varepsilon_{Z n}-\varepsilon_{Z n O}=\varepsilon_{o}\left(\frac{r_{2}}{r_{0}}\right)^{2}
$$

and

$$
1-\varepsilon_{\mathrm{Zn}}=\varepsilon_{\mathrm{o}}\left(\frac{\pi \mathrm{r}_{1}^{2} \mathrm{dx}}{\pi \mathrm{r}_{0}^{2} \mathrm{dx}}\right)
$$

or

$$
1-\varepsilon_{\mathrm{Zn}}=\varepsilon_{0}\left(\frac{\mathrm{r}_{1}}{\mathrm{r}_{0}}\right)
$$

From Eqs. 12 and 14, we derived

$$
a_{m}=a_{o}\left(\frac{1-\varepsilon_{Z n}}{\varepsilon_{o}}\right)^{1 / 2}
$$

At high overpotential, reaction (4) may occur and a compact $\mathrm{Zno}$ film (type II; porosity, 0.003) forms on the zinc surface.12,13,14,24 Therefore, the effective specific surface area per unit volume for the electrochemical reaction was assumed to be gradually reduced by the fraction of "coverage" of this type of $\mathrm{Zno}$. It was assumed that, when $\phi_{\mathrm{m}}-\phi_{\mathrm{e}}$ is greater than a threshold value, $\phi_{\mathrm{sh}}$, the formation of compact $\mathrm{ZnO}$ is initiated and the surface eventually becomes inactive. The fraction of "coverage" of the $\mathrm{ZnO}(\theta)$ is, therefore, expressed by the equation, 


$$
\frac{\partial \theta}{\partial t}=\frac{1}{a_{m} n_{A} n F} \frac{\partial i e}{\partial x}
$$

for

$$
\phi_{\mathrm{m}}-\phi_{\mathrm{e}} \geq \phi_{\mathrm{sh}}
$$

where $\mathrm{n}_{\mathrm{A}}$ is the maximum surface molar concentration of the compact $\mathrm{ZnO}$, and the effective specific surface area per unit volume for the electrochemical reaction is expressed by the equation

$$
a_{m}=a^{0}\left(\frac{1-\varepsilon_{Z n}}{\varepsilon_{0}}\right)^{1 / 2}(1-\theta)
$$

The kinetics of the precipitation of $\mathrm{Zno}$ is not well-known. However, it is believed to undergo the following steps:

(1) the electrochemical reaction of $\mathrm{Zn}$ in the electrolyte produces zincate

(2) zincate transforms to the $\mathrm{ZnO}$ on the electrode surface

(3) surface decomposition of zincate forms $\mathrm{ZnO}$

Katan et al.19 proposed that zincate decomposes at the outer boundary of the existing Zno film. Therefore, the effective specific surface area per unit volume for the precipitation of $\mathrm{ZnO}$ was assumed to be

$$
a=a_{\circ}\left(\frac{r_{2}}{r_{0}}\right)^{1 / 2}
$$

Combining Eqs. (13) and (18), we obtained

$$
a=a_{0}\left(\frac{1-\varepsilon_{Z n}-\varepsilon_{Z n O}}{\varepsilon_{0}}\right)^{1 / 2}
$$

The precipitation rate of $\mathrm{ZnO}$ depends on the rates of steps 2 and 3 above. To a first approximation, the apparent rate constant of the precipitation of $\mathrm{Zno}$, $\mathrm{k}_{\mathrm{s}}$, is expressed by

$$
\frac{1}{k_{s}}=\frac{1}{k_{d}}+\frac{1}{g k_{r}}
$$

where $k_{d}$ is the mass transfer coefficient of zincate (step 2), $k_{r}$ is the intrinsic precipitation rate constant of $\mathrm{ZnO}$ (step 3 ), and $\mathrm{g}$ is a factor to 
account for the surface roughness of the $\mathrm{ZnO}$ and depends on the discharge current density. 21 For a diffusion limiting process, the value of $k_{s}$ is in the range of $10^{-2}$ to $10^{-3} \mathrm{~cm} / \mathrm{sec}$, depending on the length of the diffusion path. For a kinetics limiting process, the value of $k_{s}$ is equal to $g k_{r}$.

\section{Conservation Equations of Solid Matrix}

These equations are

$$
\begin{aligned}
& \frac{\partial \varepsilon_{\mathrm{Zn}}}{\partial t}=\frac{-\overline{\mathrm{V}}_{\mathrm{Zn}}}{\mathrm{nF}} \frac{\partial \mathrm{i}_{\mathrm{e}}}{\partial \mathrm{x}} \\
& \frac{\partial \varepsilon_{\mathrm{Zn} 0}}{\partial t}=\overline{\mathrm{V}}_{\mathrm{ZnO}}{ }^{\text {ak }} \mathrm{s} \quad\left(\mathrm{C}_{2}-\mathrm{C}_{2}^{\mathrm{sh}}\right)
\end{aligned}
$$

and

$$
\varepsilon=1-\varepsilon_{\mathrm{Zn}}-\varepsilon_{\mathrm{ZnO}}
$$

where $\bar{V}_{\mathrm{Zn}}$ and $\overline{\mathrm{V}}_{\mathrm{ZnO}}$ are the partial molar volumes of $\mathrm{Zn}$ and $\mathrm{ZnO}$, respectively.

\section{Charge Conservation Equation}

In a porous electrode, the current is carried out by electronic current in the solid matrix and ionic current in the electrolyte phase. Thus, for a constant current discharge, the total current density at each depth in the electrode is equal to the summation of ionic and electronic current densities at that location; i.e.,

$$
i_{m}+i_{e}=I
$$

\section{B. Computation Procedures for the Model}

The two second-order equations, Eqs. 8 and 9, and the two first-order equations, Eqs. 5 and 6 , form a set of nonlinear, coupled differential equations. The four unknown variables are $i_{m}, \phi_{e}, C_{2}$, and $C_{3}$, which are all functions of time and position. These equations are solved using the initial and boundary conditions given below:

(1) At $t=0, C_{2}=C_{2}^{\circ}$ and $C_{3}=C_{3}^{\circ}$

(2) At $\mathrm{x}=\mathrm{x}_{1}, \mathrm{C}_{2}=\mathrm{C}_{2}^{\circ}$ and $\mathrm{C}_{3}=\mathrm{C}_{3}^{\circ}$

(3) For $x_{1} \leq x \leq 0 i_{e}=I$ and $L<x \leq x_{f}, I_{m}=i_{e}=0$

(4) At $x=L, i_{m}=I$ 
(5) At $x=x_{f}, \mathrm{dC}_{2} / \mathrm{dx}=0$ and $\mathrm{dC}_{3} / \mathrm{dx}=0$

(6) $\phi_{\mathrm{m}}(\mathrm{x})=0$

It is convenient to transform the set of differential equations into dimensionless expressions. The following set of definitions is used for this purpose:

$$
\begin{aligned}
y & =x / L \\
j & i_{m} / I \\
E_{2} & =C_{2} / C_{2}^{\circ} \\
E_{3} & =C_{3} / C_{3}^{\circ} \\
\psi_{e} & =\phi_{e} n F / R T \\
\zeta & =D_{3} t / L 2 \\
\psi_{m} & =\phi_{m} n F / R T
\end{aligned}
$$

Furthermore, the following groups are used:

$$
\begin{aligned}
& P_{1}=D_{2} / D_{3} \\
& \mathrm{P}_{2}=\mathrm{C}_{3}^{\circ} / \mathrm{C}_{2}^{\circ} \\
& \mathrm{P}_{3}=-4 \mathrm{IL} / \mathrm{nFD}_{3} \mathrm{C}_{3}^{\circ} \\
& P_{4}=+I L t_{2}^{\circ} / Z_{2} D_{3} C_{3}^{\circ} F \\
& P_{5}=+I L t_{3}^{\circ} / Z_{3} D_{3} C_{3}^{\circ} F \\
& P_{6}=-n F I L / k R T \\
& \mathrm{P}_{7}=\mathrm{ak}_{\mathrm{s}} \mathrm{L}^{2} / \mathrm{D}_{3} \\
& \mathrm{P}_{8}=\mathrm{a}_{\mathrm{m}}{ }^{{ }^{\circ} \mathrm{L} / \mathrm{I}}
\end{aligned}
$$

It should be noted that $I$ is negative with respect to the direction of $x$. Substituting the above definitions and groups into Eqs. 8 and 9, we obtained 


$$
\frac{\partial\left(\varepsilon E_{2}\right)}{\partial \zeta}=P_{1} \frac{\partial}{\partial y}\left(\varepsilon \frac{\partial E_{2}}{\partial y}\right)+P_{2}\left(\frac{P_{3}}{4}+P_{4}\right) \frac{\partial j}{\partial y}-P_{7}\left(E_{2}-E_{2}^{s h}\right)
$$

and

$$
\begin{aligned}
\frac{\partial\left(\varepsilon E_{3}\right)}{\partial \zeta}= & \frac{\partial}{\partial y}\left(\varepsilon \frac{\partial E_{3}}{\partial y}\right)-\left(P_{3}-P_{5}\right) \frac{\partial j}{\partial y} \\
& +2\left(P_{7} / P_{2}\right)\left(E_{2}-E_{2}^{s h}\right)
\end{aligned}
$$

Rearranging Eq. 6 and then substituting the above definitions and groups into this rearranged equation, we derived

$$
\begin{aligned}
\frac{d \psi_{e}}{d y}= & P_{6}(1-j)+\left(1+t_{2}^{\circ}\right) \frac{d \ln E_{2}}{d y} \\
& -\left(4-2 t_{3}^{\circ}\right) \frac{d \ln E_{3}}{d y}
\end{aligned}
$$

Similarly, Eq. 5 can be transformed to

$$
\frac{d j}{d y}=P_{8}\left(E_{2}\right)^{\eta_{2}}\left(E_{3}\right)^{\eta_{3}}\left\{\exp \left(-\frac{\alpha_{a}}{n} \psi_{e}\right)-\exp \left(\frac{\alpha_{c}}{n} \psi_{e}\right)\right\}
$$

Furthermore, the initial and boundary conditions become:

(1) At $\zeta=0, E_{2}=E_{3}=1$

(2) At $y=x_{1} / L, E_{2}=E_{3}=1$

(3) At $y=x_{1} / L \leq y \leq 0$ and $1<y \leq x_{1} / L, j=0$

(4) At $\mathrm{y}=1, \mathrm{j}=1.0$

(5) At $y=x_{f} / L, d E_{2} / d y=0$ and $d_{3} / d y=0$

The above equations were solved by the explicit finite difference method 25 for the local concentrations of hydroxide and zincate ions, the current in the solid matrix, and the local potential in the electrolyte solution as a function of position in the electrode. The applied constant discharge currents used for these calculations were those given in the experimental section (1.e., $10,25$, and $100 \mathrm{~mA})$. The sufficient condition for convergence of the explicit finite-difference method 25 is

$$
0<\lambda \leq 1 / 2
$$


where $\lambda=\Delta \zeta /(\Delta y)^{2}$. To save computer time and memory, a maximum allowable value of $\lambda=0.5$ and a reasonably small value of $\Delta y=0.04$ were used in the calculations. In using the finite difference technique to solve the above equations, we first expanded Eq. 25 to

$$
\begin{aligned}
\varepsilon\left(\frac{\partial E_{2}}{\partial \zeta}\right)+E_{2}\left(\frac{\partial \varepsilon}{\partial \zeta}\right)= & P_{1} \varepsilon\left(\frac{\partial^{2} E_{2}}{\partial y^{2}}\right)+P_{1}\left(\frac{\partial \varepsilon}{\partial y}\right)\left(\frac{\partial E_{2}}{\partial y}\right) \\
& +P_{2}\left(\frac{P_{3}}{4}+P_{4}\right) \frac{\partial j}{\partial y}-P_{7}\left(E_{2}-E_{2}^{s h}\right)
\end{aligned}
$$

and Eq. 26 to

$$
\begin{aligned}
\varepsilon\left(\frac{\partial \varepsilon_{3}}{\partial \zeta}\right)+E_{3}\left(\frac{\partial \varepsilon}{\partial \zeta}\right)= & \varepsilon\left(\frac{\partial^{2} E_{3}}{\partial y^{2}}\right)+\left(\frac{\partial \varepsilon}{\partial y}\right)\left(\frac{\partial E_{3}}{\partial y}\right) \\
& -\left(P_{3}-P_{5}\right) \frac{\partial j}{\partial y}+2\left(P_{7} / P_{2}\right)\left(E_{2}-E_{2}^{s h}\right)
\end{aligned}
$$

and Eq. 27 to

$$
\begin{gathered}
\frac{d \psi_{e}}{d y}=P_{6}(1-j)+\left(1+t_{2}^{\circ}\right) \frac{1}{E_{2}} \frac{d E_{2}}{d y} \\
-\left(4-2 t_{3}^{\circ}\right) \frac{1}{E_{3}} \frac{d E_{2}}{d y}
\end{gathered}
$$

A network of grid points was then established throughout the region of interest occupied by the independent variables $\mathrm{y}$ and $\zeta$. The grid spacings were $\Delta \zeta=$ $8 \times 10^{-4}$ and $\Delta y=0.04$, respectively. The time derivatives of variable $u$ were then replaced by the finite difference form

$$
\frac{\partial u}{\partial \zeta}=\frac{u_{1, n+1}-u_{1, n}}{\Delta \zeta}
$$

Subscripts $i$ and $n$ denote the space-related point having coordinates $1 \Delta y$, $\mathrm{n} \Delta \zeta$, which is also called the grid-point $(1, n)$. Similarly, the space derivatives of $u$ were replaced by the central finite-difference forms 


$$
\begin{gathered}
\frac{\partial u}{\partial y}=\frac{u_{i+1, n}-u_{i-1, n}}{2 \Delta y} \\
\frac{\partial^{2} u}{\partial y^{2}}=\frac{u_{i-1, n}-2 u_{1, n}+u_{i+1, n}}{(\Delta y)^{2}}
\end{gathered}
$$

Except at the boundary points, the space derivatives were approximated by the forward finite-difference form

$$
\frac{\partial u}{\partial y}=\frac{u_{i+1, n}-u_{i, n}}{\Delta y}
$$

or the backward finite-difference form

$$
\frac{\partial u}{\partial y}=\frac{u_{1, n}-u_{1-1, n}}{\Delta y}
$$

After the derivatives in Eqs. 29 and 30 had been replaced by the finitedifference points, the values of $E_{2}$ and $E_{3}$ at the $(n+1)$ time step were calculated from the values of the dependent variables $E_{i}, \varepsilon$, and $j$ calculated at the nth time step. In this calculation scheme, initial and boundary conditions of the hydroxide and zincate concentrations (previously given) as well as the experimental results of initial values $(n=0)$ of $j$ were used. By a similar computational method, the values of $\varepsilon, \varepsilon_{\mathrm{Zn}}$, and $\varepsilon_{\mathrm{ZnO}}$ at the $(\mathrm{n}+1)$ time step were calculated from Eqs. 21-23. These calculated values of $\mathrm{E}_{2}$, $\mathrm{E}_{3}, \varepsilon, \dot{\varepsilon}_{\mathrm{Zn}}$, and $\varepsilon_{7 \mathrm{nO}}$ were then used in Eqs. 28 and 31 . Equation 28 was first linearized with the techniques described by Newman.26 Forward and backward finite-difference forms were written for Eqs. 28 and 31 , respectively. The combination of these two finite-difference equations yielded a set of difference equations of $j$, which were solved by double precision algorithms for tridiagonal matrices (subroutine DGTSL).27 The criterion for convergence was set at $10^{-5}$, which is defined as the difference between the two successive solutions. The numerical solutions were carried out in double precision on an IBM 370/195 digital computer. Appendix A gives the numerical values used for the dependent variables in the calculations. The computer program derived to obtain the numerical solutions for this model is given in Appendix $B$.

\section{Results and Discussion}

As a result of our computations from the mathematical model, we characterized the behavior of a zinc porous electrode in alkaline electrolyte by the dimensionless groups given in Table 2. Each of these dimensionless groups indicates the relative importance of two physlochemical effects. The groups 
Table 2. The Dimensionless Groups Characterizing the Behavior of a Zinc Porous Electrode in Alkaline Electrolytes

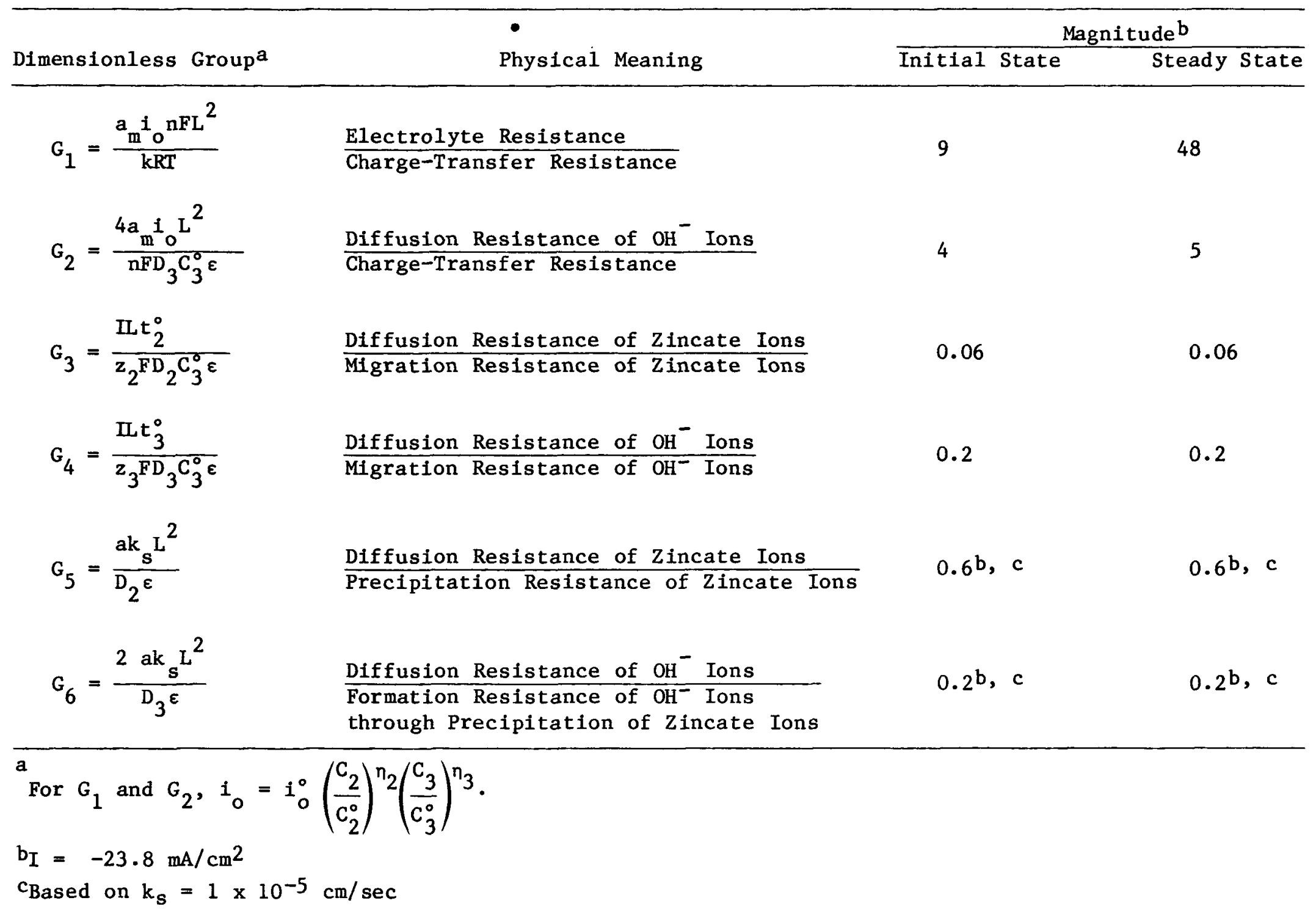


given in this table were derived from the dimensionless groups $P_{3}$ through $P_{8}$ as follows:

$$
\begin{aligned}
& G_{1}=P_{6} \cdot P_{8} \cdot\left(E_{2}\right)^{\eta_{2}}\left(E_{3}\right)^{\eta_{3}} \\
& G_{2}=P_{3} \cdot P_{8} \cdot\left(E_{2}\right)^{\eta_{2}}\left(E_{3}\right)^{\eta_{3} / \varepsilon} \\
& G_{3}=P_{4} / \varepsilon \\
& G_{4}=P_{5} / \varepsilon \\
& G_{5}=P_{7} / \varepsilon \\
& G_{6}=2 P_{7} / P_{1} \varepsilon
\end{aligned}
$$

For $G_{2}$ to $G_{6}$, the porosity is included in the denominator because the effective diffusivity of a species in a porous medium is the product of the diffusivity of the species and the porosity of the medium. In a similar manner, other dimensionless groups may be formed for comparing the relative magnitude of physical parameters. Although the performance of a porous electrode may be controlled by more than two effects, the relative magnitude of the parameters with respect to each other can be employed to estimate which particular effects are the most important ones for a particular electrode design. These parameters are discussed in terms of our simulated porous zinc electrode in the following paragraphs.

\section{Electrolyte Conductivity}

Our data on initial current distribution of the simulated electrodes, shown in Fig. 6, indicated that the reaction profiles were highly nonuniform and concentrated within the front ( 1 .e., near to bulk electrolyte) $0.02 \mathrm{~cm}$ of the first active segment. Newman et al.20 have indicated that this kind of reaction profile is a result of a much higher conductivity in the solid electrode matrix than that in the pore electrolyte; this observation is in agreement with assumption 3 given earlier. This finding indicates that $G_{1}$ controls the uniformity of the initial reaction within the simulated zinc electrodes. Indeed, we have calculated a large initial $G_{1}$ value of 9 from available physiochemical data and the pore geometry of our electrode. As an electrode continues to be discharged, the electrolyte-phase conductivity undergoes further reduction due to the increase of zincate concentration. Consequently, the reaction profile becomes more nonuniform. A concentration of zincate that has three to four times the solubility of $\mathrm{ZnO}$ in $\mathrm{KOH}$ solution has been usually observed during the discharge of zinc electrodes.28 For a zincate concentration of four times the solubility of $\mathrm{ZnO}$ in our electrolyte, according to Eq. 7, the conductivity in the pore electrolyte phase would be reduced by $82 \%$. In order to maintain the initial reaction profile by maintaining a constant $G_{1}$, a decrease of $82 \%$ in the exchange current density would be necessary. The dependence of exchange current density on the concentrations of zincate and 
hydroxide ions is expressed in Eq. 5, for which the orders of dependence, $\eta_{2}$ and $n_{3}$, are 0 and 0.45 , respectively.15 Accordingly, this equation indicates that a reduction of $98 \%$ in the hydroxide ion concentration is required to produce an $82 \%$ decrease of exchange current density, but our calculations indicate that this is not likely to occur under the experimental conditions given in Section II! Therefore, a reduction of conductivity in the pore electrolyte phase is probably responsible for the observed time dependence of the reaction profiles shown in Figs. 3-5. A further discussion of the conductivity of the electrolyte with respect to the reaction penetration depth will be given later.

\section{Precipitation of $\mathrm{ZnO}$}

Reaction (2), the precipitation of $\mathrm{ZnO}$, removes zincate ions from the electrolyte and provides a source for hydroxide ions. The precipitation of $\mathrm{ZnO}$ also affects the conductivity of the electrolyte phase, which was assumed to decrease linearly with increasing zincate concentration. As mentioned previously, the precipitation rate of $\mathrm{ZnO}$ depends on the rate of transport of zincate to the existing $\mathrm{ZnO}$ and the rate of the precipitation reaction. Although the precipitation mechanism of $\mathrm{ZnO}$ has been reported elsewhere, 22 there does not appear to be a quantitative rate expression for such a process in the literature. Therefore, the mathematical model presented in Section III.A. (Eqs. 28-31) was used to predict the current distribution and overpotential of our segmented zinc electrode at different precipitation rate constants $\left(k_{s}\right)$ and applied currents.*

Figure 9 shows the current distribution (fraction of current in active segments vs. time) predicted for the segmented zinc porous electrode in the $\mathrm{KOH}$ electrolyte discharged at a current of $10 \mathrm{~mA}\left(23.8 \mathrm{~mA} / \mathrm{cm}^{2}\right)$; the rate constants for the precipitation of $\mathrm{ZnO}$ were chosen to be $1 \mathrm{x} 10^{-5} \mathrm{~cm} / \mathrm{sec}$ (series 1 ) and $1 \times 10^{-4} \mathrm{~cm} / \mathrm{sec}$ (series 2). The active segments were labeled as A (segment 1 of simulated electrode), B (segment 2), C (segment 3), D (segment 4), and $\mathrm{E}$ (segment 5). (This same method of labeling the electrode segments will be used in figures that follow.) Figure 10 shows the overpotential calculated for the simulated electrode at $10-\mathrm{mA}$ discharge current for the two rate constants. The overpotential was defined as the difference between the potential of the electrode solid matrix at $x=L$ and the potential of the electrolyte at the reference electrode, i.e., $\psi_{m}(L)-\psi_{e}(R E)$. Our experimental data are also given in these two figures for comparison. As can be deduced from these figures, a rate constant of $1 \times 10^{-5} \mathrm{~cm} / \mathrm{sec}$ yielded the best prediction of current distribution and overpotential of the segmented electrode. Table 2 give the change of the dimensionless groups from initial values to steady-state values. An examination of the data in Appendix B indicated that the predicted current distribution and overpotentials shown in the figures for $k_{s}=1 \times 10^{-5} \mathrm{~cm} / \mathrm{sec}$ were produced by the following alterations occurring in the segmented electrode during discharge: (1) a decrease in the volume fraction of the zinc matrix due to an increase in the average $a_{m}$ by up to $40 \%$ (see Eq. 15); (2) an increase of the zincate concentration

\footnotetext{
*Numerical values of other variables needed to solve Eqs. 28-31 are given in Appendix A.
} 


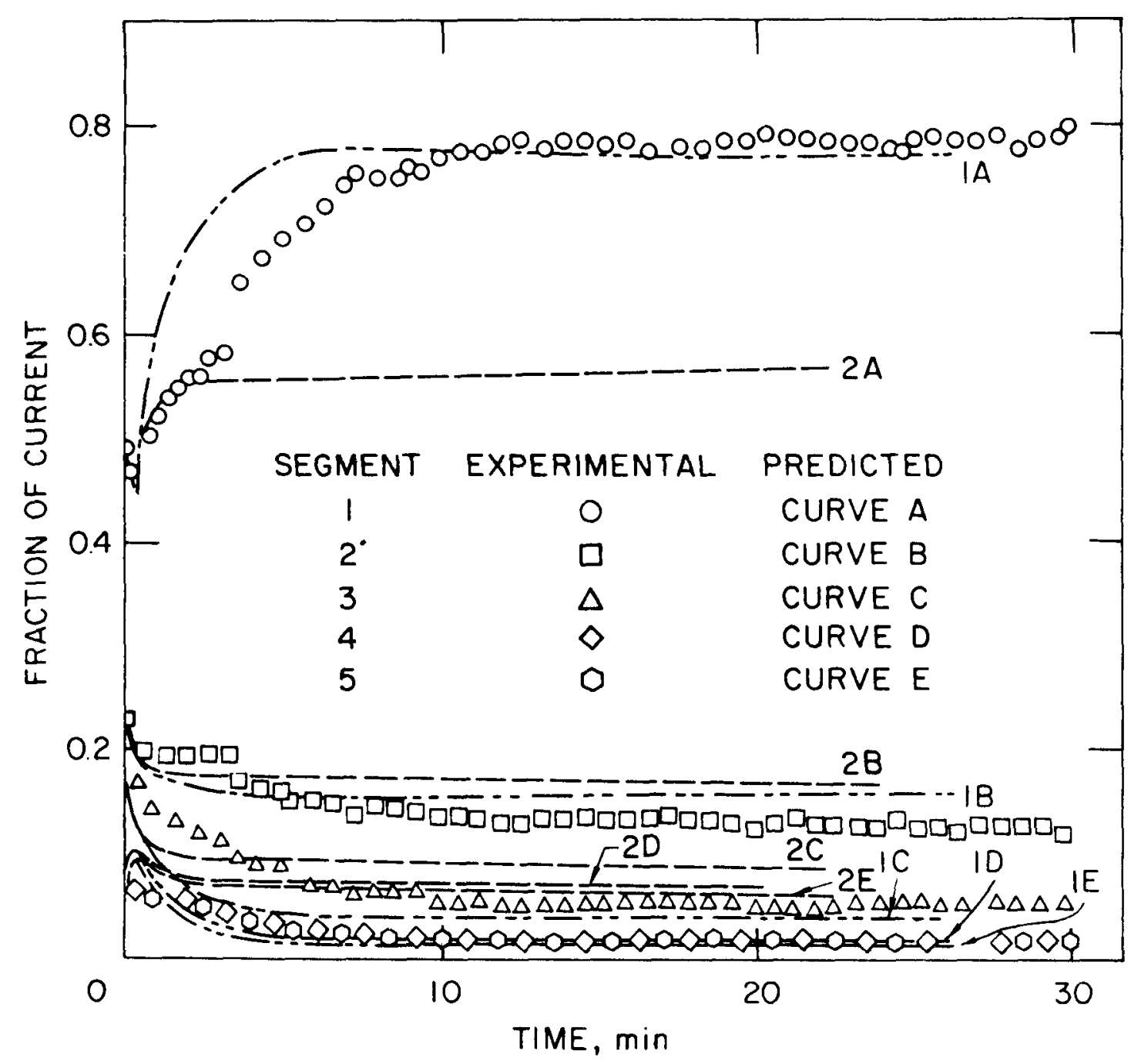

Fig. 9. Predicted and Experimental Current Distribution of Segmented Electrode Discharged at $10 \mathrm{~mA}$ (precipitation rate constant: series $1,1 \times 10^{-5} \mathrm{~cm} / \mathrm{sec}$; series $2,1 \times 10^{-4} \mathrm{~cm} / \mathrm{sec}$ )

to $2.43 \mathrm{M}$ in the pore electrolyte due to a decrease in the specific conductivity of the pore electrolyte by up to $76 \%$ (see Eq. 7); and (3) a decrease in the hydroxide concentration by $16 \%$ due to a decrease of $1_{0}$ by $7.5 \%$ (see Eq. 5). 


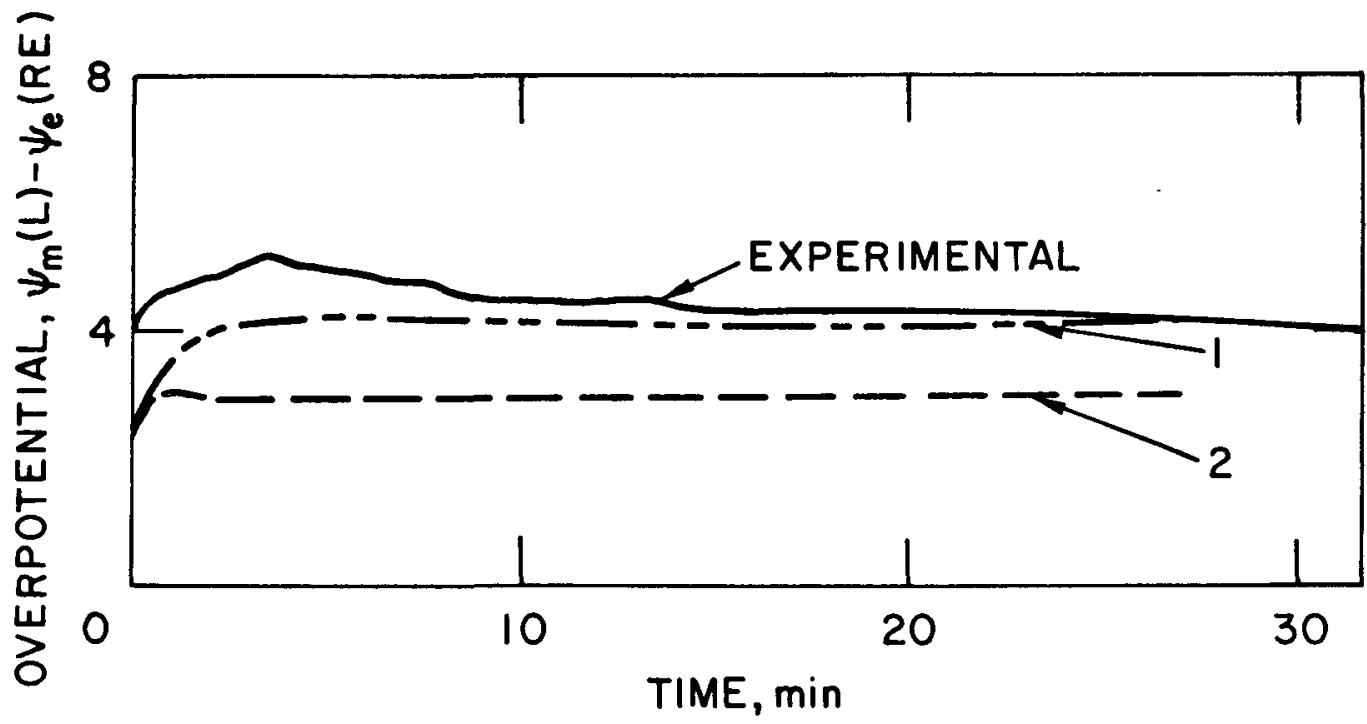

Fig. 10. Predicted and Experimental Overpotential of the Segmented Electrode Discharged at $10 \mathrm{~mA}$ (series 1 and 2 same as given in Fig. 9)

For the rate constant of $1 \times 10^{-5} \mathrm{~cm} / \mathrm{sec}$, we calculated $G_{5}$ and $G_{6}$ to be about 0.6 and 0.2 , respectively. The value of 0.6 for $G_{5}$ indicates that the precipitation of $\mathrm{ZnO}$ is relatively slow so that zincate ions may diffuse from the location of the charge-transfer reaction; and, consequently, the zincate ions formed are distributed throughout the pores. The value of 0.2 for $G_{6}$ implies that the precipitation of $\mathrm{ZnO}$ (reaction 3 ) provides a minor source of hydroxide ions for the charge-transfer reaction.

Figure 11 and 12 show the predicted reaction profiles and overpotentials, respectively, for our segmented electrode discharged at a 25-mA discharge current; three values for $k_{s}$ were used for these calculations: $1 \times 10^{-4} \mathrm{~cm} / \mathrm{sec}$ (series 1 ), $2 \times 10^{-4} \mathrm{~cm} / \mathrm{sec}$ (series 2), and $5 \times 10^{-4} \mathrm{~cm} / \mathrm{sec}$ (series 3). For series 2 in Fig. 11, the fractions of current in all five active segments are given; for the other two series, the current fractions are given only for active segments $A$ and $B$ because the current fractions in the other three segments are similar to those of series 2. Examination of the calculated results for the 25-mA discharge current indicated that the specific conductivities of the pore electrolyte were reduced during discharge and that this reduction was affected by the value of $k_{s}$. For the values of $k_{s}$ used for Fig. 11, the specific conductivity of the pore electrolyte was calculated to be reduced during discharge by up to $98 \%$ for series $1,67 \%$ for series 2 , and $38 \%$ for series 3 . The predicted electrode behavior at the very end of the curves for series 1 resulted from a great reduction (98\%) in the specific conductivity of the pore electrolyte at the first segment.

The values of $G_{5}$ and $G_{6}$ at these three assumed rate constants were greater than unity. This means that $\mathrm{ZnO}$ tends to precipitate at the location of the charge-transfer reaction, and that the precipitation reaction of $\mathrm{ZnO}$ (reaction 3) may become an important source of local hydroxide ions. 


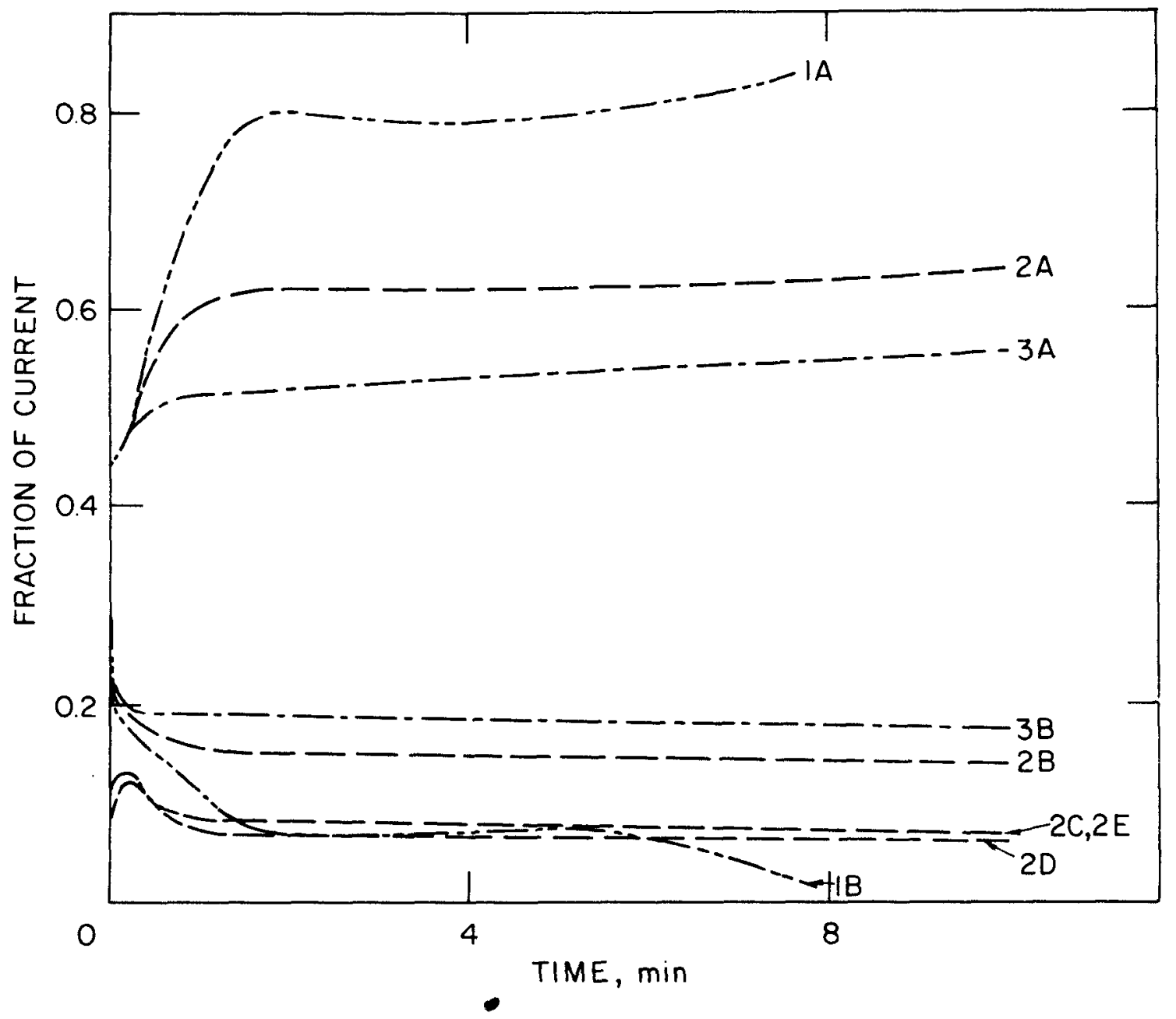

Fig. 11. Predicted Current Distribution for Three Values of $\mathrm{k}_{\mathrm{s}}$ (series $1,1 \times 10^{-4} \mathrm{~cm} / \mathrm{sec}$; series 2 , $2 \times 10^{-4} \mathrm{~cm} / \mathrm{sec}$; series $3,5 \times 10^{-4} \mathrm{~cm} / \mathrm{sec}$ ) with Segmented Electrode Discharged at $25 \mathrm{~mA}$ 


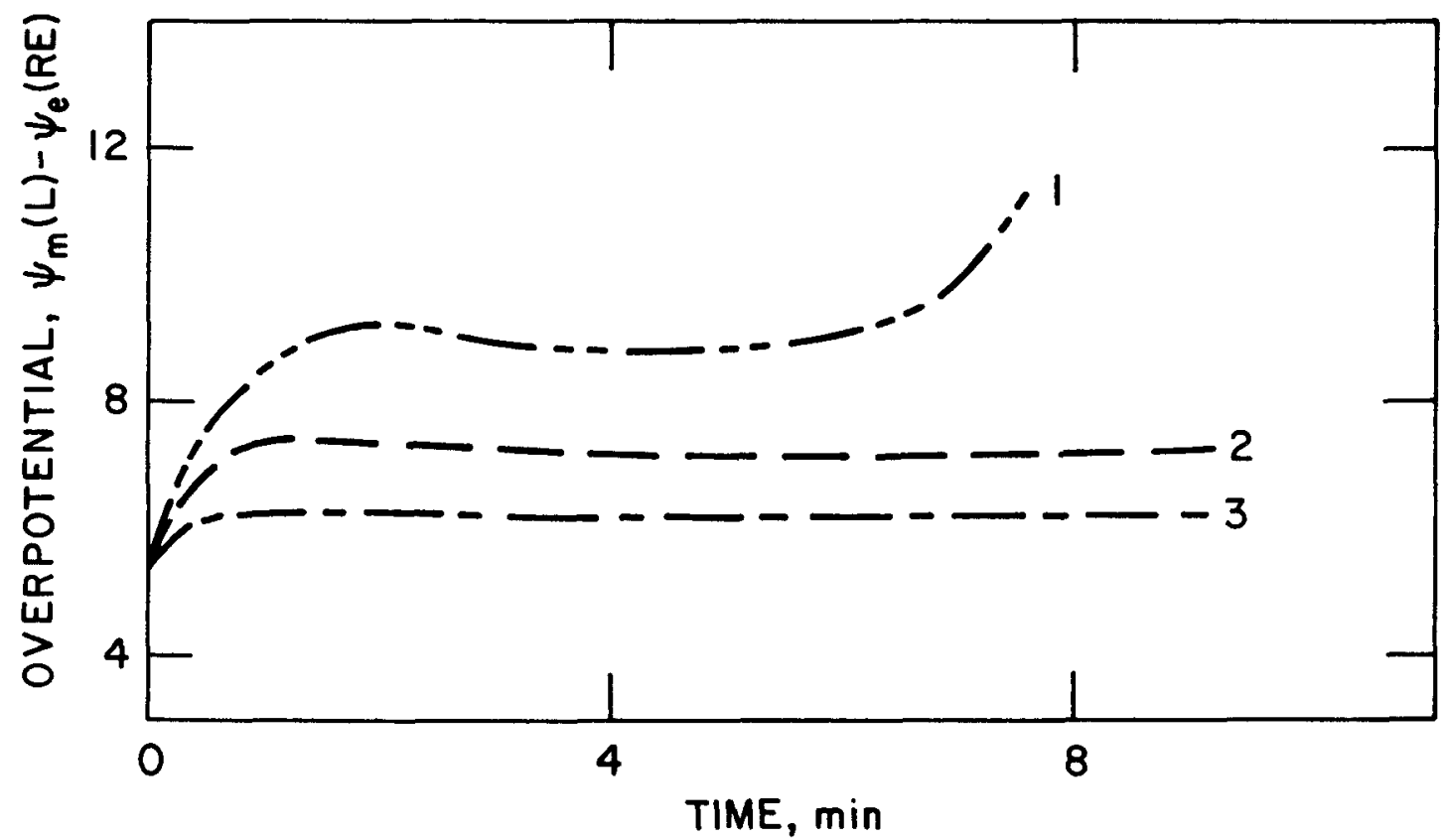

Fig. 12. Predicted Overpotentials for Three Values of $\mathrm{k}_{\mathrm{s}}$ (series $1,1 \times 10^{-4} \mathrm{~cm} / \mathrm{sec}$; series 2 , $2 \times 10^{-4} \mathrm{~cm} / \mathrm{sec}$; series $3,5 \times 10^{-4} \mathrm{~cm} / \mathrm{sec}$ ) with Segmented Electrode Discharged at $25 \mathrm{~mA}$

Figures 13 and 14 show the predicted and experimental current distributions and overpotentials, respectively, for the zinc electrode discharged at $25 \mathrm{~mA}$ with a $\mathrm{k}_{\mathrm{s}}$ of $1.5 \times 10^{-4} \mathrm{~cm} / \mathrm{sec}$; this value of $\mathrm{k}_{\mathrm{s}}$ was chosen because it had given good agreement between the predicted and the experimental results at the $25 \mathrm{~mA}$ discharge. (These two figures will be discussed in greater detail later.) As was the case for the electrode discharged at $10 \mathrm{~mA}$, the predicted results were caused by a reduction of the specific conductivity of the pore electrolyte by up to $78 \%$.

Overal1, the above results indicated that the current distributions and overpotentials can be accurately predicted from precipitation rate constants of $1 \times 10^{-5} \mathrm{~cm} / \mathrm{sec}$ for an electrode discharged at $10 \mathrm{~mA}$ and $1.5 \times 10^{-4}$ $\mathrm{cm} / \mathrm{sec}$ for one discharged at $25 \mathrm{~mA}$. By using these rate constants, we also discovered that the calculated zincate concentrations at both discharge currents were up to approximately four times chemical saturation of $\mathrm{ZnO}$ in the pore electrolyte at steady state. These calculated zincate concentrations have been observed experimentally during the discharge of zinc anodes in $\mathrm{KOH}$ electrolytes. 28,29

There is an explanation for the different precipitation rate constants determined at the two different current densities. The zincate ions formed must transfer from the charge-transfer reaction site (reaction 2) to the precipitation site (reaction 3 ). The mass transfer coefficient for this process is $k_{d}$. The formation of $\mathrm{ZnO}$ at the precipitation site (existing 


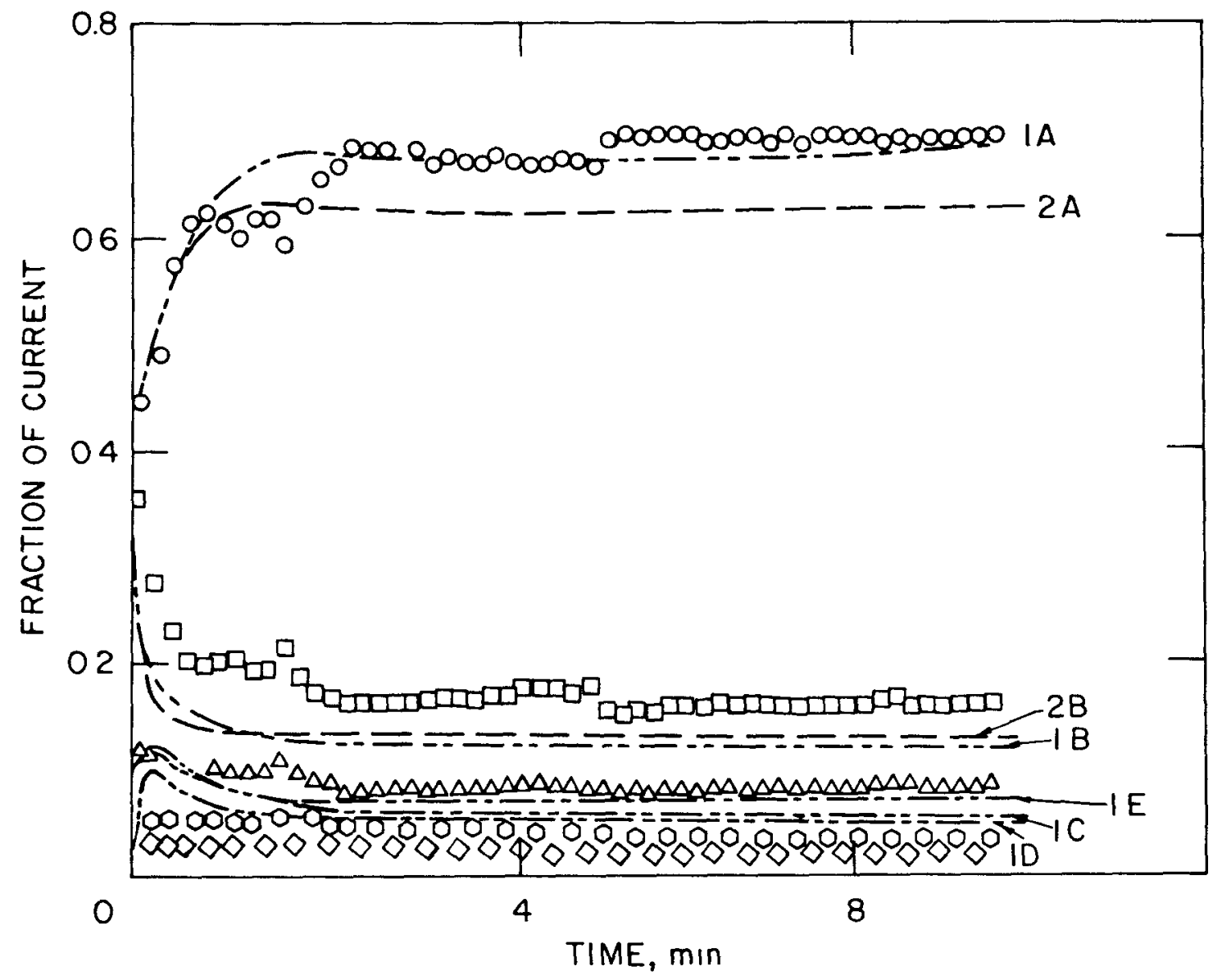

Fig. 13. Predicted and Experimental Current Distributions for Two Exchange Current Densities with Segmented Electrode Discharged at $25 \mathrm{~mA}$

Series 1 and 2: $k_{s}=1.5 \times 10^{-4} \mathrm{~cm} / \mathrm{sec}$

Series 1: $i_{0}=146 \mathrm{~mA} / \mathrm{cm}^{2}\left(C_{2} / 0.64 \underline{\mathrm{M}}\right)^{0.0}\left(C_{3} / 5.96 \underline{\mathrm{M}}\right)^{0.45}$;

$\mathrm{k}_{\mathrm{e}}=0.62-0.207\left(\mathrm{C}_{2}\right) \mathrm{mho}-\mathrm{cm}^{-1}$

Series 2: $i_{o}=224 \mathrm{~mA} / \mathrm{cm}^{2}\left(C_{2} / 0.64 \underline{M}\right)^{0.67}\left(C_{3} / 5.96 \underline{M}\right)^{0.14}$;

$k_{e}=0.4875$ mho- $\mathrm{cm}^{-1}$ 


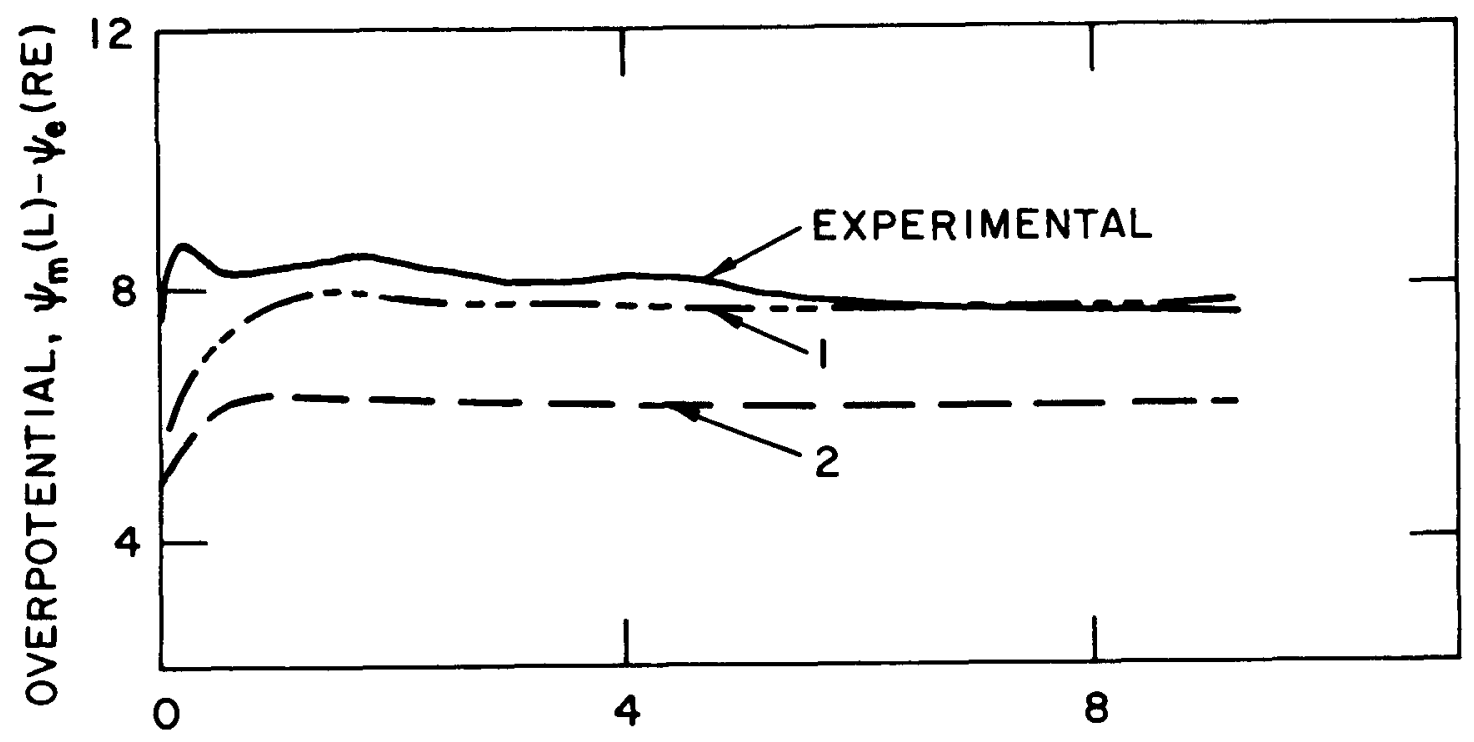

TIME, $\min$

Fig. 14. Predicted and Experimental Overpotentials for Two Exchange Current Densities (defined in Fig. 13) with Segmented Electrode Discharged at $25 \mathrm{~mA}$

$\mathrm{ZnO}$ ) depends on the roughness of the $\mathrm{ZnO}$ surface (designated by $\mathrm{g}$ ) and the intrinsic precipitation rate constant of $\mathrm{Zno}, \mathrm{k}_{\mathrm{r}}$. For diffusion limiting processes, $k_{d} \ll g \cdot k_{r}$, and, according to $\mathrm{Eq} \cdot 20, k_{s}=k_{d}$. For kinetically controlled processes, $k_{d} \gg g \cdot k_{r}$, and, again according to $\mathrm{Eq} \cdot 20, \mathrm{k}_{\mathrm{s}}=\mathrm{g} \cdot \mathrm{k}_{\mathrm{r}}$. The parameter $k_{d}$ may be approximated as $D / \delta_{m}$, where $\delta_{m}$ is the length of the path of zincate ion diffusion from the charger-transfer site to the precipitation site. The diffusion coefficient of zincate ion, $\mathrm{D}_{2}$, in the $\mathrm{KOH}$ electrolyte 30 is $6 \times 10^{-6} \mathrm{~cm}^{2} / \mathrm{sec}$. The value of $\delta_{\mathrm{m}}$ is likely to be several microns $\left(10^{-4} \mathrm{~cm}\right)$. Thus, the value of $k_{d}$ is on the order of $10^{-2}$ to $10^{-3} \mathrm{~cm} / \mathrm{sec}$. As a result, the overall $\mathrm{k}_{\mathrm{s}}$ for the diffusion-limited precipitation of $\mathrm{ZnO}$ would also be $10^{-2}$ to $10^{-3} \mathrm{~cm} / \mathrm{sec}$. Therefore, for the rate constants on the order of $10^{-4}$ to $10^{-5} \mathrm{~cm} / \mathrm{sec}$ used in the calculations, the precipitation is probably a kinetically controlled process, and thus $k_{s}=g \cdot k_{r}$. We used $g$ as a morphology factor to account for the dependence of the rate constants on the discharge current densities. A small value for $g$ implies that the surface of existing $\mathrm{ZnO}$ is smooth, while a large value of $\mathrm{g}$ implies that the surface of existing $\mathrm{ZnO}$ is more accessible for further precipitation of $\mathrm{ZnO}$. According to Szpak et al., 21 during the discharge of zinc electrodes in $\mathrm{KOH}$ electrolytes, the precipitates of $\mathrm{ZnO}$ are either boulder- or thistle-shaped; scanning electron micrographs showed that boulder-shaped $\mathrm{ZnO}$ probably formed at low current density, while $\mathrm{ZnO}$ in thistle form appeared at high current densities. The $\mathrm{ZnO}$ in thistle form may provide a higher spectfic surface area per unit area than that for the boulder form; this may account for the increase of rate constants for the precipitation of $\mathrm{ZnO}$ with increased discharge current. 


\section{Exchange Current Density}

Figures 13 and 14 show the current distributions and overpotentials, respectively, for two different specific electrolyte conductivities ( $k_{e}$ ) and exchange current densities $\left(i_{Q}\right)$. For series $1, k_{e}=0.62$ mho/ cm $-0.207\left(C_{2}\right)$ $\mathrm{mho} / \mathrm{cm} \cdot \mathrm{mol}$ and $i_{0}=146 \mathrm{~mA} / \mathrm{cm}^{2}\left(\mathrm{C}_{2} / 0.64 \mathrm{M}\right)^{0.0}\left(\mathrm{C}_{3} / 5.96 \mathrm{M}\right)^{0.45}$; the se two values are the same as those used for Figs. 9-12. For series $2, \mathrm{k}_{\mathrm{e}}=0.4875 \mathrm{mho} / \mathrm{cm}$ and $i_{o}=224 \mathrm{~mA} / \mathrm{cm}^{2}\left(\mathrm{C}_{2} / 0.64 \mathrm{M}\right)^{0.67}\left(\mathrm{C}_{3} / 5.96 \mathrm{M}\right)^{0.14}$; for this series, the values for $n_{2}$ and $n_{3}(E q .5)$ were taken from Dirkse and Hampson. 31

In these figures, at the steady state, the exchange current density for series 2 is 3.6 times that used for series 1 . Consequent1y, the dimensionless parameters are up to 32 for $G_{1}$ and 23 for $G_{2}$. From the physical meaning of $G_{1}$ and $G_{2}$, it was concluded that the discharge of the electrode was controlled by the conductivity of the pore electrolyte and the diffusion process. Although the predicted reaction profile of series 2 in Fig. 13 agrees reasonably well with the experimental data, the predicted overpotential of this series in Fig. 14 shows about 25\% deviation from the experimental values. Therefore, the increasing nonuniformity in the experimental current distributions with time shown in Figs. 3 and 4 were not brought about by an increase in exchange curent density.

\section{Mass Transfer}

As expressed in Eqs. 10 and 11 , the fluxes of zincate and hydroxide ions consisted of contributions from diffusion and migration terms. The re1ative magnitudes of these contributions can be represented by $G_{3}$ and $G_{4}$. For our system, the values of $G_{3}$ and $G_{4}$ were on the order of $10^{-1}$ for the electrode discharged at a $10 \mathrm{~mA}$ current and about 2 for the electrode discharged at $100 \mathrm{~mA}$. This finding indicates that migration transport relative to diffusion is minor at low discharge current, but is important at discharge currents above $100 \mathrm{~mA}$.

The ratio of $G_{1} / G_{2}$ contains the ratio of $D_{3} / k$ and, thus, indicates the relative importance of electrolyte resistance and diffusion resistance. In our calculations with $D_{3}=3 \times 10^{-5} \mathrm{~cm}^{2} / \mathrm{sec}$ and $\mathrm{k}_{\mathrm{s}}=1.5 \times 10^{-4} \mathrm{~cm} / \mathrm{sec}$, $G_{1} / G_{2}$ was initially 1.4 but increased to about 7.5 when the supersaturation of zincate reached four times chemical saturation of $\mathrm{ZnO}$ in the electrolyte. These results indicate that our system was not limited by charge transfer resistance; this same conclusion was reached from the above examination of exchange current density. Therefore, these $G_{1} / G_{2}$ values suggest that the nonuniformity of the current distribution for our experimental electrode is mainly due to low conductivity in the pore electrolyte. If this is true, then the ratio of $G_{1} / G_{2}$ indicates the relative importance of hydroxide ion diffusion $\left(D_{3}\right)$ to the current-distribution nonuniformity in the simulated electrode. Figure 15 shows the predicted current distributions for three diffusion coefficients of hydroxide ions $-3 \times 10^{-5} \mathrm{~cm}^{2} / \mathrm{sec}$ (series 1 ), $5 \times 10^{-5} \mathrm{~cm}^{2} / \mathrm{sec}$ (series 2), and $1 \times 10^{-5} \mathrm{~cm}^{2} / \mathrm{sec}$ (series 3) -- and a $\mathrm{k}_{\mathrm{s}}$ of $1.5 \times 10^{-4} \mathrm{~cm} / \mathrm{sec}$ during a $25 \mathrm{~mA}$ discharge of the segmented electrode. In this figure, the predicted current fractions for segments $C, D$, and $E$ are similar for all three series and are, therefore, only given for series 1. As shown in Fig. 15, the predicted current distribution of series 2 in the active segments is similar 




Fig. 15. Predicted Current Distributions for Three Values of $D_{3}$ ( $3 \times 10^{-5} \mathrm{~cm}^{2} / \mathrm{sec}$ for series $1,5 \times 10^{-5} \mathrm{~cm}^{2} / \mathrm{sec}$ for series 2, and $1 \times 10^{-5} \mathrm{~cm}^{2} / \mathrm{sec}$ for series 3) with Segmented Electrode Discharged at $25 \mathrm{~mA}$

to that for series 1. The explanation for this behavior is that the values of $G_{1} / G_{2}$ for both series $1(1.4$ to 7.5$)$ and series $2(2.3$ to 12.5$)$ are greater than unity. However, as also shown in $F$ ig. 15, a decrease of $\mathrm{D}_{3}$ from $3 \times 10^{-5} \mathrm{~cm}^{2} / \mathrm{sec}$ (series 1 ) to $1 \times 10^{-5} \mathrm{~cm}^{2} / \mathrm{sec}$ (series 3 ) decreased the fraction of current in segment $A$; this resulted because the value for $G_{1} / G_{2}$ had been reduced by approximately a factor of three.

The local supersaturation of zincate is determined by diffusion of zincate and the precipitation of $\mathrm{znO}$. Therefore, for a given precipitation rate constant of $\mathrm{ZnO}$, the local supersaturation is expected to be reduced by an increase in diffusion and conductivity (see Eq. 7). The increased conductivity would produce a reduction in electrode overpotential for the segmented electrode and less nonuniformity in the current distribution. For the electrode discharged at $25 \mathrm{~mA}$, this effect is illustrated in Fig. 16 for current distribution and Fig. 17 for overpotential $\left(\mathrm{k}_{\mathrm{s}}=1.5 \times 10^{-4} \mathrm{~cm} / \mathrm{sec}\right)$. With an increase in the diffusion coefficient of zincate from $6 \times 10^{-6} \mathrm{~cm}^{2} / \mathrm{sec}$ (series 1) to $1 \times 10^{-5} \mathrm{~cm}^{2} / \mathrm{sec}$ (series 2), the local supersaturation of zincate slightly decreases from a maximum of 3.9 to 3.2 times chemical saturation of 


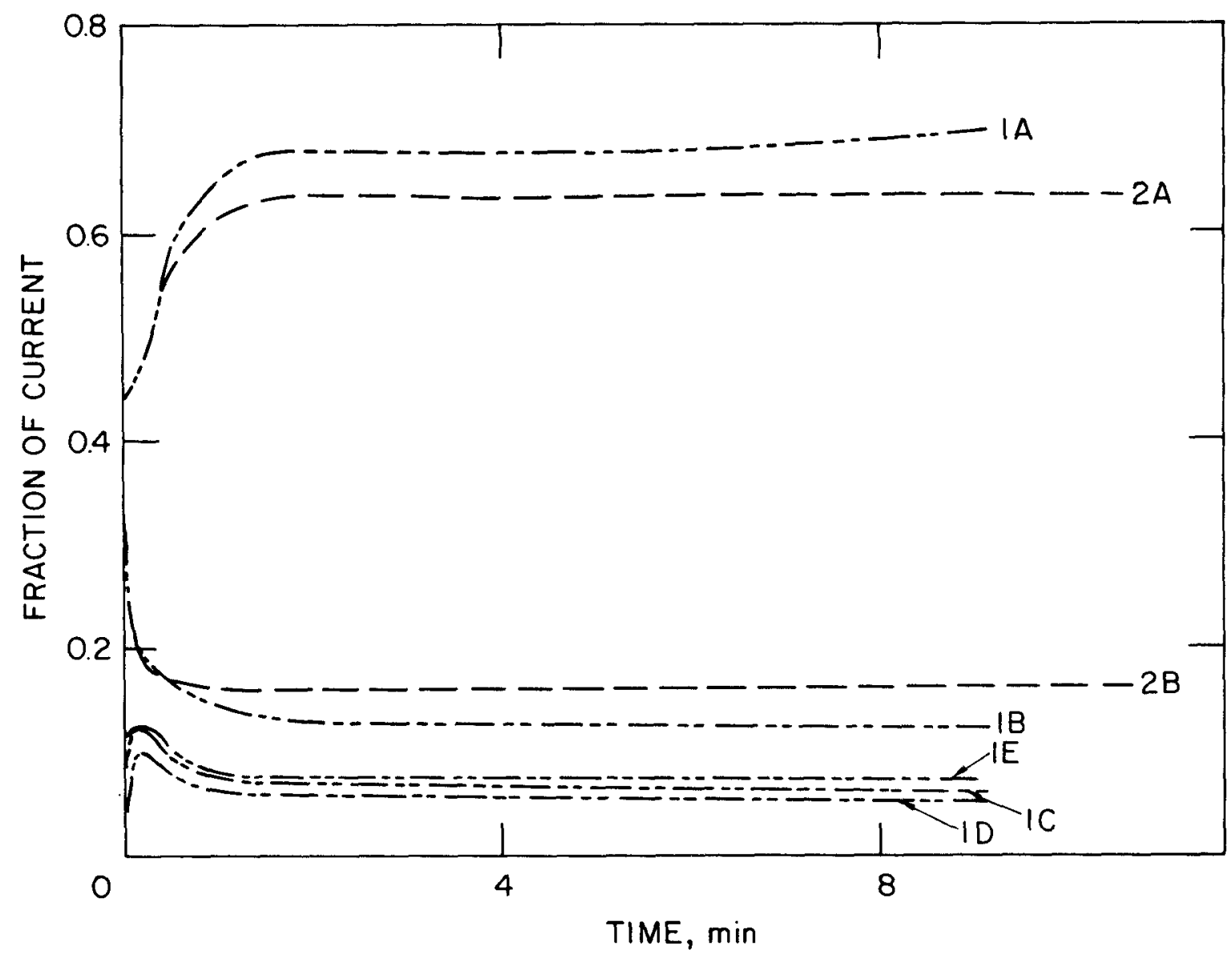

Fig. 16. Predicted Current Distributions for Two Values of $D_{2}$ ( $6 \times 10^{-6} \mathrm{~cm}^{2} / \mathrm{sec}$ for series 1 and $1 \times 10^{-5} \mathrm{~cm}^{2} / \mathrm{sec}$ for series 2) with the Segmented Electrode Discharged at $25 \mathrm{~mA}$ 


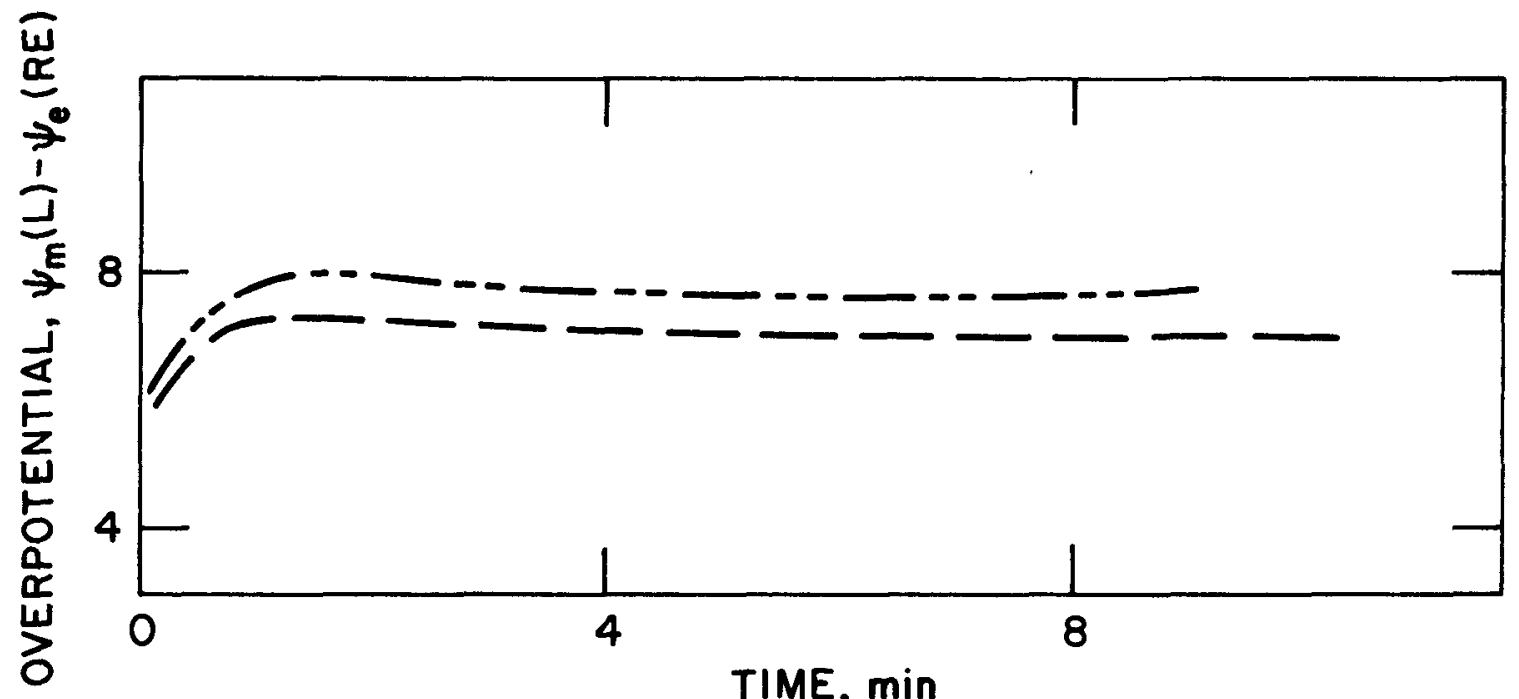

Fig. 17. Predicted Overpotentials for Two Values of $D_{3}$ $\left(6 \times 10^{-6} \mathrm{~cm}^{2} / \mathrm{sec}\right.$ for series 1 and $1 \times 10^{-5} \mathrm{~cm}^{2} / \mathrm{sec}$ for series 2) with the Segmented Electrode Discharged at $25 \mathrm{~mA}$

Zno, and the local specific conductivity of the pore electrolyte increases from $22 \%$ to $40 \%$ of the bulk value. As a result, the overpotential decreases by $10 \mathrm{mV}$ (see Fig. 17), and the current decreases by $5 \%$ for the first active segment and increases by $5 \%$ for the second active segment (see Fig. 16).

\section{Passivation}

Figure 5 shows the transient behavior of the simulated zinc electrode encountering passivation and then oxygen evolution. In our theoretical calculations, we assumed that a surface blockage by a compact type of $\mathrm{ZnO}$ formed on the electrode surface at high overpotential. The mechanism of surface blockage was formulated from our previous results of galvanostatic discharge of zinc microelectrodes in $\mathrm{KOH}$ electrolytes. 14 The surface blockage mechanism is expressed mathematically by Eqs. 18 and 19. In our predictions, we assumed that, when the local surface overpotential exceeds a threshold value, the active surface is decreased gradually and becomes totally inactive when it is covered by $\mathrm{n}_{\mathrm{A}}$ of compact $\mathrm{ZnO}$. Figures 18 and 19 show the current distributions and overpotential, respectively, predicted for a segmented electrode discharged at $100 \mathrm{~mA}$. For these predictions, the following parameters were used: threshold potential of $42 \mathrm{mV}$, a maximum coverage of $8.03 \times 10^{3}$ monolayers of compact $\mathrm{ZnO}$, and $\mathrm{k}_{\mathrm{s}}$ of $5 \times 10^{-3} \mathrm{~cm} / \mathrm{sec}$. In addition, three specific conductivities of the electrolyte at the bulk concentration $\left(k_{0}\right)$ were assumed: $0.6 \mathrm{mho} / \mathrm{cm}$ (series 1), $0.4875 \mathrm{mho} / \mathrm{cm}$ (series 2), and $0.4 \mathrm{mho} / \mathrm{cm}$ (series 3 ). The five active segments are labeled as before. Among these three series, the predicted current distribution of series 2 is in reasonably good agreement with the experimental data up to $100 \mathrm{sec}$ of discharge, but the prediction of overpotential for this series is significantly below the experimentally determined overpotential. For series 1, the overpotential was not higher than the 


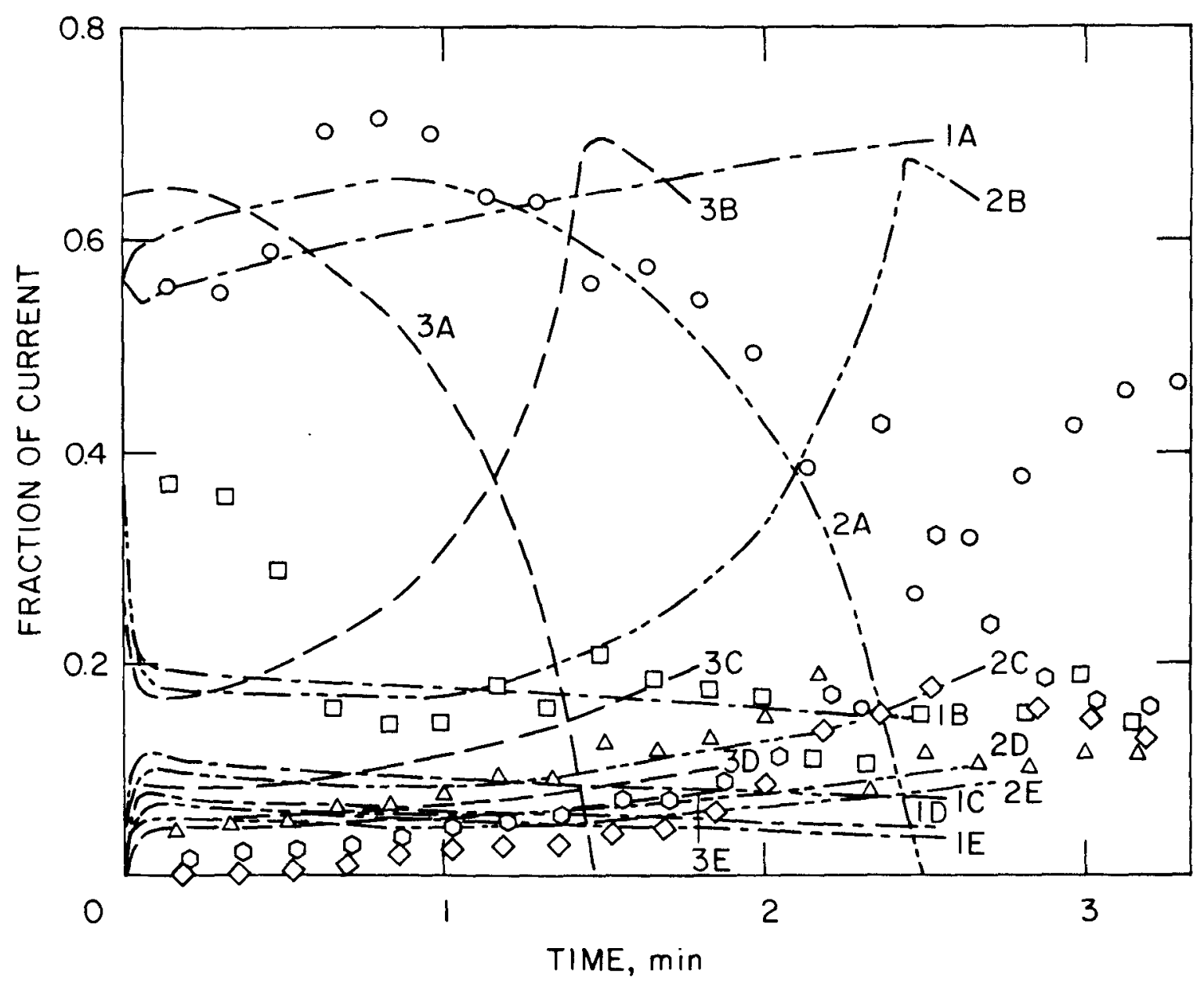

Fig. 18. Predicted and Experimental Current Distribution of the Segmented Electrode Discharged at $100 \mathrm{~mA}$ (precipitation rate constant of $\mathrm{ZnO}, 5 \times 10^{-3} \mathrm{~cm} / \mathrm{sec}$; specific conductivities at the bulk electrolyte: $0.6 \mathrm{mho} / \mathrm{cm}$ for series $1,0.4875 \mathrm{mho} / \mathrm{cm}$ for series 2 , and $0.4 \mathrm{mho} / \mathrm{cm}$ for series 3 ) 


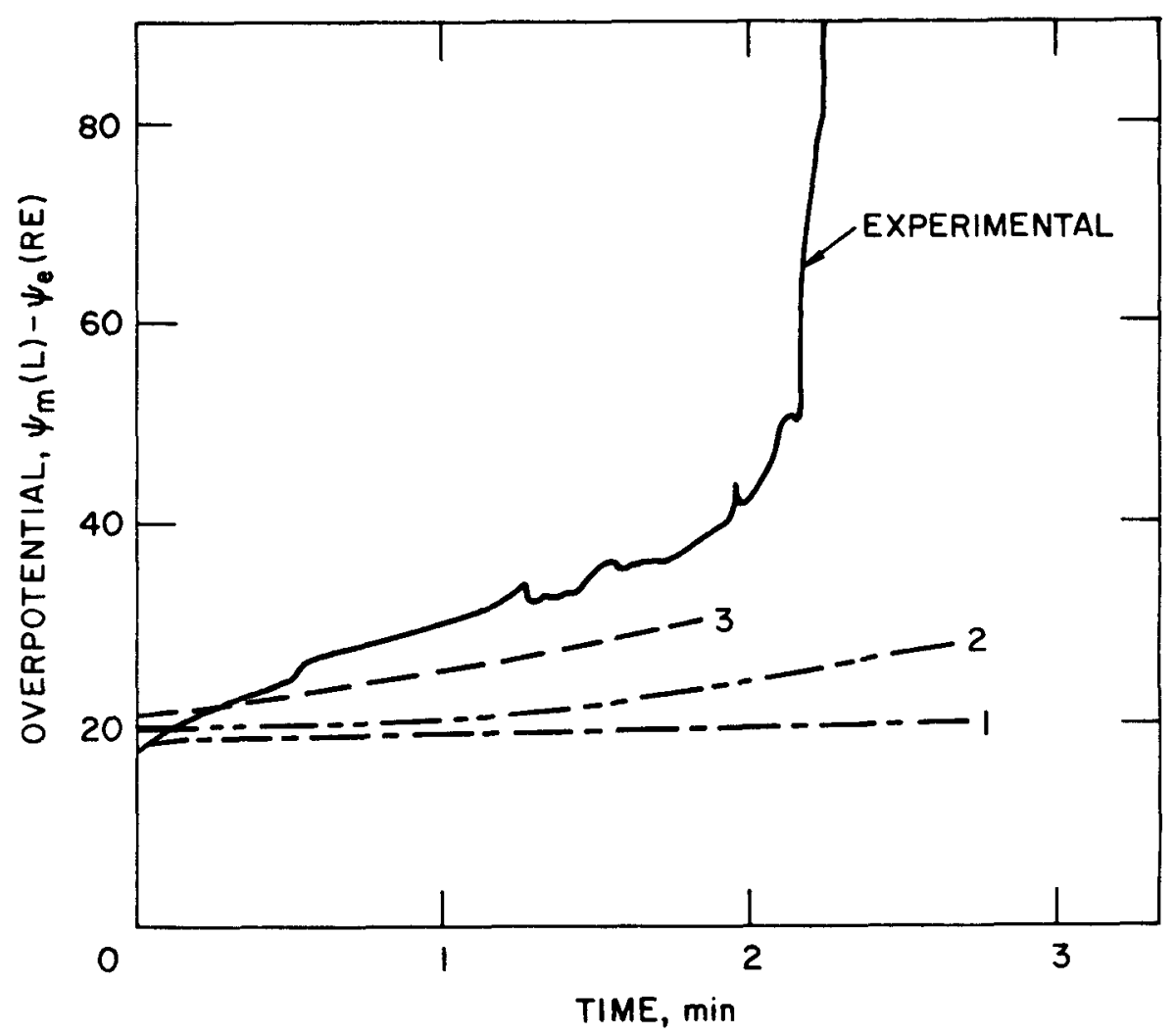

Fig. 19. Predicted and Experimental Current Overpotential for the Segmented Electrode Discharged at $100 \mathrm{~mA}$ (series 1, 2, and 3 defined in Fig. 18)

assumed threshold value, $42 \mathrm{mV}$, and thus passivation was not encountered. For series 2 and 3 , the total passivation of the electrode would occur. In addition, passivation of the first segment for series 3 occurred earlier than that of series 2; this finding resulted because, in series 3 , more incremental sections of the first active segment had higher overpotentials than the threshold value.

Formation of hydrogen bubbles during the discharge of a zinc electrode in alkaline media has been reported by Powers, 13 and this may have occurred in our electrode. Thus, high overpotentials and total passivation may be accurately predicted after a great reduction is made in the gas generated in the electrode pores, which reduces the effective conductivity of the pore electrolyte. A quantitative expression of the formation of hydrogen bubbles is not available. Thus, we did not attempt to incorporate any effect of the formation of hydrogen bubbles in our model.

\section{CONCLUDING REMARKS}

The experimental data for the reaction penetration depth of zinc porous electrodes in $\mathrm{KOH}$ electrolytes have been summarized in Table 1. (In Table 1, the effective penetration depth was defined as the electrode depth at which 
$\left(1-\frac{1}{e}\right)$ or $63.2 \%$ of the discharge reaction has been completed.) Our experimental results show that the effective penetration depth was initially about $0.015 \mathrm{~cm}$, but decreased to $0.008 \mathrm{~cm}$ at steady state.

In Fig. 20, we have used the precipitation rate constants given for Fig. 9 and the other physiochemical properties given in Appendix A to calculate the effective penetration depth at steady state and the electrode overpotential as a function of porosity for the electrode discharged at $10 \mathrm{~mA}$. In this $\mathrm{fig}-$ ure, the predicted effective reaction penetration depths are normalized with respect to the electrode thickness $(0.05 \mathrm{~cm})$, and the overpotential was defined as the difference between the potential of the electrode solid matrix at $x=L$ and that of the pore electrolyte at $x=0$. Curves 1 (penetration depth) and $1 \mathrm{~A}$ (overpotential) are predicted for $\mathrm{k}_{\mathrm{s}}=10^{-5} \mathrm{~cm} / \mathrm{sec}$; curves 2 (penetration depth) and $2 \mathrm{~A}$ (overpotential) are predicted for $\mathrm{k}_{\mathrm{s}}=10^{-4} \mathrm{~cm} / \mathrm{sec}$. In Fig. 20 ,

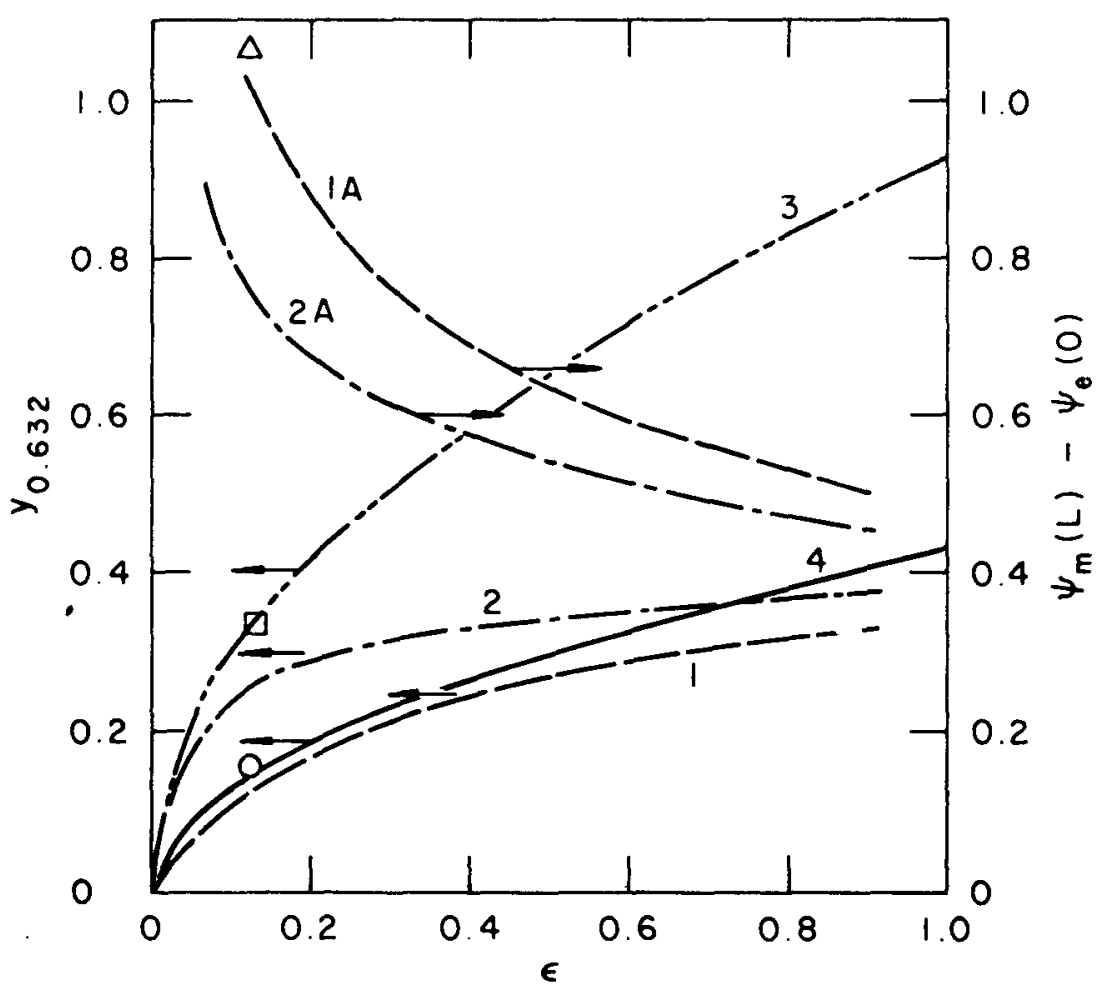

Fig. 20. Predicted Overpotential and Effective Reaction Penetration Depth $\left(\mathrm{y}_{0.632}\right)$ vs. Porosity for Electrode Discharged at $10 \mathrm{~mA}$

Series 1. $k_{s}=1 \times 10^{-5} \mathrm{~cm} / \mathrm{sec}$

Series 2. $\mathrm{k}_{\mathrm{s}}=1 \times 10^{-4} \mathrm{~cm} / \mathrm{sec}$

Series 3. $k_{e}=0.4875 \mathrm{mho} / \mathrm{cm}$

Series 4. $\mathrm{k}_{\mathrm{e}}=0.1 \mathrm{mho} / \mathrm{cm}$ 
the penetration depths obtained at the initial state and steady state are represented by a square and a circle; the overpotential at steady state is represented by a triangle. In general, these curves show that, as the porosity is increased, the effective penetration depth is increased slightly, but the overpotential is reduced notably.

The magnitudes of the dimensionless groups of initial and steady-states obtained with $\mathrm{k}_{\mathrm{s}}=10^{-5} \mathrm{~cm} / \mathrm{sec}$ are given in Table 2 . At the initial state, since the concentration of species throughout the pores is uniform, there is, consequently, no effect of mass transfer resistance. Therefore the current distribution in our electrode is determined by $G_{1}$. Since the value of $G_{1}$ is greater than unity, the nonuniformity of initial current distribution in our electrode is thus due to high electrolyte resistance relative to chargetransfer resistance. At steady state, the value of $G_{1}$ increases to 48 , which is the highest value as compared with those of other groups. This indicates that the increase of nonuniformity of the current distribution in our electrode from initial state to steady state is due to the increase in electrolyte resistance. According to the expression of $G_{1}$ in Table 2, one way to deal with high electrolyte resistance is to reduce the electrode thickness, L. Reduction of electrode thickness also yields decrease of the diffusion resistance of $\mathrm{OH}^{-}$ions (see $\mathrm{G}_{2}$ in Table 2). If we reduce the electrode thickness so that $G_{1}$ is equal to unity, $G_{2}$ thus becomes less than unity. If we define this electrode thickness as the effective reaction penetration depth, $d$, then by rearranging $G_{1}$, we obtain the expression,

$$
d=\sqrt{\frac{k R T}{A_{m}^{i} n F}}
$$

In Fig. 20, curves 3 and 4 show predictions of this penetration using Eq. 32 . For these predictions, the specific conductivities of the electrolyte ( $k_{e}$ ) were assumed to be the previously determined value of 0.4875 tho/ $\mathrm{cm}$ for curve 3 and $20 \%$ of this value, or $0.1 \mathrm{mho} / \mathrm{cm}$, for curve $4\left(k=k_{e} \varepsilon^{1+t_{e}}\right)$. Other parameters used in these calculations are given in Appendix A. As shown in Fig. 20, curves 1 and 4 are in reasonably good agreement. For both of these curves, the specific conductivities of the pore electrolyte are of the same magnitude (steady state value for curve 1 and assumed value for curve 4), although the calculational methods were different. It was concluded that the reaction profiles within the electrodes were controlled by the conductivity of the pore electrolyte. Curve 3 shows that a great increase of the effective penetration depth will occur with increased porosity if the specific conductivity of the pore electrolyte is unchanged during the discharge. Furthermore, our initial effective penetation depth (square in Fig. 20) is predicted by this curve. Equation 32 implies that the effective penetration depth is proportional to the square root of $\varepsilon^{1+t} e$ if other parameters remain fixed. Using the data given by Sunu et al., 2 we determined the effective penetration depths to be $6.5 \times 10^{-3} \mathrm{~cm}$ and $9.0 \times 10^{-3} \mathrm{~cm}$ for porosities of 0.33 and 0.60 , respectively; the ratio of these two penetration depths is 0.72 . This ratio is only $13 \%$ greater than the ratio of 0.64 , which was obtained from the ratio of 0.64 , which was obtained from the ratio of $\varepsilon^{1+t_{e}}$ for $\varepsilon=0.33$ and 0.60 , 
where $t_{e}$ is the commonly accepted tortuorsity factor of 0.5 . Therefore, Eq. 32 may be used to estimate the effective penetration depth of zinc porous electrodes having a solid matrix with a very high conductivity compared with that of the electrolyte. For other cases, the value of $k$ in Eq. 32 is replaced by $\mathrm{k \sigma} / \mathrm{k}+\sigma$, where $\sigma$ is equal to $\sigma_{\mathrm{m}} \varepsilon_{\mathrm{Zn}}$.

\section{ACKNOWLEDGMENT}

This work was supported by the U. S. Department of Energy, Division of Electrochemical Energy Storage Systems. One of the authors (MBL) would like to thank J. R. Selman, Illinois Institute of Technology, Chicago, Illinois, for his valuable comments. We also thank $\mathrm{J}$. Becker for the fabrication of the operation amplifier circuit. 
- 
APPENDIX A

Numerical Values Used in Calculations of Current Distributions and Electrode Overpotentials

\begin{tabular}{|c|c|}
\hline Variable & Value \\
\hline $\mathrm{L}$ & $0.05 \mathrm{~cm}$ \\
\hline $\mathrm{C}_{2}^{\circ}, \mathrm{C}_{3}^{\circ}$ & $0.64 \underline{\mathrm{M}}, 5.96 \underline{\mathrm{M}}$ \\
\hline$k_{0}$ & $0.62 \mathrm{mho} / \mathrm{cm}$ \\
\hline$\gamma$ & $0.207 \mathrm{mho} / \mathrm{cm} \mathrm{M}$ \\
\hline$\sigma_{\mathrm{m}}$ & $2 \times 10^{5} \mathrm{mho} / \mathrm{cm}$ \\
\hline$t_{e}$ & 0 \\
\hline$\varepsilon_{0}$ & 0.13 \\
\hline$\alpha_{a}, \alpha_{c}$ & $1.5,0.5^{a}$ \\
\hline$i_{0}^{0}$ & $146 \mathrm{~mA} / \mathrm{cm}^{2} \mathrm{~b}$ \\
\hline$\eta, \zeta$ & $0,0.45^{b}$ \\
\hline$a_{0}$ & $19.8 \mathrm{~cm}^{2} / \mathrm{cm}^{3}$ \\
\hline$t_{2}^{\circ}, t_{3}^{\circ}$ & $0.05,0.72^{c}$ \\
\hline$\overline{\mathrm{V}}_{\mathrm{Zn}}, \overline{\mathrm{V}}_{\mathrm{ZnO}}$ & $9.15 \mathrm{~cm}^{3} / \mathrm{mol}, 14.5 \mathrm{~cm}^{3} / \mathrm{mol}$ \\
\hline $\mathrm{T}$ & $298 \mathrm{~K}$ \\
\hline $\mathrm{D}_{2}$ & $6 \times 10^{-6} \mathrm{~cm}^{2} / \mathrm{sec}$ \\
\hline $\mathrm{D}_{3}$ & $3 \times 10^{-5} \mathrm{~cm}^{2} / \mathrm{sec}$ \\
\hline
\end{tabular}

abtained from Ref. 18 . bobtained from Ref. 15 .

cobtained from Ref. 2 . 
๑.

. 


\section{APPENDIX B}

\section{Computer Programs}

For the discharge of the simulated zinc electrode in the KOH electrolyte at $10 \mathrm{~mA}$, Program $A$ was used. Passivation did not occur at this current and the electrode had six segments. For the other two discharge currents, the electrodes had seven segments. For the other two discharge currents, Program B was used and a surface blockage mechanism by compact ZnO was assumed. These two programs were written specifically for $\Delta y=0.04$ and $\Delta \zeta \leq 8 \times 10^{-4}$.

\section{Input Data}

DT

dimensionless time increment $\left(\leq 8 \times 10^{-4}\right)$

DJ overa11 current density (discharge current $/ 0.42 \mathrm{~A} / \mathrm{cm}^{2}$ )

$\mathrm{XL} \quad$ total thickness of active segments in the electrode $(\mathrm{L}=0.05 \mathrm{~cm})$

ALPHA order of dependence of exchange current density on the concentration of hydroxide ions $\left(n_{3}\right)$

$\mathrm{XB}$ bulk concentration of hydroxide ions $\left(C_{3}^{0}=5.96 \times 10^{-3} \mathrm{~mol} / \mathrm{cm}^{3}\right)$

PSTY initial porosity of the electrode $(\varepsilon=0.13)$

VZN partial molar volume of $\mathrm{Zn}\left(\overline{\mathrm{V}}_{\mathrm{Zn}}=9.15 \mathrm{~cm}^{3} / \mathrm{mol}\right)$

ALPHZ order of dependence of exchange current density on the concentration of zincate ions $\left(n_{2}\right)$

XSZ

bulk concentration of zincate ions $\left(C_{2}^{\circ}=6.4 \times 10^{-4} \mathrm{~mol} / \mathrm{cm}^{3}\right)$

$\mathrm{DOH}$ diffusivity of hydroxide ions $\left(\mathrm{D}_{3}\right)$

DZN diffusivity of zincate ions $\left(D_{2}\right)$

VZND partial molar volume of $\mathrm{ZnO}\left(\overline{\mathrm{V}}_{\mathrm{ZnO}}=14.51 \mathrm{~cm}^{3} / \mathrm{mol}\right)$

AO initial specific surface area per unit volume $\left(a_{0}=19.8 \mathrm{~cm}^{2} / \mathrm{cm}^{3}\right.$ )

EJ exchange current density evaluated at the bulk concentrations of zincate and hydroxide ions $\left(i_{0}^{\circ}=0.146 \mathrm{~A} / \mathrm{cm}^{2}\right)$

RKS

overall precipitation rate constant of $\mathrm{Zno}\left(\mathrm{k}_{\mathrm{S}}\right)$

CNDI specific conductivity of bulk electrolyte $\left(k_{i}=0.4875 \mathrm{mho}^{-1} \mathrm{~cm}^{-1}\right.$

DY dimensionless increment of the distance through the electrode $(\Delta y=0.04)$ 


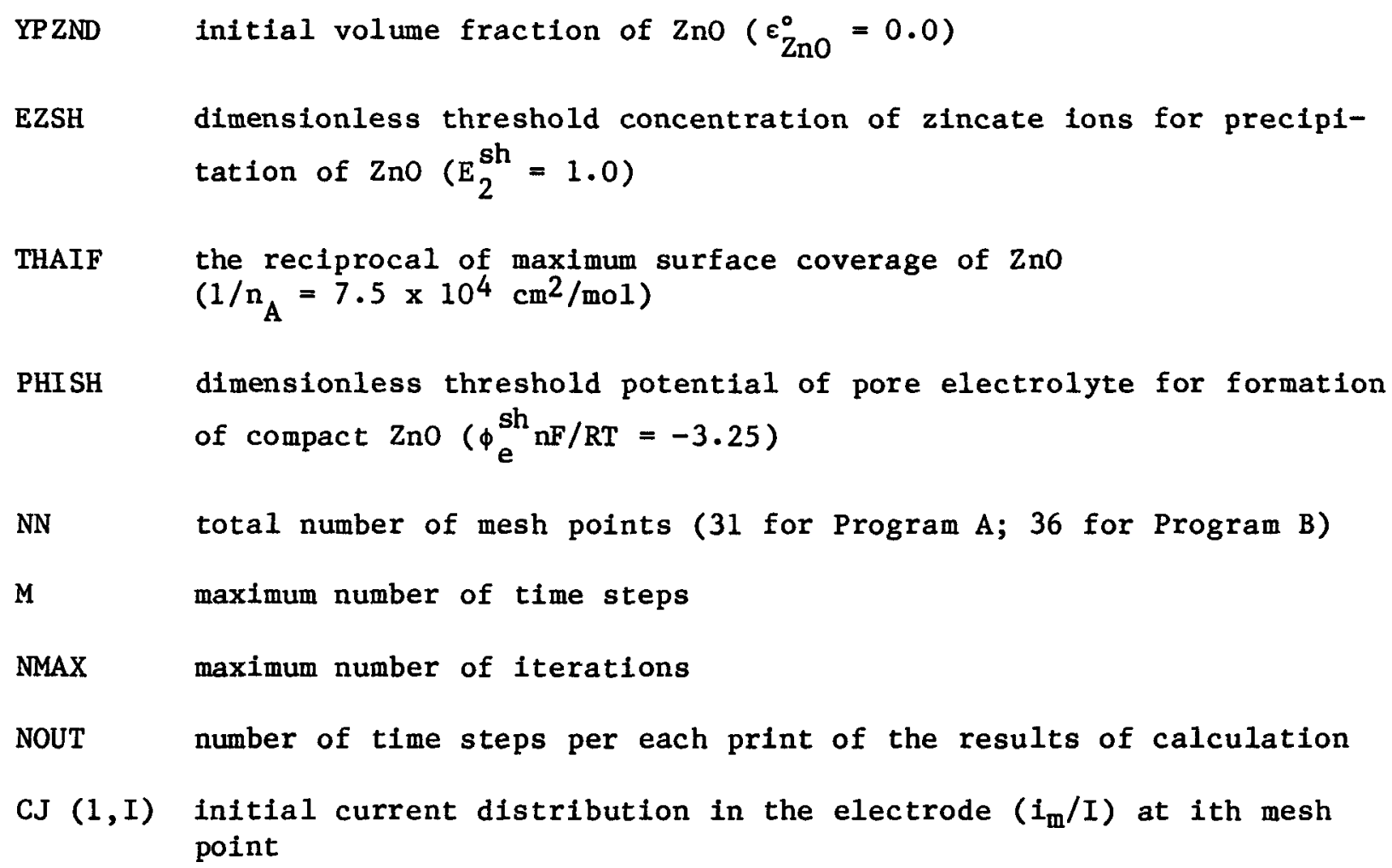

\section{Computer Output}

The execution of the computer programs by the computer will print the input data, and values of the groups defined in the programs. Other output includes the concentration of hydroxide ions (E), the concentration of zincate ions ( $E Z$ ), volume fraction of $\mathrm{Zn}$ (PZN), volume fraction of $\mathrm{ZnO}$ (PZNO), porosity $(P)$, current density in the electrode matrix $(J)$, potential in pore electrolyte (SIE), and value of $\theta$ (THETA) at each mesh point. Finally, the current densities in the segments are printed. 
PROGRAM A 
0001

0002

0003

0004

0005

0006

0007

0008

0009

0010

0011

0012

0013

0014

Co15

0016

0017

0018

0019

0020

0021

0322

0023

0024

0025

0026

0027

0028

0029

0030

0031

0032

0033

0034

0035

0036

0037

0038

0039

0040

0041

0042

0043

0044

0045

0046

0047

0048

0049

0050

C PROGRAM TO CALCULATE CURRENT DISTRIBUTION FOR ZINC ELECTRODE IN KOH IMPLICIT REAL $* 8(A-H, O-Z)$

DIMENSION $E(2,36), E(12,36), C J(2,36), C J 1(2,36), C N D E(36)$

DIMENSION P( 36$), P Z N(36)$, PZNO $(36)$, AM 36$), A(36)$

DIMENSIOH D(26), XMUF $(26), \mathrm{CM}(26), \operatorname{DM}(26), \operatorname{EM}(26), \operatorname{BM}(26)$

DIMENSION YIUUF (26́),BT(26)

DATA FN $/ 1.93000 E+5 /, R T / 2.47757 E+3 /, D R / 3.6563664 E-2 /, N P A S S / 5 /$

DATA YCOND $/ 0.1325 /$, CHECK $/ 1.0 D-5 /$

READ $(5,100) D T, D J, X L, A L F H A, X B$, PSTY

READ ( 5,100 IVZN, ALFHZ, XSZ, DOH, DZN, VZNO

READ $(5,100) A O, E J, R K S, C N D I, D Y, Y P Z N O$

READ ( 5,100$) E 2 S H$

C INPUT NO OF MESHES, NO OF TIME STEPS, MAX NO OF ITERATIONS, NO OF STEPS

C PER FRINT

READ $(5,101) N N, M, N M A X, N O U T$

HRITE $(6,103) N N, M$, NMAX, NOUT

HII $=$ HNY-NPASS

$N L=Y M M-2$

NL. $1=N L-1$

$N I=N P A S S+1$

$X L 2=X L * * 2$

$G A=D J * X L / F N$

$G, Y=G A /(D C H * X B)$

$G N Z=G A /(D Z N * X S Z)$

$X N \mathrm{X}=A O * E J * F N * X L 2 / R T$

$C R=X B / X S Z$

HRITE $(6,102) D T$, GM, XMU, DY, ALPHA, XB, PSTY

HRITTE $(6,106) G: 1 Z, A L P H Z, X S Z, D O H, D Z N, V Z N$

C START TO CALCULATE CONSTANTS IN EQHS

$F=D Z N / O O H$

$F P=V Z N * X B$

$F P Z=V Z N * X S Z$

$\mathrm{FFOH}=V Z \mathrm{NO} * X \mathrm{~B}$

$F F Z N=V Z N O * X S Z$

OTY $=D T / D Y$

$Y S Q=D Y * * 2$

$G=D T / Y S Q$

$G Z \approx F * G$

$H=D T Y * G M$

$H Z=D T Y * G M Z * F$

$B E L T A=D J * V Z N * X L * D T Y * 0.5 /(F N * D O H)$

$R A=X S Z * X L 2 * D T / D O H$

FHI $=R A / X B$

$Q=F N * D J * X L / R T$

$\mathrm{ZZ}=\mathrm{Q} / \mathrm{CH} \mathrm{OI}$

$X$ COND $=Y$ COND $/$ CNDI

$Z 3=A O * E J * X L / D J$

$E L T A=V Z N O * R A$

WRITE $(6,120) E 2 S H$

WRITE $(6,110) D \mathrm{~J}, X L, V Z N O, A O, E J$, RKS

KRITE $(6,111) \mathrm{F}$, FP, FPZ, FPOH, FPZN,CR

HRITE $(6,112) 6, G Z, H, H Z, C N D I, X C O N D$

WRITE $(6,113)$ BELTA, PHI, ELTA , 22, 23, YPZNO

C INITIAL CONDITIONS

ZPSTY $=1$. -PSTY -YPZNO

( contd) 


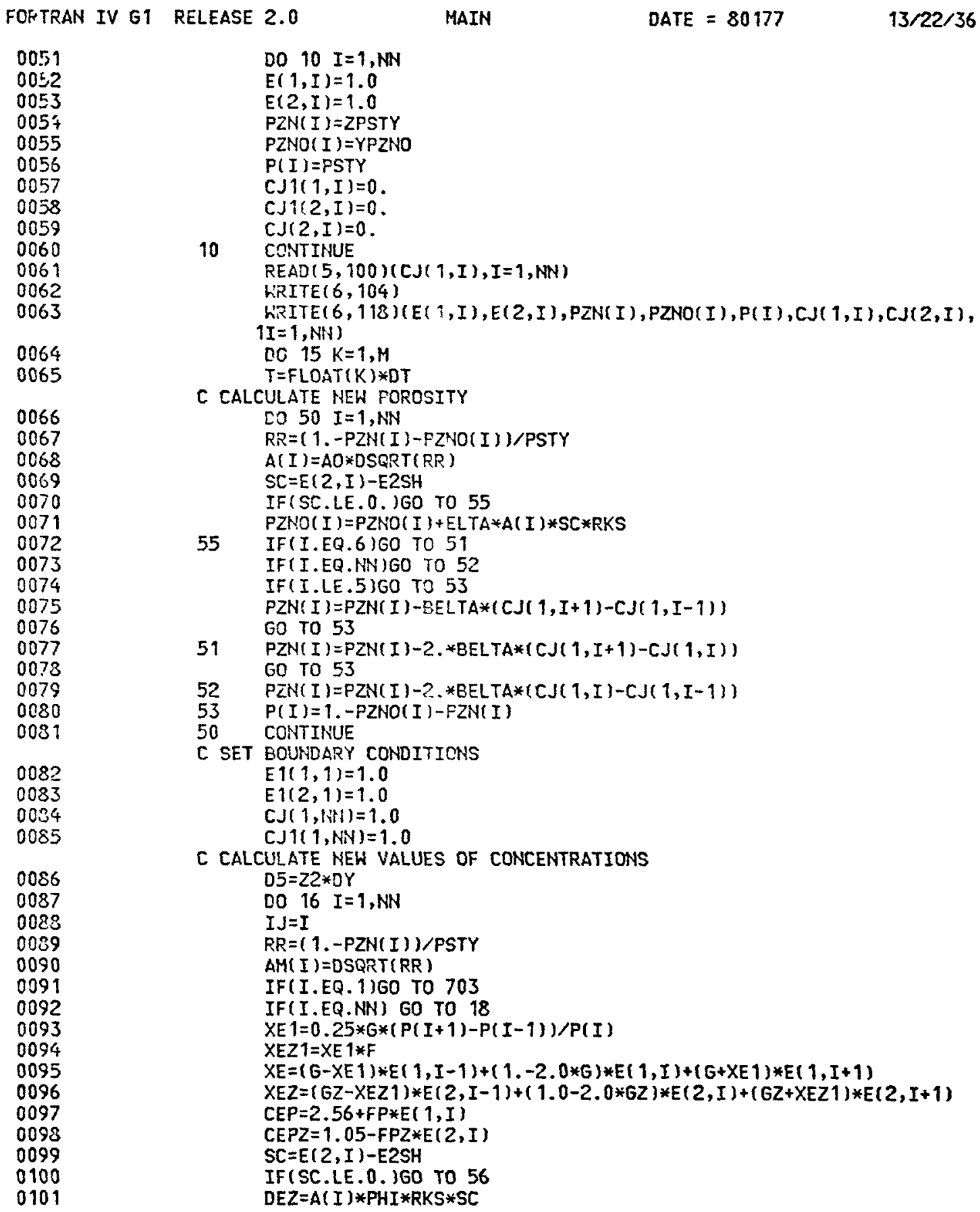

(contd) 
FORTRAN IV G1 RELEASE 2.0

MAIN

DATE $=80177$

$13 / 22 / 36$

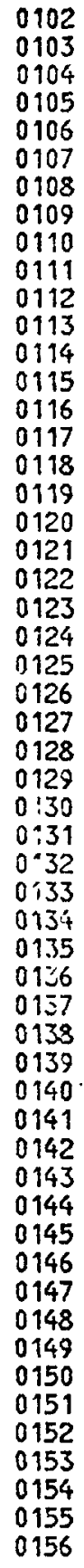

60 To 91

$56 \quad \mathrm{DEZ}=0$.

91 IF(I.LE.5)GO TO 301

$Y J=0.5 *(C J(1, I+1)-C J(1, I-1))$

GO TO 302

$301 \quad Y J=0$.

$302 \quad D E=(2 .+F P O H * E(1, I)) * D E Z / P(I)$

$D E O=C R *(1 .-F P Z N * E(2, I) * D E Z / P(I)$

$E(1, I)=X E+D E-Y J * H * C E P / P(I)$

IF(E1( $1, I) . L E .0 .160$ TO 41

$E 1(2, I)=X E Z-D E O+Y J * H Z * C E P Z / P(I)$

GO TO 703

$18 E 1(1, I)=E 1(1, N N-1)$

$E 1(2, I)=E\{(2, N N-1)$

$703 \operatorname{CNDE}(I)=D 5 /(P(I) *(1 .-X C O N D *(E(2, I)-1.0)))$

16 CONTINUE

DO $800 \quad I=1$, NM

$J=N P A S S+I$

$D 1=1.05 *(E 1(2, J+1)-E\}(2, J)) / E 1(2, J)$

$D 2=2.56 *(E 1(1, J+1)-E(1, J)) / E(1, J)$

$D(I)=D 1-02$

YMUF $(I)=23 * D Y * A M(J) *(E 1(1, J) * * A L P H A) *(E 1(2, J) * * A L P H Z)$

800 CONTI!'HE

IF (K.GT. 1)EO TO 956

$\operatorname{cJ}(2, N N)=0.0$

DO $801 I=2, N M$

$J=N N-I+1$

$C J(2, J)=C J(2, J+1)-D(N M-I+1)-\operatorname{CNDE}(J) *(1 .-C J(1, J))$

801 CONTINUE

956 JCONT $=0$

951 JCONT $=$ JCONT +1

IF ( JCONT.GT. NMAX)GO TO 31

DO $802 I=1$, NM

$J=N P A S S+I$

$01=-0.75 * \mathrm{CJ}(2, \mathrm{~J})$

$\mathrm{D} 2=0.25 * \mathrm{CJ}(2, \mathrm{~J})$

$03=0 \mathrm{EXP}(01)$

$D 4=D E X P(D 2)$

$X M U F(I)=1 . /(Y M U F(I) *(0.75 * 03+0.25 * 04))$

$D 5=(1 .-01) * 03-(1 .-02) * 04$

$B T(I)=\operatorname{YMUF}(I) * D 5$

802 CONTINUE

$\operatorname{DM}(1)=X P U F(2)+X M U F(3)+\operatorname{CNDE}(7)$

$\operatorname{EM}(1)=-X M U F(3)$

$\operatorname{BM}(1)=\mathrm{CNDE}(7)+D(2)+B T(2) * X M U F(2)-\operatorname{BT}(3) * X M U F(3)$

DO $803 \mathrm{I}=2, \mathrm{NL} 1$

$\mathrm{NL} 2=\mathrm{I}+1$

$N L 3=I+2$

$J=N P A S S+I+1$

$C M(I)=-X M U F(N L 2)$

$E M(I)=-X M U F(N L 3)$

DM\{ I $)=X M U F(N L 2)+X M U F(N L 3)+C N D E(J)$

$B M(I)=C N D E(J)+D(N+2)+B T(N L 2) * X M U F(N L 2)-B T(N L 3) * X M U F(N L 3)$

803 CONTINUE

$N 1=N N-1$

(contd) 
0157

0158

0159

0160

0161

0162

0163

0164

0165

0166

0167

0168

0169

0170

0171

0172

0173

0174

0175

0176

0177

0178

0179

0180

0181

0182

0183

0134

0185

0186

0187

0123

0139

0190

0191

0192

0193

0194

0195

0106

0197

0198

0199

0200

0201

0202

0203

0204

0205

0206

0207

0208

0209

$N L 2=N L+1$

$\mathrm{NL} 3=\mathrm{NL}+2$

$J=N P A S S+N L 2$

$C M(N L)=-X M U F(N L 2)$

$D M(N L)=X Y H U F(N L 2)+X M U F(N L 3)+C N D E(N 1)$

$B M(N L)=C N D E(N 1)+D(N L 2)+B T(N L 2) * X M U F(N L 2)+(1 .-B T(N L 3)) * X M U F(N L 3)$

CALL DGTSL(NL, CM, DM, EM, BM, INFO)

IFI INFO.NE.O)GO TO 31

DO $804 I=1, N L$

$J=N P A S S+I+1$

$(1, J)=B M(I)$

DO $805 I=2$, NM

$J=N P A S S+I$

805

$\operatorname{CJ} 1(2, J)=(-\operatorname{cs} 1(1, J)+C J 1(1, J-1)+B T(I)) * X M U F(I)$

CONTIHUE

CJ $1(2,6)=$ CJ $1(2,7)-D(1)-\operatorname{CNDE}(6)$

DO $810 \quad I=1,2$

DO $810 \mathrm{~J}=\mathrm{NI}, \mathrm{NN}$

IF(DABS(CJ1(I,J)).LE.1.00-6) E0 TO 810

810

IF(DABS(CJ(I,J)-CJ1(I,J)).GT.CHECK)GO TO 806

CONTINUE

$J=K /$ NOUT

$\mathrm{J}=\mathrm{J}$ *NOUT

IF (J.NE.K)GO TO 402

DO $601 \mathrm{I}=1$, NPASS

$J=N P A S S+1-I$

$D 1=1.05 *(E 1(2, J+1)-E 1(2, J)) / E 1(2, J)$

$D 2=2.56 *(E 1(1, J+1)-E(1, J)) / E 1(1, J)$

601

$C J 1(2, J)=C J 1(2, J+1)-D 1+D 2-C N D E(J)$

HRITE $(6,108) T$

WRITE $(6,104)$

HRITE $(6,117)(E(1, I), E(2, I), P Z N(I), P Z N O(I), P(I), C J 111, I), C J 1(2, I)$, 1CNDE ( I ), $I=1$, NN)

DO $815 I=1,5$

$J=I * 5+1$

$815 \operatorname{CM}(I)=\operatorname{CJ} 1(1, J+5)-\operatorname{CJ} 1(1, J)$

$\operatorname{WRITE}(6,117)(\mathrm{CM}(I), I=1,5)$

IF(IJ.LT.NN)GO TO 40

402

DO $955 I=1,2$

Do $955 \mathrm{~J}=1, \mathrm{NN}$

955

$E(I, J)=E 1(I, J)$

GO TO 15

806

DO $401 \mathrm{~J}=\mathrm{NI}, \mathrm{NN}$

$\operatorname{CJ}(1, J)=\operatorname{CJ} 1(1, J)$

$401 \quad \operatorname{cJ}(2, J)=0.5 *(\operatorname{CJ}(2, J)+\operatorname{CJ}(2, J))$

GO TO 951

15 CONTINUE

60 TO 40

31 WRITE $(6,109)$

100 FORMAT(6E 12.5)

101 FORMAT(4I8)

102 FORMAT 5 HODT $=, E 12.5 / 5 \mathrm{H}$ GM $=, E 12.5 / 5 \mathrm{H} X M \mathrm{XU}=, \mathrm{E} 12.5 / 5 \mathrm{H}$ DY $=, E 12.5 /$

$17 \mathrm{H}$ ALPHA $=, E 12.5 / 5 \mathrm{H} C \mathrm{CO}=, \mathrm{E} 12.5 / 11 \mathrm{H}$ POROSITY $=, E 12.51$

103

FORMAT ( $5 H O N N=, I 5 / 5 H \quad M=, I 8 / 1$ NMAX $=1, I 5 /$, NOUT $=1$, I5)

(contd) 
FORTRAN IV G1 RELEASE 2.0

MAIN

DATE $=80177$

$13 / 22 / 36$

0210

104 FORMAT $7 X, 1 H E, 13 X, 2 H E Z, 13 X, 3 H P Z N, 12 X, 4 H$ ZNO, 12X, 1HP, 14X, 1HJ, 11X,

0211

1 'SIE', 12X, 'CNDE')

106 FORMAT $5 \mathrm{H}$ GHZ $=, E 12.5,8 \mathrm{H}$ ALPHZ $=, E 12.5,6 \mathrm{H}$ COZ $=, E 12.5 / 5 \mathrm{H}$ DOH $=, E 12.5$

0212

0213

0214

0215

0216

0217

0218

0219

0220

0221

0222

$1,5 \mathrm{H} \quad \mathrm{BZN}=, \mathrm{E} 12.5,5 \mathrm{H} \quad \mathrm{ZZN}=, \mathrm{E} 12.5$ )

108 FORMAT(5HO T $=, E 12.5)$

109 FORMAT(' NOT CONVERGENT')

110 FORMAT( ' $D J, X L, V Z N O, A O, E J, R K S ', 6 E$ 12.5)

111 FORILAT(' F,FP,FPZ,FPOH,FPZI, CR', 6E 12.5)

112 FORMATS ' $G, G Z, H, H Z, C N D I, X C O N D$ ', $6 E 12.5$ )

113 FORMAT(" BELTA,PHI, ELTA,Z2,Z3, YPZNO',6E 12.5)

117 FORMAT( $1 X, 8$ E 14.5)

118 FORMAT ( TX, TE 15.5)

120 FORMAT(' E2SH', E12.5)

40 STOP

END 
PROGRAM B 
FORTRAN IV G1 RELEASE 2.0

MAIN

DATE $=80177$

$12 / 13 / 35$

C PROGRAM TO CALCULATE CURRENT DISTRIBUTION FOR ZINC ELECTRODE IN KOH

0001

0002

0003

0004

0005

0005

0007

0008

0009

0310

cu11

OC: 12

0013

$00 ! 4$

$00: 5$

0016

0017

0018

0019

0020

0321

0022

0023

0024

0025

0026

0027

0023

0029

0030

0031

0032

0033

0034

0035

0036

0037

0038

0039

0040

0041

0042

0043

0044

0045

0045

0047

0043

0049

0050

0051

IMPLICIT REAL *8(A-H,O-Z)

DINENSION $E(2,36), E 1(2,36), C J(2,36), C J 1(2,36)$, CNOE $(36)$

DIMENSION P( 36$),$ PZN $(35)$, PZNO( $36 ́)$, AN $(30 ́)$, A $(36)$, THETA $(36)$

DIMENSION D(26), XMUF( 26$), C M(26), D M(26)$, EM( 26$),$ EM(26)

DIMENSION YMUT $(26)$, BT $(26)$

DATA FN/1.93000E+5/,RT/2.47757E+3/,OR/3.6563364E-2/

DATA YCOND $/ 0.1325 /$, CHECK $/ 1.00-5 /$

READ $(5,100) D T, D J, X L$, ALPHA, XB, FSTY

READ $(5,100)$ VZN, ALPHZ, XSZ, DOH,DZH, VZN:O

READ (5,100)AO,EJ,RKS, CNDI, DY, YFZNO

READ (5, 100) ECSH, THAIF, PHISH

C INPUT NIO OF MESHES, $:$ OO OF TIME STEPS, MAX NO OF ITERATIONS, NO OF STEPS

C PER PRIHT

READ 5,101$)$ NN, M, NMAX, NOUT

HRITE $(6,103)$ HW, M, NMAX,NOUT

$N P \perp S S=5$

$M N=N W-2 \times N A P A S S$

$N L=r i:-2$

MLL $1=$ YIL -1

$N I=N P A S S+1$

$N=N F A S S+N M$

$X L 2=X L * * 2$

$G A=0 J * X L / F N$

$G^{\prime} 1=G A /(D O H * \times B)$

$G M Z=G A /(D Z H * X S Z)$

$X+Y J=A O+E J * F N * X L 2 / R T$

$C R=X B / X S Z$

WRITE $(6,102) 10 T$, G , XYU, DY, ALPHA, XB, FSTY

HRITE 6,106$)$ IGHZ, ALPHZ, XSZ, DOH, DZN, VZN

C START TO CALCULATE CONSTANTS IN EQNS

$F=D Z N / D O H$

$F P=V Z N * X B$

$F P Z=V Z N * X S Z$

$F P O H=V Z N O O X B$

FPZN $=V Z \mathrm{~N} O * X S Z$

$D T Y=D T / D Y$

$Y S Q=D Y * * 2$

$G=D T / Y S Q$

$G Z=F * G$

$H=D T Y * G M$

$H Z=D T Y * G M Z * F$

$B E L T A=D J * V Z N * X L * D T Y * 0.5 /(F N * D O H)$

$R A=X S Z * X L 2 * D T / D O H$

$\mathrm{PHI}=\mathrm{RA} / \mathrm{XB}$

$Q=F N \div D J * X L / R T$

$\mathrm{Z2}=\mathrm{Q} / \mathrm{CNDI}$

$X C O N D=Y C O N D / C N D I$

$Z 3=A O * E J * X L / D J$

$E L T A=V Z N O * R A$

THAI $=G A * D T Y * T H A I F /(A O * D O H)$

WRITE $(6,120)$ E2SH, THAIF, THAI, PHISH

WRITE $(6,110 \mathrm{IDJ}, X \mathrm{X}, \mathrm{VZNO}, A D, E J, R K S$

WRITE $(6,111) \mathrm{F}, \mathrm{FP}, \mathrm{FPZ}, \mathrm{FPOH}, \mathrm{FPZN}, \mathrm{CR}$

HRITE $(6,112) 6, G Z, H, H Z, C N D I, X C O N D$

(contd) 


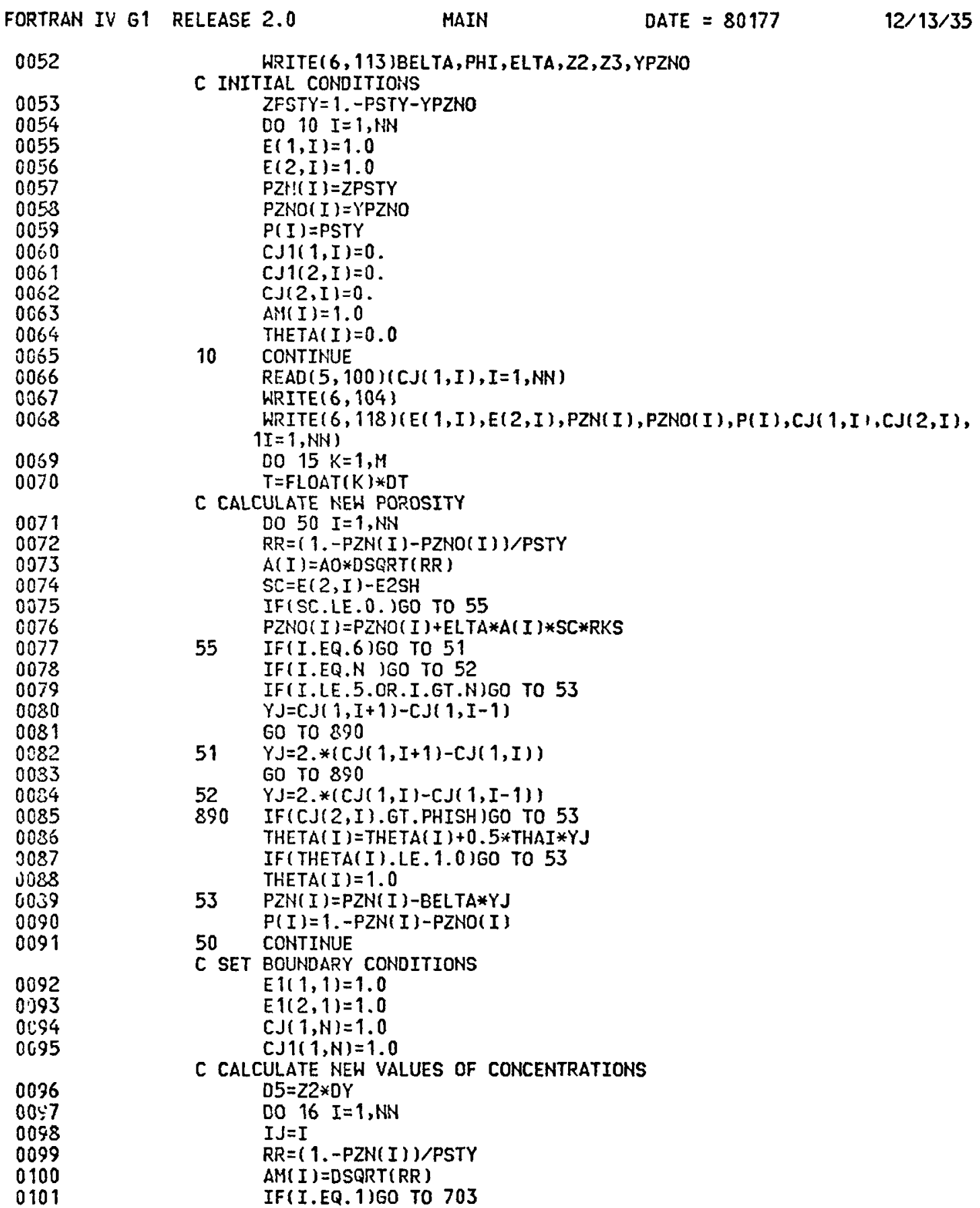

(contd) 


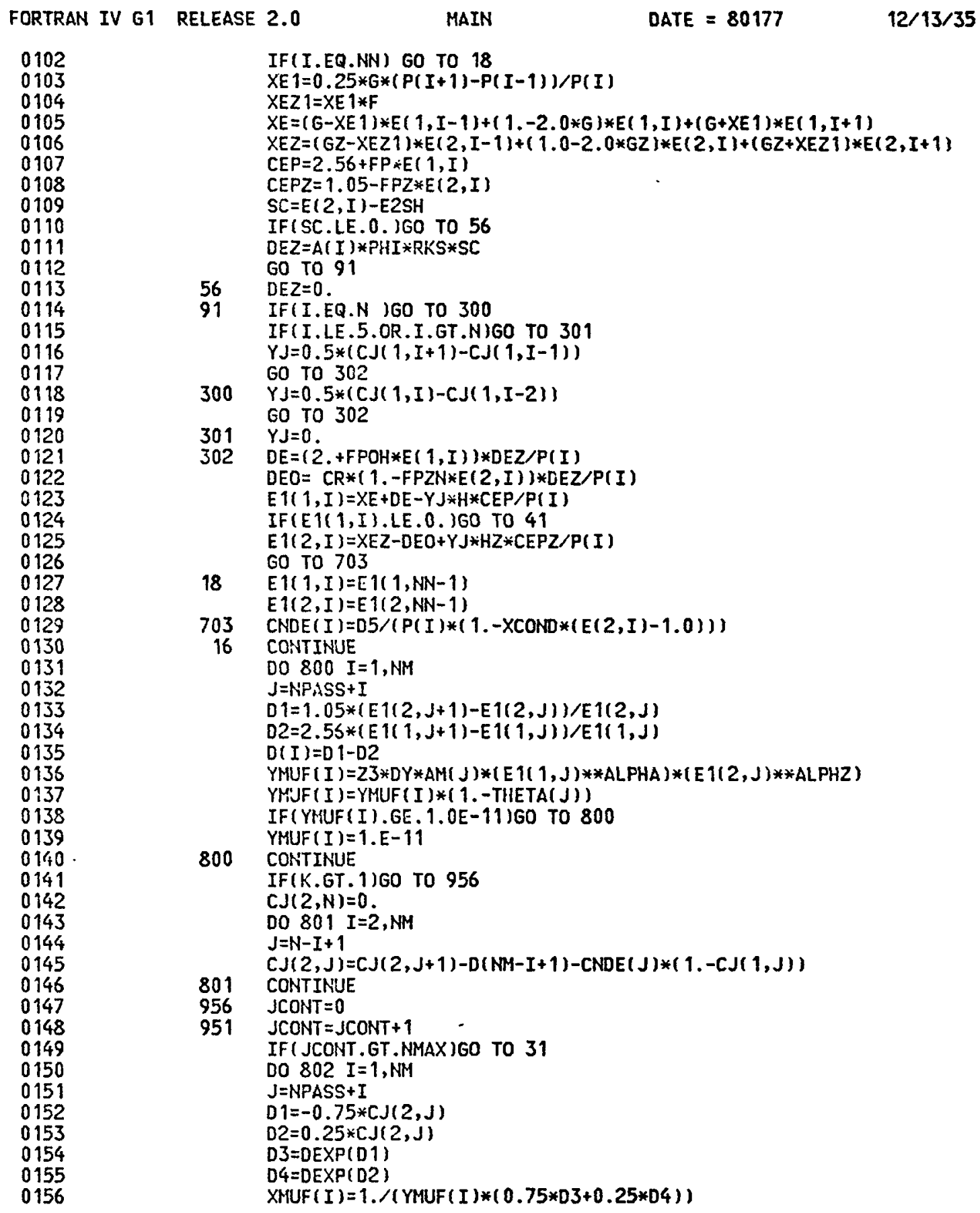

(contd) 
FORTRAN IV G1 RELEASE 2.0 MAIN DATE $=80177 \quad 12 / 13 / 35$

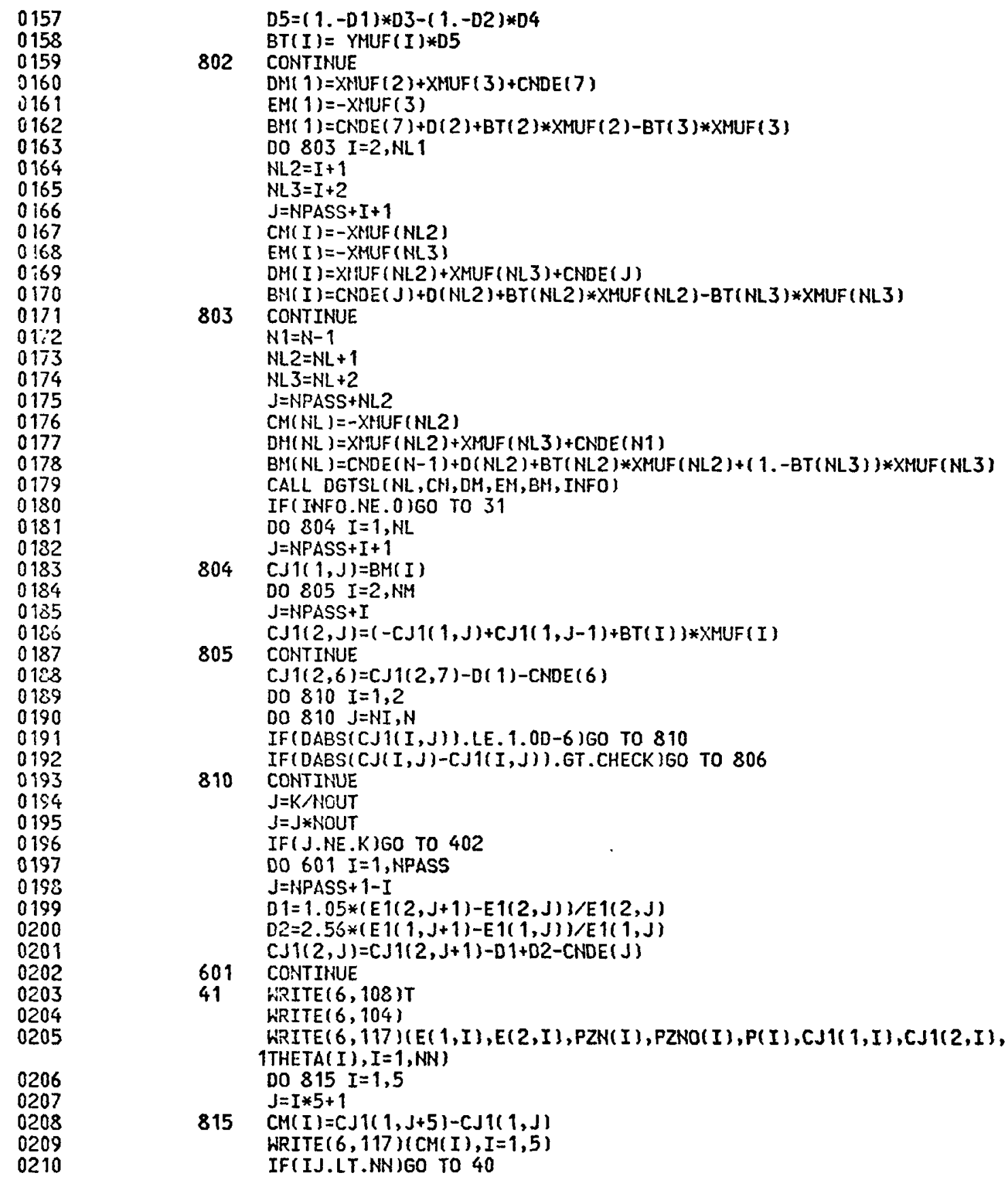

(contd) 


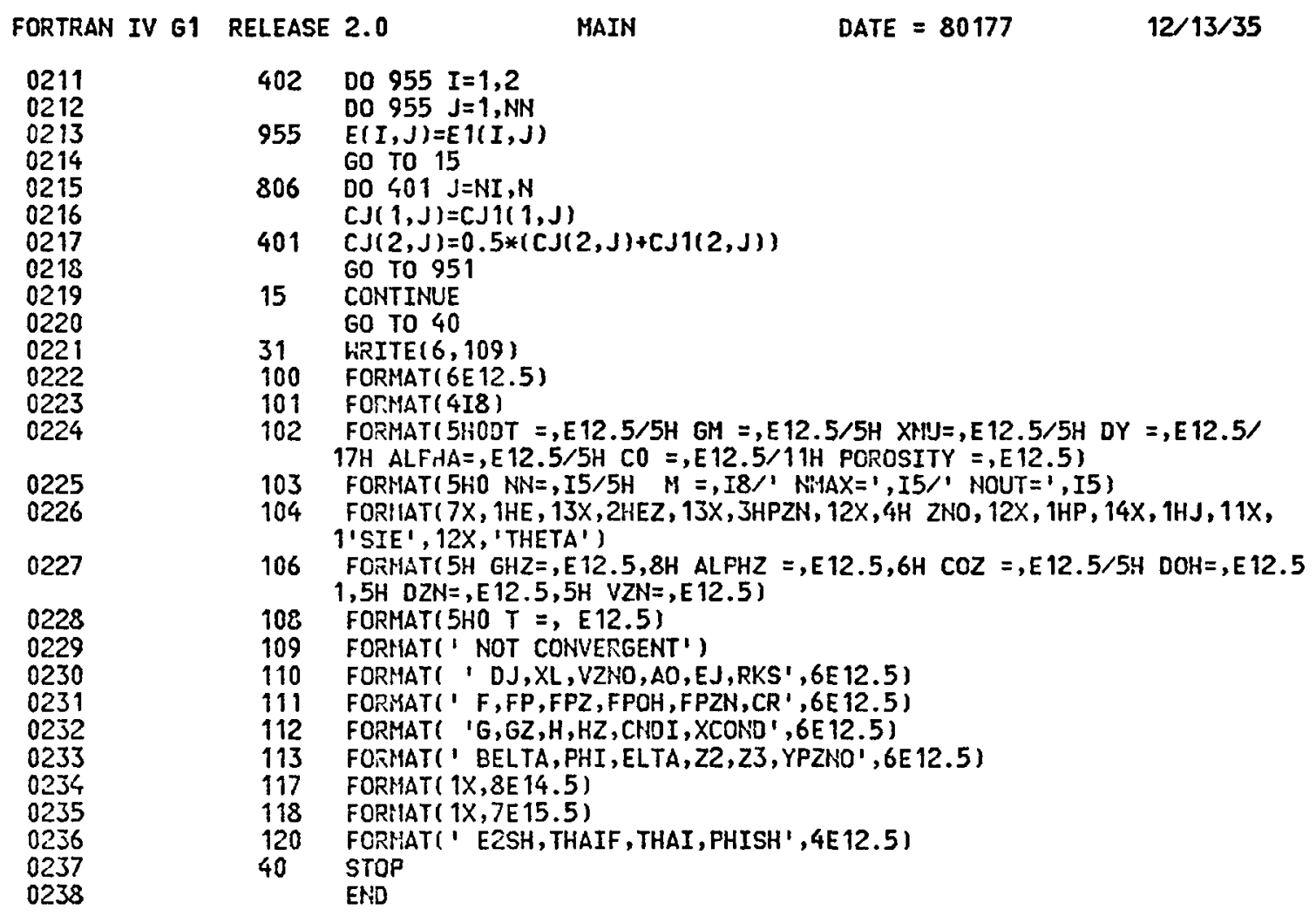




\section{REFERENCES}

1. Z. Nagy and J. O'M Bockris, J. Electrochem. Soc. 119, 1129 (1972).

2. W. G. Sunu, Transient and Failure Analyses of Porous Zinc Electrodes, Ph. D. Thesis, Univ. of Calif., Los Angeles (1978).

3. P. Bro and H. Y. Kang, J. Electrochem. Soc. 118, 519 (1971).

4. R. C. Alkire, Reaction Distribution in a Dissolving Porous Anode, Ph.D. Thesis, Univ. of Calif., Berkeley (1968).

5. S. Szpak and T. Katan, J. Electrochem. Soc., 122, 1063 (1975).

6. J. McBreen, J. Electrochem. Soc., 119, 1620 (1972).

7. J. J. Coleman, J. Electrochem. Soc., 98, 26 (1951).

8. E. C. Gagnon and L. G. Austin, J. Electrochem. Soc. 118, 497 (1971).

9. R. J. Brodd, Electrochem. Acta 11, 1107 (1966).

10. Kodak Publication No. P-246, Photofabrication Methods with Kodak Photosensitive Resists, Eastman Kodak Co., Rochester, NY (1975).

11. W. Engelmaier, T. Kessler, and R. Alkire, J. Electrochem. Soc., 125, 209 (1978).

12. R. W. Powers and M. W. Breiter, J. Electrochem. Soc. 116, 719 (1969).

13. R. W. Powers, J. Electrochem. Soc. 118, 685 (1971).

14. M. Liu, G. M. Cook, and N. P. Yao, Galvanostatic Polarization of Zinc Microanodes in $\mathrm{KOH}$ Electrolytes, Argonne National Laboratory Report ANL-OEPM-80-1 (1980).

15. T. P. Dirkse, J. Electrochem. Soc. 126, 541 (1979).

16. J. Euler and W. Nonnenmacher, Electrochem. Acta $\underline{2}, 268$ (1960).

17. J. Newman and C. W. Tobias, J. Electrochem. Soc. 109, 1183 (1962).

18. J. O'M Bockris, Z. Nagy, and A. Damj anovic, J. Electrochem. Soc. 119, 285 (1972).

19. T. Katan, J. R. Savory and J. Perkings, J. Electrochem. Soc. 126, 1835 (1979).

20. J. Newman and W. Tiedemann, AICHE J., 21, 25 (1975).

21. S. Szpak and C. J. Gabriel, J. Electrochem. Soc. 126, 1914 (1979).

22. W. H. Dyson, L. A. Schreier, W. P. Shotetle, and A. J. Salkind, J. Electrochem. Soc. 115, 567 (1968). 
23. M. Nitabah, D. Lucesoli, and P. Degobert, Electrochem. Acta 17, 327 (1972).

24. C. G. Smith, Ellipsometry of Anodic Film Growth, LBL-8082 (1978).

25. B. Carnahan, H. A. Luther, and J. 0. Wilkes, Applied Numerical Methods, John Willey \& Sons, Inc., New York (1969).

26. J. Newman, I\&EC Fundamentals 1, 514 (1968).

27. J. J. Dongarra, C. B. Moler, J. R. Bunch, and G. W. Stewart, LINPACK User's Guide, Society for Industrial and Applied Mathematics, Philadelphia, PA (1979).

28. A. Langer and E. A. Pantier, J. Electrochem. Soc. 115, 990 (1968).

29. R. J. Hoffman, H. F. Gibbard, R. J. Ekern, and B. L. McKinney, Extended Abstract, Electrochem. Soc., Fall Meeting, Los Angeles, Calif., p. 304 (1979).

30. J. McBreen and E. J. Cairns, Advances in Electrochemistry and Electrochemical Engineering, 10, 273 (1978).

31. T. P. Dirkse and N. A. Hampson, Electrochem. Acta 17, 383 (1972).

32. C. T. Baker and I. Tracktenberg, J. Electrochem. Soc. 114, 1045 (1967). 
Distribution for ANL/OEPM-80-6

Interna1:

$\begin{array}{ll}\text { J. J. Barghusen } & \text { E. C. Gay } \\ \text { D. L. Barney } & \text { J. Geller } \\ \text { C. Bean } & \text { M. Genge } \\ \text { E. S. Beckjord } & \text { J. Harmon } \\ \text { E. C. Berrill } & \text { F. Hornstra } \\ \text { M. Blander } & \text { C. C. Hsu } \\ \text { A. Brown } & \text { J. Kilinger } \\ \text { L. Burris } & \text { V. Kremesec } \\ \text { F. A. Cafasso } & \text { A. B. Krisciunas } \\ \text { G. Chapman } & \text { M. Krumpelt } \\ \text { A. A. Chilenskas } & \text { M. Kronenberg } \\ \text { E. Creamer } & \text { M. L. Kyle } \\ \text { C. C. Christianson } & \text { T. Lee } \\ \text { G. Cook } & \text { M. Liu } \\ \text { D. Corp } & \text { R. Loutfy } \\ \text { W. Deluca } & \text { W. E. Massey } \\ \text { R. C. Elliott } & \text { C. A. Melendres } \\ \text { P. R. Fields } & \text { J. Miller } \\ \text { D. Fredrickson } & \text { W. Miller }\end{array}$

N. Minh

$\mathrm{J}$. Meisenhelder

Z. Nagy

P. A. Nelson

D. Poa

J. Rajan

J. J. Roberts

M. F. Roche

H. Sh imot ake

R. K. Steunenberg

C. A. Swoboda

Z. Tomc zuk

R. Varma

P. D. Vashishta

D. R. Vissers

D. S. Webster

N. P. Yao $(60)$

ANL Contract File

ANL Libraries

B. R. T. Frost

TIS Files (6)

\section{External:}

DOE-TIC, for distribution per UC-94ca (318)

Manager, Chicago Operations and Regional office, DOE

Chief, Office of Patent Counse1, DOE-CORO

V. H. Hummel, DOE-CORO

R. Gariboldi, DOE-CORO

Argonne Universities Association:

President

C. B. Alcock, U. Toronto

W. L. Worrell, U. Pennsylvania

S. Abens, Energy Research Corp., Danbury, CT

E. T. Ames, TRW Systems, Redondo Beach

S. J. Angelovich, Mallory Battery Co., Tarrytown, NY

G. M. Arcand, Idaho State University, Pocatello

G. N. Ault, NASA Lewis Research Center

A. D. Babinsky, T. R. Evans Research Center, Painesville, OH

K. F. Barber, DOE, Office of Transportation Programs

T. Barber, Jet Propulsion Lab.

T. M. Barlow, Lawrence Livermore Lab.

D. Barron, Delco-Remy Div. GMC, Anderson, IN

R. Bassett, Sandia Labs, Albuquerque

R. G. Bautista, Iowa State U.

L. Belove, Marathon Battery Corp., Waco, TX

D. N. Bennion, Brigham Young $U$.

J. B. Berkowitz, Arthur D. Little, Cambridge, MA

L. Berkowitz, Esso Research \& Engineering Co., Linden; NJ

C. Berlsterling, Franklin Institute, Philadelphia

D. P. Boden, C\&D Batteries, Plymouth Meeting, PA 
D. Bowman, United States Postal Service, Washington

J. Brennand, General Research Corp., Santa Barbara, CA

P. Bro, J. R. Mallory \& Co., Inc., Burlington, MA

E. P. Broglio, Eagle-Picher Industries, Joplin, MO

P. J. Brown, DOE, Office of Transportation Programs

R. Buchholz, Honeywell Corp., Minneapolis

T. Burgess, Lucas Industries, Troy, MI

H. Burghart, Cleveland State U.

B. W. Burrows, Gould Inc., Rolling Meadows, IL

E. Buzzelli, Westinghouse Electric Corp., Pittsburgh

E. J. Cairns, Lawrence Berkeley Lab.

P. Campbe11, U. Southern California, Los Angeles

R. T. Carpenter, Kimberly Clark Corp., Neenah, WI

T. V. Carvey, Hughes Aircraft Corp., Culver City, CA

T. W. Chapman, U. Wisconsin, Madison

D-T. Chin, Clarkson College of Technology

L. D. Christian, General Electric Co., Gainesville, FL

J. E. Clifford, Battelle Memorial Inst.

J. G. Colin, Englehard Industries Inc., Edison, NJ

W. B. Collins, Martin Marietta Corp., Denver

D. Davis, Lawrence Livermore Lab.

P. Davis, DOE, Office of Transportation Programs

R. J. Dawson, Exide Management \& Technology, Madison, WI

D. Dharia, Energy Research Corp., Danbury, CT

G. A. DiBari, International Nickel Co., New York

W. J. Dippold, DOE, Office of Transportation Programs

T. P. Dirske, Calvin College, Grand Rapids, MI

F. M. Donahue, U. Michigan, Ann Arbor, MI

D. B. Eisenhaure, Charles Stark Draper Lab., Inc., Cambridge, MA

M. W. Ellison, Hughes Aircraft Corp., E1 Segundo

R. P. Epple, Div. of Material Sciences, USDOE

J. Evans, U. California, Berkeley

A. Ewing, DOE, Office of Transportation Programs

F. Fedor, Bell Laboratories, Murray Hill, NJ

R. Ferraro, Electric Power Research Inst., Palo Alto

A. Fleischer, Orange, NJ

G. S. Foerster, NL Metals/NL Industries, Hightstown, NJ

R. F. Fogle, North American Rockwe11, Anaheim, CA

R. T. Foley, American University, Washington, DC

J. S. Fordyce, NASA Lewis Research Center

D. N. Goens, Hazen Research, Golden, CO

G. Goodman, Globe Battery Div., Milwaukee

R. E. Goodson, Purdue U.

J. A. S. Green, Martin Marietta Laboratories, Baltimore

R. Guess, General Electric Research Lab., Schenectady

R. G. Gunther, General Motors Research Labs., Warren, MI

G. Hagey, DOE, Division of Technology Overview

H. Hamilton, U. Pittsburgh

V. Hampel, Lawrence Livermore Lab.

K. L. Hanson, General Electric Co., Philadelphia

J. H. Harrison, Naval Ship R\&D Center, Annapolis

G. Hartman, Exide Management \& Technology, Yardley, PA

J. Hartman, General Motors Research Labs., Warren, MI 
E. A. Henry, U. California, Livermore

V. Hlavin, NASA Lewis Research Center

G. Hobbib, Exude Management \& Technology, Cleveland

J. E. Hoffman, Exxon Research and Engineering Co., Florham Park, NJ

R. Hudson, Eagle-Picher Industries, Joplin, MO

H. L. Hughes, Oklahoma State U.

W. B. Iaconelli, Ionics Inc., Watertown, MA

G. H. Jantz, Rensselaer Polytechnic Inst.

W. P. Jensen, Idaho National Engineering Lab.

L. Jok1, MERADCOM, Fort Belvoir, VA

W. J. Jones, Westinghouse Electric Corp., Pittsburgh

J. Jorné, Wayne State U.

W. Juda, Prototech, Inc., Newt on Highlands, MA

E. Kanter, Gulton Battery Corp., Metuchen, NJ

N. Kaplan, Harry Diamond Laboratories, Washington, DC

T. Katan, Lockheed Palo Alto Research Lab.

J. A. Kerrella, Delco-Remy Division/GMC, Anderson, IN

R. A. Keyes, Robert A. Keyes Associates, Martinsville, IN

W. C. Kincaide, Teledyne Energy Systems, Timonium, MD

R. Kirby, U. S. Bureau of Mines, Washington

R. S. Kirk, DOE, Office of Transportation Programs

K. Klein, U. S. Department of Energy, Washington

J. G. Krisilas, Aerospace Corporation, E1 Segundo, CA

V. Kudryk, ASARCO Inc., South Plainfield, NJ

A. Landgrebe, U. S. Department of Energy, Washington

R. Lund, St. Joe Minerals Corp., Monaca, PA

J. Mader, Electric Power Research Inst.

J. T. Maloy, Seton Hall U.

J. Maise1, Cleveland State U.

R. E. Maize11, O1 in Research Center, New Haven, CT

V. Manson, National Aeronautics and Space Adm., Washington

C. E. May, NASA Lewis Research Center

J. McBreen, Brookhaven National Lab.

B. McCormick, Los Alamos Scientific Lab.

L. A. McCoy, E. I. duPont de Nemours \& Co., Wilmington

L. R. McCoy, Atomics International

R. P. Mikkelson, General Dynamics, San Diego

D. G. Miley, U. S. Naval Ammunition Depot, Crane, IN

F. J. Mollura, Rome Air Development Center, Griffiss AFB, NY

J. Moseley, Dow Chemical R\&D, Pittsburg, CA

A. Moss, Leesona Moos Laboratories, Warwick, RI

T. Mukherjee, National Science Foundation, Washington

J. P. Mulling, National Aeronautics and Space Adm., Washington

G. Murphy, Northwestern U.

N. T. Musial, NASA Lewis Research Center

W. J. Nagle, NASA Lewis Research Center

K. Nobe, U. California, Los Angeles

J. Norberg, Exide Management \& Technology, Philadelphia

W. Opie, AMAX Inc., Carteret, NJ

B. N. Otzinger, North American Aviation, Downey, CA

J. E. Oxley, Gould Inc., Rolling Meadows, IL

J. S. Parkinson, Johns-Manville R\&D Center Manville, NJ

C. Pax, DOE, Office of Transportation Programs 
J. P. Pemsler, Castle Technology Corporation, Lexington, MA

G. F. Pezdirtz, DOE, Office of Advanced Conservation Technologies

A. G. Plunckett, General Electric R\&D Center, Schenectady

V. J. Puglisi, Yardney Electric Corp., Pawcatuck, CT

A. D. Raynard, AiResearch Manufacturing Co., Torrance, CA

H. L. Recht, Atomics International Div., Canoga Park

E. Rizkalla, DOE, Washington

L. Rosenblum, NASA Lewis Research Center

N. Rosenburg, Department of Transportation, Cambridge, MA

R. Rosey, Westinghouse Electric Corp., Pittsburgh

J. Rossmon, Cornell U.

G. Rowland, General Electric Co., Schenectady

J. Rubenzer, NASA Ames Research Center

A. J. Salkind, Rutgers Medical School

F. J. Salzano, Brookhaven National Lab.

L. W. Schopen, NASA Lewis Research Center

S. Schuldiner, Naval Research Lab., Washington

W. R. Scott, TRW Systems Inc., Redondo Beach

H. Seiger, Waterford, CT

I. Servi, Kennecott Copper Corp., Lexington, MA

R. C. Shair, Hollywood, FL

H. Shalit, ARCO Chemical Corp., Glenolden, PA

D. W. Sheibley, NASA Lewis Research Center

G. P. Smith, Oak Ridge National Lab.

J. Smits, Nevada Operations Office, DOE, Las Vegas

F. Solomon, Electrode Media, Inc., Englewood, NJ

G. M. Thur, DOE, Office of Transportation Programs, Washington

B. V. Tilak, Hooker Research Center, Grand Island, NY

I. Trachtenberg, Texas Instruments, Dallas

L. E. Vaaler, Battelle Columbus Labs.

C. J. Venuto, C\&D Batteries, Plymouth Meeting, PA

M. E. Wadsworth, U. Utah

R. D. Wherle, Sandia Labs, Albuquerque

T. C. Wilder, Lexington, MA

M. E. Wilke, Burgess Battery Company, Freeport, IL

J. M. Williams, E. I. duPont de Nemours \& Co., Wilmington

E. Willihnganz, C\&D Batteries, Plymouth Meeting, PA

J. F. Wing, Booz-Allen \& Hamilton Inc., Bethesda

J. C. Withers, Pora, Inc., Berea, $\mathrm{OH}$

J. Wooldridge, Boeing Corp., Seattle

V. Wouk, Petro-Electric Motor Ltd., New York

L. Yanni, Booz-Allen \& Hamilton Inc., Bethesda

J. E. Zanks, NASA Langley Research Center

M. Zlotnick, DOE, Conservation Research and Technology

N. R. Bharucha, Noranda Research Center, Pointe Claire, Quebec, Canada

B. E. Conway, U. Ottawa, Canada

V. Ette1, INCO, Mississauga, Canada

M. Ducarroir, C.N.R.S., Font-Romeu, France

H. H. Horowitz, Alsthom-Exxon, Massy, France

N. Ibl, Technisch-Chemisches Laboratorium, Zurich, Switzerland

D. Landolt, Swiss Federal Institute of Technology, Lausanne, Switzerland 